Universidade de São Paulo

Faculdade de Medicina de Ribeirão Preto

\section{6}

\title{
O IMPACTO DA SÍNDROME DA FIBROMIALGIA NA MUSCULATURA MASTIGATÓRIA E CERVICAL: ANÁLISE ELETROMIOGRÁFICA, ULTRASSONOGRÁFICA, FORÇA DE MORDIDA E EFICIÊNCIA MASTIGATÓRIA
}
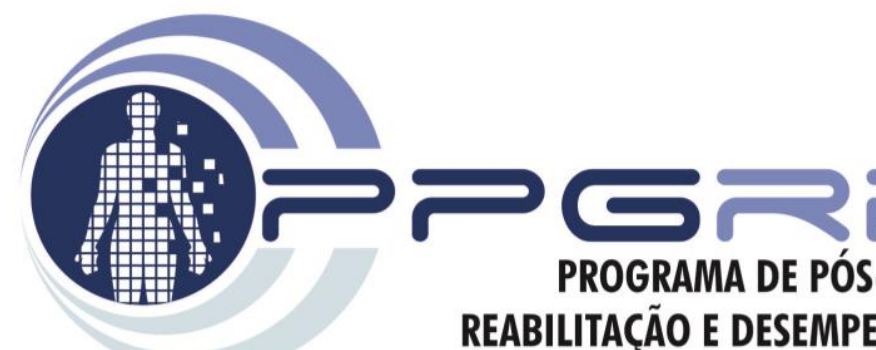

PROGRAMA DE PÓS-GRADUAÇÃO EM REABILITAÇÃO E DESEMPENHO FUNCIONAL FMRP-USP

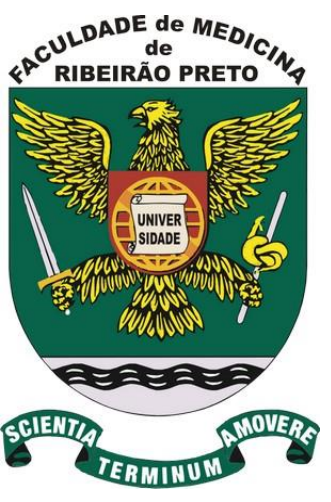

Doutorando: Victor Rodrigues Nepomuceno

Tese apresentada ao Programa de Reabilitação e Desempenho Funcional da Faculdade de Medicina de Ribeirão Preto Universidade de São Paulo

Área de Concentração:

Fisioterapia 


\title{
VICTOR RODRIGUES NEPOMUCENO
}

\author{
O IMPACTO DA SÍNDROME DA FIBROMIALGIA NA MUSCULATURA \\ MASTIGATÓRIA E CERVICAL: ANÁLISE ELETROMIOGRÁFICA, \\ ULTRASSONOGRÁFICA, FORÇA DE MORDIDA E EFICIÊNCIA \\ MASTIGATÓRIA
}

Tese apresentada ao Programa de Reabilitação e Desempenho Funcional da Faculdade de Medicina de Ribeirão Preto da Universidade de São Paulo para obtenção do título de Doutor em Ciências

Versão Corrigida. A versão original encontra-se disponível tanto na Biblioteca da Unidade que aloja o Programa, quanto na Biblioteca de Teses e Dissertações da USP (BDTD)

Área de Concentração: Fisioterapia

Orientadora: Profa. Dra. Simone Cecilio Hallak Regalo

Coorientadora: Profa. Dra. Thais Cristina Chaves 
Autorizo a reprodução e divulgação total ou parcial deste trabalho, por qualquer meio convencional ou eletrônico, para fins de estudo e pesquisa, desde que citada a fonte.

\section{FICHA CATALOGRÁFICA}

Ficha catalográfica elaborada pela Biblioteca Central do Campus da Universidade de São Paulo - SP - Ribeirão Preto

Nepomuceno, Victor Rodrigues

O impacto da síndrome da fibromialgia na musculatura mastigatória e cervical: análise eletromiográfica, ultrassonográfica, força de mordida e eficiência mastigatória. Ribeirão Preto, 2016.

95 p. : il. ; $30 \mathrm{~cm}$

Tese de Doutorado, apresentada à Faculdade de Medicina de Ribeirão Preto/USP. Área de concentração: Fisioterapia.

Orientadora: Regalo, Simone Cecilio Hallak,

Coorientadora: Chaves, Thais Cristina.

1. Fibromialgia. 2. Eletromiografia. 3. Ultrassonografia. 4. Força de mordida. 5. Eficiência Mastigatória. 


\title{
ATA DE DEFESA
}

\section{Janus}

\author{
Universidade de Sắ Paulo
}

\section{ATA DE DEFESA}

Ats de defesa publica te Tese do(a) Senhor(a) Victor Rodrugues Nepomuceno no Programa: Reabilitacajo e Desempenho Funcionsi, do[ a) Faculdads de Meditins de fubeirso Preto Aa Universidode de Sdo Paulo.

Aos 04 dias do mphs de maio de 2016, no\{a\} FMke-USP realizou-se a Defesa da Tese to(a) Senhar(a) Victor flodrigues Vepomuceno, apresprziada para a obtencso do ticula de Dosutor intibulada:

"O impacto da sincicome da fibromialoa na musculatura mastigatóra e cervicals analise eletramiográfica, utrossenográfica, força do mordids e efickençia massigetéria"

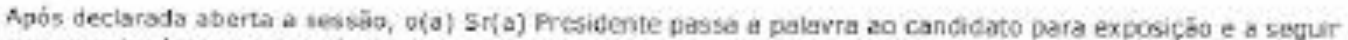
ans examinadones para as devdas anguigses dua se desenvowom nos tarmas regimentais. Em seguida, a Comiesio Julgadora oroclama o resultaco:

\begin{tabular}{|c|c|c|c|}
\hline Nome dos Participantes da danca & Funcse & Sigla da CPG & Resultado \\
\hline Smone Cecilo Hailak Itegaile & Presidente & FOFP = USP & \\
\hline Esam Pereira Cerqueira & Titular & ICD - USP & gevine \\
\hline Mansa Semprini & Titular & FOPP-USP & 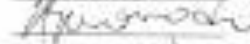 \\
\hline Elane Caldeira de Oliveira Guirro & Titular & FMFF - USP & 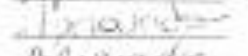 \\
\hline Renato de Moraes & Titular & EEFERP - USP & Aforecsis= \\
\hline
\end{tabular}

Resultado Finali 1 prot-

Parecer da Cemissăo Julgadora *

Eu, Moura Henrique Bernardo faures a presente ats, que aseino

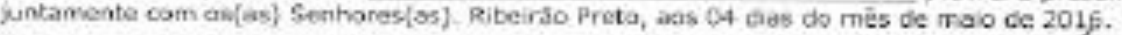
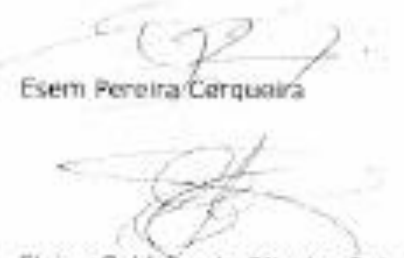

Elaine Caldeî̀e de Oliveiran Guirro

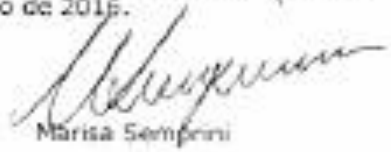

Márisa 5 emprin

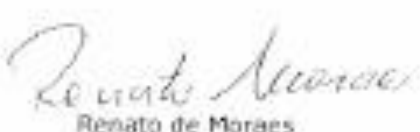

Penato de Moraes

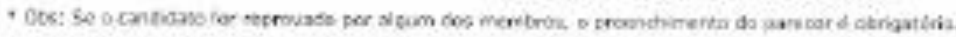

A defesal fai hamologada pela Camsas̃o de Pda Craduacăo em c, portanta, o(a) alunc $\langle a\rangle$ fac jus as titulo de Douter em Ciencias obtido no Programa Reabutacho e Descmoenho Funoional - ires de concentraças Fisiotorapia. 


\section{DEDICATÓRIA}

À minha avó Hilda Rodrigues Furtado, exemplo de pessoa, mulher e avó. Responsável pela formação de minha fé e por suas orações nos momentos de tribulação. Suas lições permanecerão comigo para sempre.

Agradeço aos meus pais pelo amor, carinho, incentivo, força e pela formação do ser humano que sou hoje.

Dedico este trabalho aos meus irmãos, professores, mestres, amigos e a todos que de alguma forma contribuíram para a realização deste. 


\section{AGRADECIMENTOS ESPECIAIS}

Deus

Obrigado, Pai, por ser meu Caminho, minha Luz e minha Verdade.

“...meu Deus em quem eu confio..."

(S1 91:2).

\section{Minha orientadora Profa. Dra. Simone Cecilio Hallak Regalo}

Fantástica orientadora, pessoa com uma energia contagiante! Agraciada com sabedoria, inteligência, carisma, profissionalismo e humildade. Obrigado por acreditar em mim, pelo carinho, paciência e temperança empregados no momento mais difícil que vivi até hoje. Obrigado por me defender, ensinar e me deixar fazer parte de seu ciclo de convivência.

\section{Profa. Dra. Marisa Semprini}

Pessoa calma, sensível, ponderada e detentora de um conhecimento e didática de se admirar. Exemplo de SER HUMANO de verdade.

\section{Profa. Dra. Selma Siéssere}

Pessoa paciente, ponderada e amável. Exemplo de professora e educadora.

Agradeço vocês pelas correções da tese em grupo, por me ensinar que adversidades sempre vão existir, mas com amigos, tudo podemos enfrentar. Obrigado pelos ensinamentos que foram muito além da elaboração desta pesquisa. Obrigado pela paciência e disponibilidade de sempre. Adoro vocês!

\section{Minha Coorientadora Profa. Dra. Thais Cristina Chaves}

Exemplo de profissional, sincera e doce. Sempre com dicas de fundamental importância para a elaboração e concretização dessa pesquisa. Obrigado por auxiliar sempre.

\section{Grandes amigos Luiz Gustavo de Sousa e Paulo Batista de Vasconcelos}

Agradeço pelas conversas, conselhos e auxílio nos cursos de técnicas anatômicas, quer fornecendo os materiais, quer auxiliando na preparação das peças. 


\section{Amiga Clélia Aparecida Celino}

Uma pessoa alegre. Obrigado pela ajuda prestada em todos os momentos de meu doutorado.

Professores do programa de pós-graduação de Reabilitação e Desempenho Funcional

Profa. Dra. Ada Clarice Gastaldi, Profa. Dra. Débora Bevilaqua Grossi, Prof. Dr. Hugo Celso Dutra de Souza, Prof. Dr. Rinaldo Roberto de Jesus Guirro, por acreditarem e permitirem que eu fizesse parte da Primeira Turma desse Programa.

\section{Amigos da Primeira Turma do Programa de Reabilitação e Desempenho Funcional}

Agradeço a amizade e o companheirismo do início ao final de todas as nossas atividades. 


\section{AGRADECIMENTOS}

Ao meu amigo, muito querido, Bruno Rezende Moreno (In memoriam) que com seu exemplo de força e determinação, representou um papel de fundamental importância em meu crescimento, amadurecimento e busca de ideais.

Agradeço à minha irmã, pela paciência, apoio, conversas, exemplo de mulher, caráter e pela dedicação no auxílio deste trabalho.

Agradeço meus pais, Tereza Mont Serrath Nepomuceno e Victor Nepomuceno, pela ajuda, carinho empenho, dedicação e esforço empregados na construção de meu caráter.

Agradeço à Emanuela Juvenal Martins pelo tempo compartilhado.

\section{Universidade Ibirapuera - UNIB:}

Aos Profs. Drs. Daniel Rogério e Ana Cristina de Sousa pela ajuda nos momentos difíceis e indicação para a vida acadêmica.

Ao Prof. Dr. Fábio Faro Passos que apostou em mim, e me direcionou para a vida acadêmica.

\section{Instituto de Ciências Biomédicas III da Universidade de São Paulo - USP:}

Ao Prof. Dr. Esem Pereira Cerqueira, professor, mestre, amigo e irmão. Exemplo de educador, professor e ser humano. Sempre te admirei, admiro e vou admirar. Obrigado pelos conselhos.

Professores, colegas e amigos do Departamento de Morfologia, Fisiologia e Patologia Básica da Faculdade de Odontologia de Ribeirão Preto e Laboratório de Eletromiografia Prof. Dr. Mathias Vitti:

Ao Prof. Dr. Mathias Vitti (In memorian), obrigado pela criação desse espaço de saber e prestação de serviço, onde pessoas do bem vivenciam o dia a dia da pesquisa.

Aos amigos Bruno Ferreira e Gabriel Pádua Silva pelo auxílio na facilitação da coleta dos dados no Centro Universitário - UNIFAFIBE e na elaboração dos resultados, conversas e brincadeiras que ajudaram a tornar o trabalho e a permanência em Ribeirão Preto mais 
prazerosa.

Ao Dr. Marcelo Palinkas pelo auxílio na busca de referências, dicas, elaboração uv artigo e conselhos importantes que enriqueceram sempre nosso estudo.

À Dra. Tânia Borges de Freitas pelas conversas, pelo exemplo de pesquisadora e pessoa que sempre foi.

À Ms. Laíse Angélica pela ajuda na tabulação dos dados.

E a toda equipe do Laboratório, Geraldo Celso da Silva Onety, Carla Moreto Santos, Tânia de Freitas Borges, Daniel Vilela Leonel, João Batista Mattos Lellis, André Mario Maia Dante, Richard Honorato de Oliveira, Sandra Valéria Rancan, Saulo Fabrin, Lígia Oliveira, Veridiana Wanshi, Nayara Soares, Danilo Esposto, Evandro Fioco, Edson Verri, Camila Roza e Bárbara de Lima Lucas, pela agradável convivência.

\section{Programa de Reabilitação e Desempenho Funcional da Faculdade de Medicina Fisioterapia de Ribeirão Preto da Universidade de São Paulo:}

Aos secretários do Programa, Marília dos Reis Pereira Viana Trioli e Samuel Ribeiro Filipini, que sempre auxiliaram em todas as etapas do doutorado.

À amiga Mariana Cândido Ferreira que com sua paciência, calma e serenidade mostrou quais passos deveriam ser dados para a realização desta tese.

\section{Escola de Educação Física e Esporte de Ribeirão Preto - EEFERP:}

Prof. Dr. Renato de Moraes, obrigado por suas contribuições, desde o momento de nosso primeiro encontro, em sua disciplina de Bases Neuromecânicas do Movimento Humano. Em virtude de suas qualidades, saber e sensibilidade, foi o Professor que mais admirei. Obrigado por fazer parte dessa trajetória.

\section{Pensionato VITA ET PAX:}

À Irmã Marina e Dara, no pronto atendimento e hospedagem.

À Madre Maria Lúcia pelas conversas, conselhos e momentos de alegria.

Às meninas Carolina de Resende Damas Cardoso, Giovanna Ottoni, Izabela da Silva Santos, Marcinha da Silva Evangelista e Poliane Freitas, pelas longas conversas, carinho, brincadeiras amizade e apoio nos momentos longe de casa.

\section{Colegas de trabalho da Universidade Federal do Tocantins - UFT:}

À Profa. Dra. Poliana Guerino Marson pelas conversas, conselhos e auxílio nos 
momentos de dúvida e tribulação.

Aos Profs. Drs. Giovanni Montinni Sandoval e Pedro Eduardo Nader Ferreira, colegas e amigos, que sempre me auxiliaram na substituição de aulas e supriram minha ausência com os acadêmicos em todos os momentos.

À Cora Cunha pela sua sensatez, carisma e tranquilidade na resolução de problemas "a distância”.

À Karine Araújo Milhomem pela ajuda durante as viagens informando sobre os procedimentos a serem tomados, auxiliando nas datas e preenchimento de documentos essenciais.

À Rejane Cardoso Rezende e Ana Carla Duarte Queiroz pelo auxílio e meiguice durante as conversas.

Servidores removidos e toda equipe (Anderson da Silva Muniz, Elisana Ligia Garcia Barboza, Luzia Vieira da Silva Bernardes, Marja Diane Pereira Brito de Oliveira, Dimas Magalhães Neto, Raíssa Moura Santos Carvalho) que me auxiliaram nesse tempo que passamos juntos.

\section{Centro Universitário de Bebedouro - UNIFAFIBE:}

Ao Professor e amigo Oswaldo Luiz Stamato Taube por abrir as portas da Clínica Escola de Fisioterapia, ação essa, pela qual conseguimos nossas participantes, assim como de toda a Instituição.

À Lucimara Negri que auxiliou na aquisição das voluntárias da nossa pesquisa. Amiga, que sempre posso contar.

À Roci Lina Mota, participante da pesquisa pelas conversas e apoio dentro da Instituição.

\section{Centro Universitário Luterano de Palmas:}

As Professoras e amigas Rosângela dos Reis (Coordenadora do Curso de Fisioterapia) e Luciana Fernandes Maia (Coordenadora da Clínica Escola de Fisioterapia) por abrir as portas da Instituição e nos receber tão bem, ação essa, pela qual conseguimos nossas participantes.

\section{Família Guidoni:}

Juliana Guidoni, Luiz Scharf, Henrique Guidoni Scharf, Daniel Guidoni Scharf, Maria 
Tereza Guidoni, Renata Guidoni de Moraes por nos acolher e proporcionar alegria. Obrigado por nos ajudar nesse momento especial. 


\section{EPÍGRAFE}

"A lei de ação e reação não é exclusiva da física. Ela está presente também nas relações humanas. Se eu ajo com bondade, recebo bondade. O que os nossos avós nos disseram é a pura verdade: receberás o que desejas aos outros. Ser feliz não é uma questão de destino, é uma questão de opção, ou escolha. Finalmente ele disse: Tome cuidado com os teus pensamentos, porque tornar-se-ão palavras. Tome cuidado com as tuas palavras porque elas tornar-se-ão ações. Tome cuidado com as tuas ações porque elas tornar-se-ão hábitos. Tome cuidado com os teus hábitos porque eles formarão o teu caráter. Tome cuidado com o teu caráter, porque ele formará teu destino e o teu destino será a tua vida."

Ninguém perde por dar amor,

Perde, quem não sabe receber.

“Não preciso de grandes coisas não, ainda prefiro minha simplicidade, minhas levezas, meu sossego de ser quem eu sou, pois este negócio de grandeza não faz bem a ninguém, e o que eu preciso tem o tamanho exato, e se encaixa perfeitamente na minha alma, no meu coração, no meu sorriso e na minha gratidão por tudo que Deus faz na minha vida."

Kláudia Romanholi

Que a gente obedeça ao coração e não esqueça que é preciso manter pelo menos um pé no chão.

Que a gente mantenha um sorriso na boca e não esmoreça quando a vida fechar uma porta.

Que a gente entenda que não dá pra abraçar o mundo, mas dá pra abraçar algumas pessoas e fazer delas o nosso mundo.

Clarissa Corrêa 
A síndrome da fibromialgia é caracterizada pela presença de dor muscular crônica e difusa em pelo menos 11 pontos do corpo humano denominados tender points, rigidez matinal, fadiga, distúrbios do sono, sintomatologia dolorosa extensa na face, e que se manifestam principalmente nos músculos mastigatórios, articulação temporomandibular e na região auricular. O objetivo desta pesquisa foi analisar os músculos mastigatórios (masseter e temporal) e cervicais (esternocleidomastóideo e trapézio) em mulheres com diagnóstico de síndrome da fibromialgia. Participaram dessa pesquisa 68 mulheres entre 40 a 60 anos de idade, distribuídas em dois grupos distintos: GF: síndrome de fibromialgia $(n=34)$ e GC: controle saudável $(n=34)$. O eletromiógrafo Myosystem-Br1 foi utilizado para analisar a atividade EMG. As imagens das espessuras dos músculos mastigatórios e cervicais foram adquiridas pelo ultrassom Sonosite Titan. A força de mordida molar máxima foi obtida por meio de dinamômetro digital Kratos. Os dados da atividade EMG, espessura muscular e força de mordida molar foram tabulados, normalizados e submetidos à análise estatística (SPSS 21.0). Houve diferença estatística significante $(\mathrm{p} \leq 0,05)$ entre GF e GC em todas as condições posturais mandibulares, na mastigação (habitual e não habitual), na espessura muscular e na força de mordida molar, com dados médios menores para GF. Baseados nos resultados desta pesquisa, os autores concluíram que mulheres com síndrome da fibromialgia apresentaram alterações no sistema estomatognático.

Palavras-chave: fibromialgia, eletromiografia, ultrassonografia, força de mordida, sistema estomatognático. 
Fibromyalgia syndrome is characterized by chronic and diffuse muscle pain in at least eleven points of the human body (tender points), morning stiffness, fatigue, sleep disturbances, extensive pain symptoms in the face, which is mainly manifested in the masticatory muscles, temporomandibular joint and ear region. The aim of this study was to analyze the masticatory (masseter and temporal) and cervical (sternocleidomastoid and trapezius) muscles in women with diagnosis of fibromyalgia syndrome. Sixty-eight women aged between 40 and 60 years participated in this research. They were divided into two distinct groups: FG: fibromyalgia syndrome $(n=34)$ and CG: healthy control $(n=34)$. The Myosystem-Br1 electromyography was used to analyze the EMG activity. The thicknesses of the masticatory and neck muscles were acquired by ultrasound Sonosite Titan. The maximum molar bite force was obtained using a digital force gauge Kratos. The data of EMG activity, muscles thickness and maximal molar bite force were tabulated, standardized and subjected to statistical analysis (SPSS 21.0). There were statistically significant differences $(p \leq 0.05)$ between FG and CG at all mandibular postural conditions, chewing, muscle thickness and molar bite force, with lower average data for FG. Based on the results of this research, the authors concluded that women with fibromyalgia syndrome have alterations in the stomatognathic system.

Keywords: fibromyalgia, electromyography, ultrasound, bite force, skeletal striated muscles, stomatognathic system. 
INTRODUÇÃO

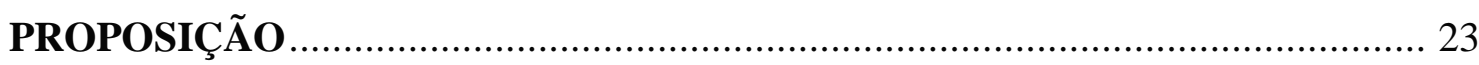

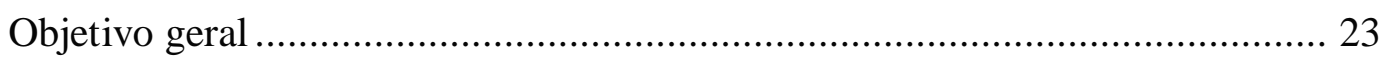

MATERIAL E MÉTODOS ……………………………………………………. 24

Características da população e amostra .............................................................. 24

Avaliação física quanto à presença de dor ........................................................ 27

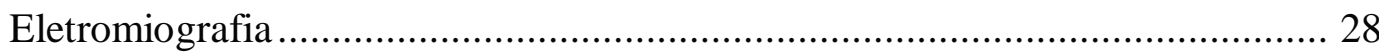

Análise dos ciclos mastigatórios - Eficiência mastigatória .................................. 32

Análise da força de mordida molar máxima ....................................................... 33

Análise da espessura muscular ........................................................................ 34

Análise dos dados e estatística ...................................................................... 36

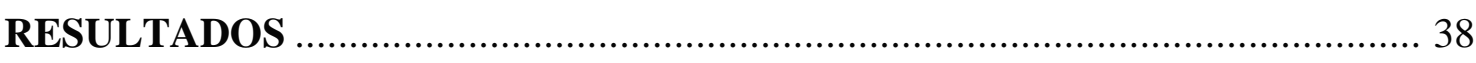

Resultados da análise eletromiográfica (RMS) - Padrões Posturais .................... 39

Resultados da análise eletromiográfica (fENV) - Função Mastigatória ............. 47

Resultados da análise da Força de Mordida Molar Máxima ................................. 53

Resultados da análise ultrassonográfica - Espessura Muscular ............................ 54

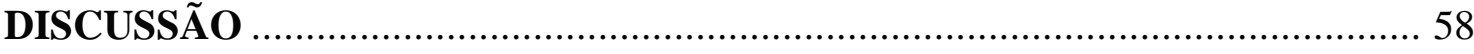

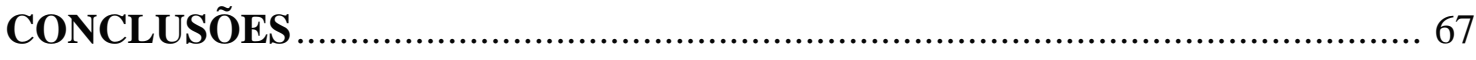

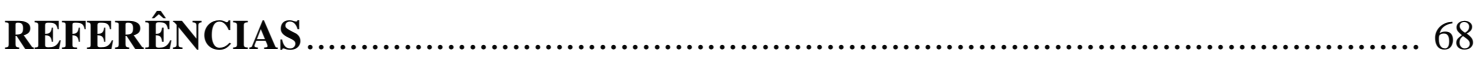

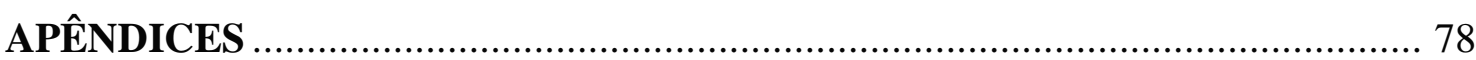

Apêndice A - Termo de consentimento livre e esclarecido.................................. 78

Apêndice B - Ficha de avaliação dos voluntários ................................................ 82

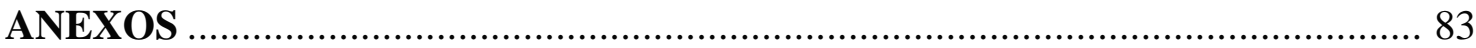

Anexo A - Declaração das instituições............................................................ 83

Anexo B - Certificado de apresentação para apreciação ética (CAAE) ............... 85

Anexo C - Avaliação das áreas dolorosas ……………………………………. 88

Anexo D - Avaliação dolorosa ou escala numérica de dor .................................. 89

Anexo E - Research Diagnostic Criteria For Temporomandibular Disorders

(RDC/TMD) - Versão em Português ......................................................................90 


\section{INTRODUÇÃO}

A palavra fibromialgia deriva do latim fibro (tecido fibroso, presente em ligamentos, tendões e fáscias), e do grego mio (tecido muscular), algos (dor) e ia (condição). Ela foi estabelecida inicialmente por Yunus et al. (1981), com o intuito de substituir o termo fibrosite (VALENTINE, 1947), até então utilizado para denominar um tipo particular de reumatismo caracterizado pela presença de pontos musculares dolorosos e endurecidos à palpação, partindo do pressuposto de que não havia nessa doença inflamação tecidual (SPAETH, 2009).

Acredita-se que a síndrome da fibromialgia apresenta alta prevalência, afetando de 2 a $7 \%$ da população mundial, com maior prevalência no gênero feminino do que no masculino, em proporção de 9:1, com idades entre 45 e 60 anos (FRAGA et al., 2011). Estima-se que no Brasil, a prevalência para essa doença esteja em torno de $2,5 \%$ na população adulta (MARTINEZ et al., 2013).

Segundo os critérios estabelecidos pelo Comitê do American College of Reumathology (WOLFE, 1990), a síndrome da fibromialgia é caracterizada pela presença de dor difusa e crônica (por pelo menos 3 meses), sintomas de rigidez matinal, fadiga, distúrbios do sono e presença de dor à palpação (4 kgf) em pelo menos 11 dos 18 pontos anatomicamente específicos - denominados tender points (TP) localizados em regiões específicas do corpo, a saber: (1-2) Occipital: inserção dos músculos suboccipitais; (3-4) Cervical inferior: anteriormente, entre os processos transversos de C5-C7; (5-6) Trapézio: ponto médio das fibras superiores do músculo trapézio; (7-8) Supraespinal: inserção do músculo supraespinal, acima da espinha da escápula, próximo ao ângulo medial; (9-10) Segunda articulação costocontral: lateral e superior à articulação; (11-12) Epicôndilo lateral: 2 cm distalmente ao epicôndilo lateral; (13-14) Glúteo: quadrante superior e lateral das nádegas; (15-16) Trocânter maior: posterior à proeminência trocantérica; (17-18) Joelho: coxim adiposo medial, próximo à linha articular (WOLFE et al., 1990; SAWADA et al., 2016).

Outros sintomas frequentes encontrados na síndrome da fibromialgia são a parestesia, dificuldade de memorização, palpitação, tontura, sensação de inchaço, dor torácica, cefaleia crônica, ansiedade, depressão, irritabilidade, zumbido, epigastralgia, dispneia, enjoo, dificuldade de digestão, fenômeno de Raynauld, dismenorreia e colo irritável (HELFENSTEIN, FELDMAN, 2002; RIBERTO, BATTISTELLA, 2002; QUEIROZ, 2013), síndrome miofascial e síndrome uretral específica (MARTINEZ et al., 2013).

Estudos de Yunus et al. (1981) e Drewer (1993) verificaram se a síndrome da fibromialgia poderia ser originária da alteração do sistema musculoesquelético. Em estudo de 
revisão bibliográfica sobre a morfologia muscular de indivíduos com síndrome da fibromialgia verificou-se presença de isquemia e/ou alterações metabólicas (SIMMS, GOLDENBERG, 1988; OKIFUJI et al., 1997), com a diminuição do fluxo sanguíneo, predispondo à diminuição do oxigênio nas fibras musculares, ocasionando anormalidade no metabolismo celular, como ocorre em níveis mais baixos de adenosina-trifosfato (ATP), que resulta em dor muscular durante a realização de atividades (OLSEN, PARK, 1998). Outros autores compartilharam dessa hipótese etiológica associando a utilização de eletromiografia de superfície para investigar essa condição (ELERT et al., 2001; HÄKKINEN et al., 2002; MARQUES et al., 2002; KLAVER-KRÓL et al., 2007; GERDLE et al., 2008; BAZZICHI et al., 2009; CASALE et al., 2009; NASSIRI et al., 2009; FALLA et al., 2010; GERDLE et al., 2010; MAQUET et al., 2010; CASALE, RAINOLDI, 2011; KLAVER-KRÓL et al., 2012).

A eletromiografia de superfície é uma técnica não invasiva que mensura a atividade muscular, por meio do potencial de ação, na qual eletrodos são colocados sobre a pele que recobre o músculo ou o grupo muscular para registrar sua contração e relaxamento, e avalia seu comportamento gerado durante contrações voluntárias dinâmicas. Durante o registro do potencial de ação, este pode fornecer informações sobre os intervalos de ativação muscular, assim como auxiliar na administração de estratégias de controle neural e propriedades do sistema neuromuscular (DROST et al., 2006; MERLETTI et al., 2009). Portanto, é um método de estudo que pode ser aplicado na verificação da função muscular e na monitorização dos efeitos fisiológicos da reabilitação e treinamento (STYLIANOU et al., 2005; KIMURA et al., 2007). Dessa forma, a eletromiografia tem evidenciado informações sobre os intervalos de ativação muscular, as medidas indiretas do diâmetro das fibras musculares e os meios indiretos para verificar a constituição do tipo de fibra, podendo portanto ser utilizada para avaliar as alterações musculares de indivíduos com síndrome da fibromialgia (BAZZICHI et al., 2009).

Estudos que utilizaram a eletromiografia de superfície, a área transeccional e o treinamento de força nos músculos vastos medial e lateral (VÄLKEINEN et al., 2005) e bíceps femoral (HÄKKINEN et al., 2002; VÄLKEINEN et al., 2004) em indivíduos com síndrome da fibromialgia e controles, não mostraram diferenças. Outros estudos registraram diferentes valores na velocidade de condução e/ou outros parâmetros eletromiográficos durante exercícios isométricos em indivíduos com síndrome da fibromialgia (ELERT et al., 2001; GERDLE et al., 2008). Além disso, na literatura há heterogeneidade em relação às técnicas utilizadas, contudo existe concordância em relação ao aumento da tensão muscular em indivíduos com dor crônica (BAZZICHI et al., 2009). 
$\mathrm{Na}$ síndrome da fibromialgia, a dor localizada na face é somente um aspecto da desordem que envolve toda a musculatura corporal (MOLDOFSKY, 2001). Por muitos anos considerou-se a síndrome da fibromialgia e a desordem temporomandibular acometimentos distintos. Atualmente, há consenso na literatura a respeito dos sintomas orofaciais, que são vivenciados de modo mais evidente pelos indivíduos com síndrome da fibromialgia do que por indivíduos com desordem temporomandibular, e que as duas situações clínicas possuem semelhanças entre si (BALASUBRAMANIAM et al., 2007; PIMENTEL et al., 2013; GUI, PIMENTEL, RIZZATTI-BARBOSA, 2015). No entanto, quando Pimentel (2011) observou alterações no sistema estomatognático com o quadro de desordem temporomandibular, avaliando 40 mulheres diagnosticadas com síndrome da fibromialgia e em tratamento, mostrou que a prevalência da desordem temporomandibular foi alta: em torno de $78 \%$, sendo que $85 \%$ do grupo apresentou queixa de dor orofacial.

A desordem temporomandibular apresenta um grande número de alterações clínicas que podem envolver a musculatura mastigatória, as articulações temporomandibulares e as estruturas associadas, tendo como principais sinais e sintomas a dor, a sensibilidade à palpação dos músculos da mastigação e das articulações temporomandibulares, os ruídos articulares e a mudança da dinâmica mandibular (ACOSTA-ORTIZ et al., 2004; DWORKIN et al., 2002; NASSIRI et al., 2009; ). Essa desordem pode comprometer também os vasos sanguíneos e as estruturas nervosas (AQUINO et al., 2012; BRAGATTO et al., 2016). Indivíduos com desordem temporomandibular também podem apresentar dor na mandíbula, orelha e na cabeça (CONSALTER, SANCHES, GUIMARÃES, 2010; CORREIA et al., 2014).

Aquino et al. (2012) verificaram que a desordem temporomandibular tem prevalência em mulheres com idade entre 20-45 anos, e quase $10 \%$ da população adulta apresenta algum sinal ou sintoma (anatômico, trauma, patofisiológico e psicossocial) que afeta o equilíbrio dinâmico do sistema mastigatório. Essa desordem pode ser classificada como doença multifatorial, ou seja, não apresenta fator etiológico específico e sim fatores de risco, subdivididos em predisponentes, iniciadores e perpetuantes. Segundo a Academia Americana de Dor Orofacial (American Academy Oral Pain - AAOP), a desordem temporomandibular pode ser classificada como muscular, articular ou mista (CONSALTER, SANCHES, GUIMARÃES, 2010).

Uma característica relacionada à síndrome da fibromialgia e desordem temporomandibular é a presença de dor muscular cervical, associada também a dor nos músculos levantadores da mandíbula, que nessas condições, têm sua força de contração e 
atividade elétrica alteradas. Um dos músculos atingidos pela dor muscular cervical, que pode provocar disfunção nos músculos mastigatórios, é o esternocleidomastóideo, diretamente relacionado com a postura da cabeça (STRINI et al., 2013).

Existe considerável sobreposição de sinais e sintomas entre desordem temporomandibular e distúrbios da dor muscular cervical. $\mathrm{O}$ desenvolvimento de sinais e sintomas de desordem temporomandibular associada a lesões cervicais fornece fortes evidências para a correlação entre esses dois grupos de distúrbios, embora a natureza do envolvimento dos músculos cervicais e seu significado, incluindo os mecanismos neurológicos dessa relação, ainda precisam ser esclarecidos. A explicação para essa associação está no envolvimento de estruturas anatômicas do crânio para a cintura escapular, em que o acometimento de uma pode trazer consequências para a outra. Estudos neuropsicológicos forneceram forte evidência para a existência de tal ligação funcional entre estas duas regiões (PALLEGAMA, 2004).

Diferenças significativas na atividade eletromiográfica durante o sono de indivíduos com dor associada à desordem temporomandibular e indivíduos sem dor foram observadas, com correlação significativa entre a atividade eletromiográfica e a intensidade da dor (YACHIDA et al., 2012).

Em indivíduos saudáveis, na condição clínica de apertamento dental, houve aumento da atividade eletromiográfica do músculo esternocleidomastóideo, ipsilateral aos músculos levantadores da mandíbula recrutados para essa tarefa, evidenciando a associação e o trabalho em conjunto desses músculos. A redução das atividades dinâmicas dos músculos masseter e esternocleidomastóideo, durante a deglutição da saliva, depois do uso de placas oclusais, forneceram evidências adicionais para a existência de ligação funcional entre os músculos da região craniocervical (PALLEGAMA et al., 2004). Durante a aplicação de anestésico local no músculo masseter, pode-se observar diminuição da atividade muscular na região do músculo trapézio (CARLSON et al., 1993).

Embora existam evidências para demonstrar possível ligação funcional entre músculos da mastigação e cervicais em indivíduos com desordem temporomandibular em diferentes situações clínicas (estáticas e dinâmicas), as características das atividades elétricas em repouso dos músculos esternocleidomastóideo e trapézio nos indivíduos com desordem temporomandibular ainda não foram relatadas. Devido à existência de ligação funcional entre estes dois grupos de músculos, é razoável esperar estado de hiperatividade dos músculos esternocleidomastóideo e trapézio em indivíduos com desordem temporomandibular mesmo em repouso (PALLEGAMA et al., 2004). 
Durante o apertamento dental, exercício de contração voluntária máxima, os níveis médios dos picos eletromiográficos dos músculos digástrico e esternocleidomastóideo aumentaram a partir da posição de repouso em indivíduos saudáveis, revelando coativação dos músculos da região anterior do pescoço durante os movimentos da mandíbula, assim como, associação funcional entre os músculos da mastigação e cervicais. As compensações musculares entre o sistema motor mandibular e as estruturas cervicais podem representar mecanismo necessário para obtenção da estabilidade durante a função mastigatória e podem influenciar a estrutura muscular (STRINI et al., 2013).

Indivíduos com desordem temporomandibular e indivíduos com síndrome da fibromialgia demonstram sintomas semelhantes, como dor durante os movimentos da mandíbula, ruídos articulares e cefaleia, além de similaridades quanto à presença e intensidade de dor à palpação dos músculos da mastigação (CIMINO et al., 1998; AQUINO et al., 2012). Na literatura observa-se que as duas condições clínicas normalmente estão associadas por quatro formas: 1) a diminuição do limiar doloroso na síndrome da fibromialgia é relacionada com a dor musculoesquelética da face e, nesse caso, a síndrome é o problema principal que predispõe à desordem temporomandibular; 2) a síndrome da fibromialgia e a desordem temporomandibular estão relacionadas a alterações psicológicas primárias, dessa forma, não apresentam relação causal direta, mas se originam em virtude de alguma anormalidade psicológica; 3) a angústia psicológica observada em indivíduos com síndrome da fibromialgia é observada pelos relatos de maior preocupação, de aumento em consultas médicas e, à prevalência diagnóstica; nesse caso, o indivíduo apresenta a síndrome da fibromialgia como problema inicial e a desordem temporomandibular não constitui diagnóstico para a sua queixa; 4) todas as disfunções dolorosas estão relacionadas ao aumento na incidência da síndrome da fibromialgia; logo, a desordem temporomandibular favorece a origem da síndrome da fibromialgia (FRAGA et al., 2011).

Dessa forma, é essencial o entendimento das possíveis alterações em indivíduos com síndrome da fibromialgia, fazendo-se necessário melhor investigação do sistema estomatognático, tendo em vista que se observa alta prevalência (75-97\%) de dores orofaciais (MANFREDINI et al., 2006; FRAGA et al., 2011).

A força de mordida molar máxima é componente extremamente relevante para o sistema estomatognático (TSUGA et al., 1998; ZIVKO-BABIĆ et al., 2002) e varia com a morfologia facial, a estrutura física geral, o gênero do indivíduo, o estado de dentição e a idade (BONJARDIM et al., 2005). A força de mordida e o número de dentes são ainda determinantes no desempenho da função mastigatória (PEREIRA et al.. 2006). No entanto, a 
força de mordida não é afetada pela desordem temporomandibular, embora tenham encontrado associação entre força de mordida máxima, peso e estatura nos indivíduos portadores de desordem temporomandibular, como também foi encontrado correlação positiva entre aumento da força de mordida e maior atividade eletromiográfica dos músculos levantadores da mandíbula (GEORGIAKAKI et al., 2007).

Pesquisas recentes têm dado importância na determinação da força de mordida em seres humanos visando a avaliação e a compreensão da funcionalidade do sistema da mastigação, a anatomia craniomandibular, os mecanismos neuromusculares, a eficiência da mastigação e a força muscular. Dessa forma, a força de mordida está diretamente relacionada à mastigação e é determinada pelas características morfológicas dos músculos levantadores da mandíbula (especialmente em sua secção transversal) e sua interação com os sistemas ósseo, nervoso e dental. A condição desses sistemas interfere diretamente na capacidade de mastigar e morder (PALINKAS et al., 2010).

$\mathrm{O}$ ato de mastigar é compreendido como processo complexo que envolve a atividade dos músculos levantadores da mandíbula, faciais, suprahioideos e língua, que colaboram para a formação do sistema estomatognático e apresentam ação conjunta, ou seja, unidos trabalham proporcionando de modo satisfatório a mastigação. Sendo assim, qualquer mudança ou redução na capacidade das etapas que envolvem a formação do bolo alimentar até a deglutição podem ter como causa alterações na atividade da musculatura mastigatória. A avaliação da atividade eletromiográfica se traduz em um mecanismo importante para a investigação de alterações fisiopatológicas que afetem o desempenho muscular durante o processo mastigatório. A eficiência dos ciclos mastigatórios é determinada pela média do conjunto de ciclos mastigatórios adquiridos a partir do sinal eletromiográfico (microvolts/segundo), importante fonte de informações clínicas para a análise do sistema da mastigação (PALINKAS et al., 2013).

A utilização da integral da envoltória do sinal eletromiográfico tem sido pouco explorada em trabalhos para avaliar a eficiência mastigatória, no entanto, quando aplicada nos proporcionam importantes informações clínicas referentes ao sistema da mastigação (BIASOTTO, BIASOTTO-GONZALES, PANHOCA, 2005; YVEN et al., 2006; FUEKI et al., 2008; SIÉSSERE et al., 2009; AP BIASOTTO - GONZALEZ et al., 2010; BORGES, et al., 2013; PALINKAS et al., 2013), tornando-se uma metodologia de grande importância no acompanhamento da evolução do quadro de indivíduos com síndrome da fibromialgia, como também em indivíduos portadores de desordem temporomandibular.

A ultrassonografia é definida como técnica não invasiva que permite avaliar a área 
transeccional dos músculos e, diferentemente da tomografia computadorizada, não tem efeito biológico cumulativo, sendo segura para a avaliação da dinâmica muscular (BERTRAM, 2003; PALINKAS et al., 2010) e a verificação de mudanças estruturais musculares, como contratura muscular, hipertrofia, lesões e alterações na superfície de tecidos moles (STRINI et al., 2013).

$\mathrm{Na}$ análise do sistema estomatognático, a espessura dos músculos masseter e temporal tem sido relacionada a fatores oclusais, desordem temporomandibular, crescimento e morfologia facial (SERRAet al., 2008).

A ultrassonografia pode ser considerada como técnica confiável para a avaliação dos músculos da cabeça e do pescoço, incluindo os músculos temporal, masseter, ventres anterior e posterior do digástrico e o esternocleidomastóideo, além disso, é importante na investigação da relação entre a atividade eletromiográfica e a espessura muscular (STRINI et al., 2013).

Não há exames laboratoriais ou radiológicos que confirmam ou excluam o diagnóstico de síndrome da fibromialgia, pois os indivíduos não apresentam alterações evidentes em órgãos ou sistemas, embora mencionem elevados níveis de dor, fadiga e outros sintomas associados, semelhantes aos portadores de outras doenças reumáticas (MARTINEZ et al., 1994). Portanto, consideramos que as metodologias escolhidas para desenvolver este trabalho (a eletromiografia de superfície e a ultrassonografia, bem como, a força de mordida, a eficiência da mastigação) são ferramentas úteis na avaliação de alterações das características musculares dos indivíduos com síndrome da fibromialgia participantes do nosso trabalho, podendo ser instrumentos que reforcem o diagnóstico, direcionem terapias individuais, além de colaborar na avaliação da evolução da doença ao longo do tempo.

Considerando ainda que dados epidemiológicos referentes à prevalência da fibromialgia, assim como, os sintomatológicos são variáveis e dependentes da população avaliada e da metodologia aplicada, entendemos que todos esses fatos são importantes para evidenciar a necessidade de desenvolvimento de mais trabalhos sobre o assunto. Somente assim, os resultados poderão incentivar os profissionais da saúde, os portadores dessa síndrome, os familiares e a saúde pública. 


\section{PROPOSIÇÃOO}

\section{Objetivo geral}

Avaliar os músculos da mastigação e cervicais de indivíduos portadores da síndrome da fibromialgia e comparar os achados com indivíduos saudáveis, por meio das seguintes análises: eletromiografia de superfície, ultrassonografia, força de mordida e eficiência mastigatória. 


\section{MATERIAL E MÉTODOS}

\section{Características da população e amostra}

Para o desenvolvimento deste trabalho foram selecionados 68 indivíduos do gênero feminino, com idades entre 40 e 60 anos distribuídos em dois grupos: 34 controle (GC) e 34 com fibromialgia (GF), provenientes das Instituições (ANEXO - A): Clínica Escola de Fisioterapia do Centro Universitário (UNIFAFIBE) - Bebedouro/SP (17 indivíduos, sendo 7 controle e 10 fibromialgia) e do Centro Universitário Luterano de Palmas (CEULP/ULBRA) - Palmas/TO (51 indivíduos, sendo 27 controle e 24 fibromialgia). A descrição da amostra das participantes dos GC e GF estão na Tabela 1.

Tabela 1. Média e erro padrão das características físicas das participantes. Grupo Controle (GC); Grupo Fibromialgia (GF); Índice de Massa Corpórea (IMC).

\begin{tabular}{lll}
\hline \multicolumn{1}{c}{ Variáveis } & \multicolumn{1}{c}{ GC } & GF \\
\hline Idade (anos) & $46,32 \pm 1,23$ & $51,17 \pm 1,22$ \\
Peso $(\mathrm{Kg})$ & $66,21 \pm 1,24$ & $72,88 \pm 1,92$ \\
Estatura $(\mathrm{cm})$ & $1,63 \pm 0,01$ & $1,60 \pm 0,00$ \\
IMC & $25,02 \pm 0,53$ & $28,36 \pm 0,71$ \\
\hline
\end{tabular}

A pesquisa foi aprovada pelo Comitê de Ética em Pesquisa da Faculdade de Odontologia de Ribeirão Preto da Universidade de São Paulo - FORP/USP, com Certificado de Apresentação para Apreciação Ética (CAAE no 15268413.7.0000.5419) (ANEXO - B), de acordo com a Resolução no 466/12, do Conselho Nacional de Saúde. Todas as participantes assinaram o Termo de Consentimento Livre e Esclarecido (APÊNDICE - A).

Foram incluídas nos grupos GC e GF somente participantes com capacidade de compreensão das informações referentes às tarefas motoras solicitadas, sem alterações posturais clinicamente significativas e oclusão normal. Para o GF, foram selecionadas mulheres com diagnóstico médico de síndrome da fibromialgia, classificadas conforme os critérios do American College of Reumathology, que incluem: dor por mais de três (03) meses nos quatro (04) quadrantes do corpo, no esqueleto axial e a dígito-pressão em pelo menos onze (11) dos dezoito (18) tender points bilateralmente. Foram excluídas do GC participantes que se encaixavam nos critérios do American College of Reumathology para síndrome da fibromialgia, que utilizaram relaxantes musculares nos últimos 5 dias antes da coleta das 
análises, utilizavam próteses bucais e apresentavam sinais e sintomas de desordem temporomandibular. Para o GF, foram excluídas participantes que utilizaram outros medicamentos que não aqueles para o tratamento farmacológico comum da síndrome da fibromialgia, como antidepressivos tricíclicos (amitriptilina, ciclobenzaprina); bloqueadores seletivos de recaptação de serotonina (fluoxetina); benzodiazepínicos (alprazolam); analgésicos; e outros (hormônio do crescimento recombinante ou tabaco) (PROVENZA et al., 2004), além de próteses bucais (Fig. 1). 


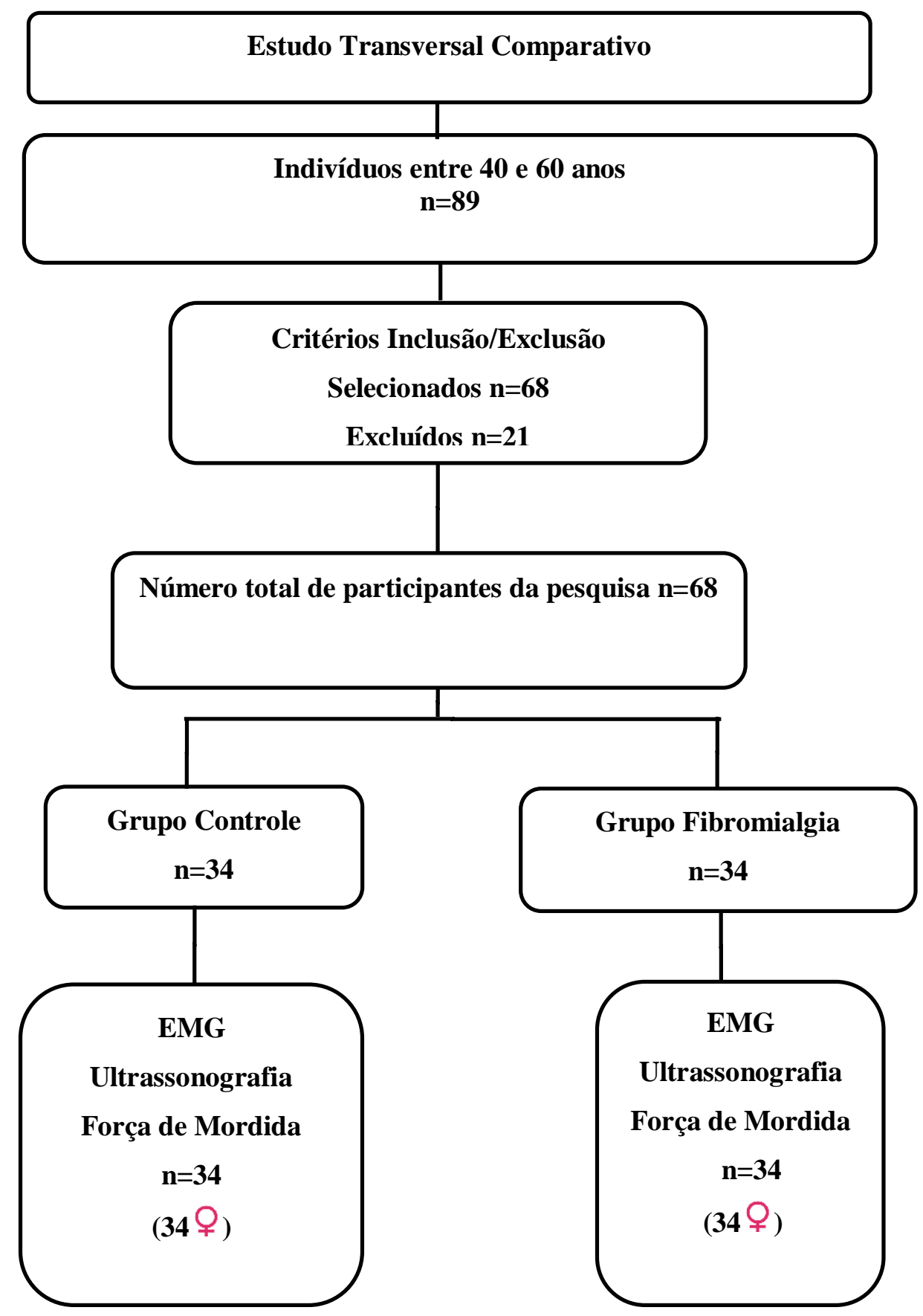

Figura 1. Diagrama da amostra da pesquisa. 
Previamente à realização do protocolo experimental, uma entrevista individual foi realizada com cada uma das participantes de ambos os grupos (GC e GF) para a realização da anamnese, em que foi possível coletar dados referentes à idade, estatura, peso e informações como a atividade física que realizavam (tipo, duração e frequência), terapias que desenvolviam (Fisioterapia e/ou cognitivo-comportamental), além dos medicamentos que utilizavam (APÊNDICE - B). Após essa fase, as participantes de ambos os grupos receberam informações sobre cada uma das técnicas a que seriam submetidas e foi possível, também, esclarecer todas as dúvidas que as mesmas levantaram para a realização do estudo.

As participantes do estudo foram orientadas que, para o desenvolvimento do protocolo experimental, deveriam permanecer sentadas e recostadas (postura ereta), com o olhar dirigido ao horizonte, os membros superiores apoiados confortavelmente nas coxas e os pés apoiados no solo, e que deveriam permanecer calmas, respirando lenta e pausadamente. Informamos ainda que o ambiente em que seriam realizadas as coletas dos dados seria tranquilo e silencioso (Fig. 2).

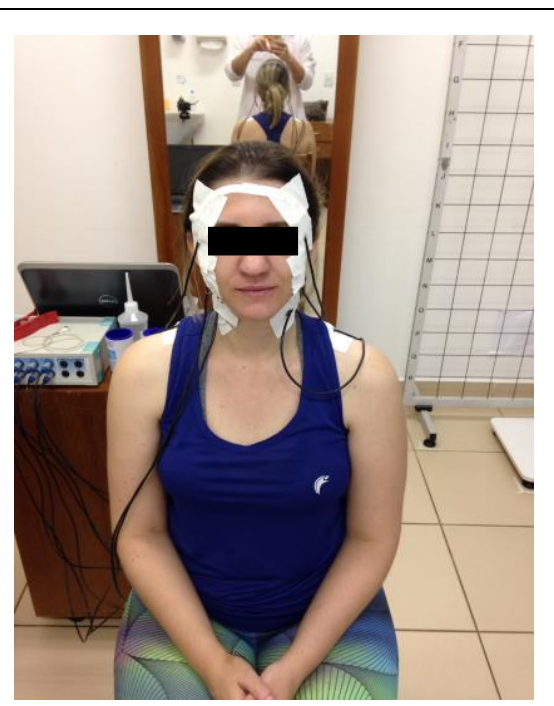

Figura 2. Posicionamento das participantes da pesquisa.

\section{Avaliação física quanto à presença de dor}

Os tender points foram avaliados em cada participante usando um dolorímetro de Fischer (algômetro de pressão), que é um aparelho desenvolvido para mensurar a intensidade de pressão suficiente para provocar dor. Ese instrumento foi aplicado em uma taxa de $1 \mathrm{kgf} / \mathrm{s}$ e a participante foi instruída a dizer quando o procedimento passou a ser doloroso. O limiar de dor foi calculado para os 18 tender points, e foram considerados apenas aqueles que tiveram 
limiar doloroso $\leq 4 \mathrm{kgf} / \mathrm{s}$, em ambos os lados do corpo (ANEXO - C). A escala de pontos dolorosos totais dos lados direito e esquerdo foram utilizadas para análise estatística (Tabela 2). Foi também aplicada a Escala Numérica de Dor para avaliação de dor (ANEXO - D).

Tabela 2. Valores médios e erro padrão de tender points e dor (Escala Numérica de Dor) dos grupos Controle e Fibromialgia. Grupo Controle (GC); Grupo Fibromialgia (GF).

\begin{tabular}{cccc}
\hline Variáveis & Grupo GC & GF & Significância \\
\hline Tender points & $0,25 \pm 0,25$ & $15,25 \pm 0,86$ & $\mathbf{0 , 0 0}^{*}$ \\
Escala Numérica de Dor & $0,00 \pm 0,00$ & $7,62 \pm 1,11$ & $\mathbf{0 , 0 0}^{*}$ \\
\hline
\end{tabular}

*significante para $\mathrm{p} \leq 0,05$

As participantes do trabalho foram submetidas à versão em português do questionário produzido pelo Research Diagnostic Criteria of Temporomandibular Disorders (RDC/TMD) com o objetivo de diagnosticar a presença ou não da desordem temporomandibular (ANEXO - E) e identificar seus aspectos clínicos e psicossociais (Eixo I e Eixo II).

\section{Eletromiografia}

Para a análise eletromiográfica utilizou-se o Eletromiógrafo MyoSystem-Br1 P84, de doze canais, portátil, sendo oito canais para eletromiografia de superfície (para eletrodos ativos e passivos), quatro canais auxiliares, sistema de aquisição de dados de alta performance e software para controle, armazenamento, processamento e análise de dados. Os conectores possuem saídas de tensão CC de $\pm 12 \mathrm{~V} @ \pm 100$ mA, CMRR (relação de rejeição em modo comum) de $112 \mathrm{~dB} @ 60 \mathrm{~dB}$, impedância de entrada para eletrodos passivos $10^{1^{\circ}} \mathrm{Ohms} / 6 \mathrm{pf}$, correntes bias de entrada para eletrodos ativos de $\pm 2 \mathrm{nA}$, proteção contra sobretensões e filtros passa faixa para eliminação de ruídos de $5 \mathrm{~Hz}$ a $5 \mathrm{KHz}$ (Fig. 3). 


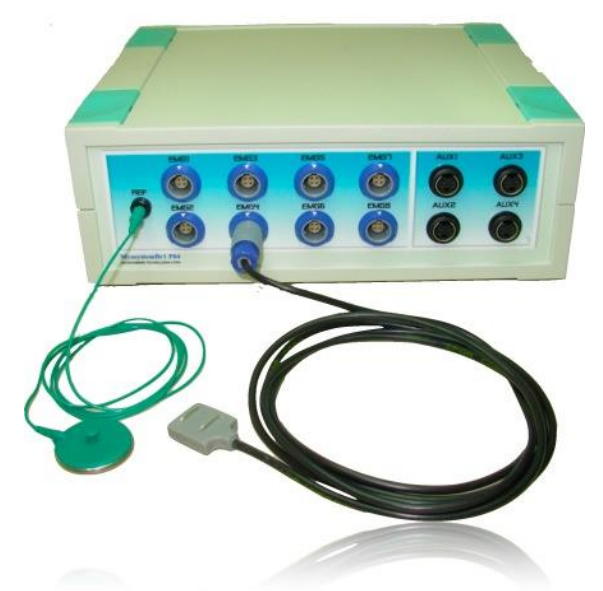

Figura 3. Eletromiógrafo MyoSystem-Br-1.

Foram utilizados eletrodos de prata, com encapsulamento de resina de 40 x 20 x 5 mm, ativos simples diferenciais de superfície com dois contatos de 10 x $1 \mathrm{~mm}$ e distância de $10 \mathrm{~mm}$ entre eles, e para o parâmetro eletromiográfico de coleta utilizou-se eletrodos ativos com ganho de sinal de 20x, amplificação analógica do sinal com ganho de 124x e filtros analógicos em frequência de $2 \mathrm{Khz}$ (Fig. 4).

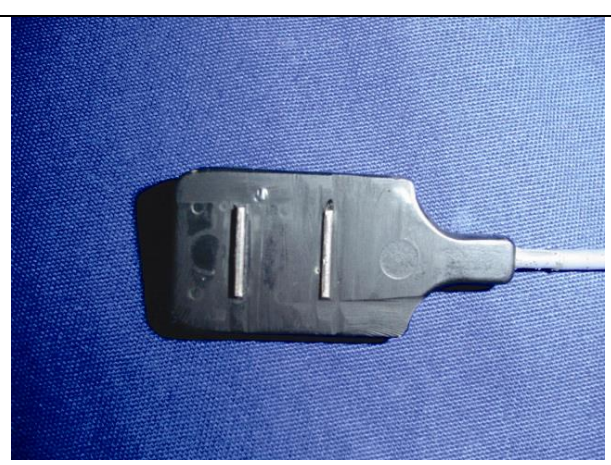

Figura 4. Eletrodo ativo diferencial de superfície.

Os eletrodos foram posicionados sobre a pele dos músculos temporal (ventres anteriores), masseter, esternocleidomastóideo e trapézio superior bilateralmente (Fig. 5). Para isso, foi realizada a medição e demarcação do melhor ponto para eletromiografia de superfície, seguindo a padronização do protocolo internacional, Surface Electromyography for the Non-Invasive Assessment of Muscles (SENIAM) (HERMENS et al., 2000). Foi realizada a manobra de contração voluntária máxima para localização do melhor ponto para análise eletromiográfica (CRAM et al., 1998). 


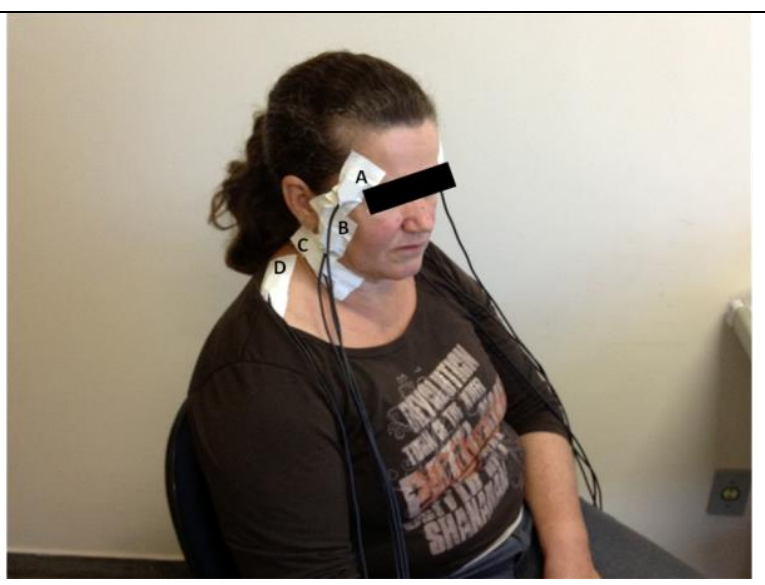

Figura 5. Posicionamento dos eletrodos nos músculos: (A) temporal direito; (B) masseter direito; (C) esternocleidomastóideo direito; e (D) trapézio superior direito.

Foi utilizado um eletrodo de referência (terra), com disco redondo de aço inoxidável de $3 \mathrm{~cm}$ de diâmetro, 1,5 de espessura e um cabo de $1 \mathrm{~m}$ de comprimento (Fig. 6). Esse eletrodo foi umedecido com um gel eletrocondutor para facilitar a condutibilidade entre pele e eletrodo, minimizando assim o risco de interferências (Fig. 7) (BASMAJIAN, DE LUCA, 1985).

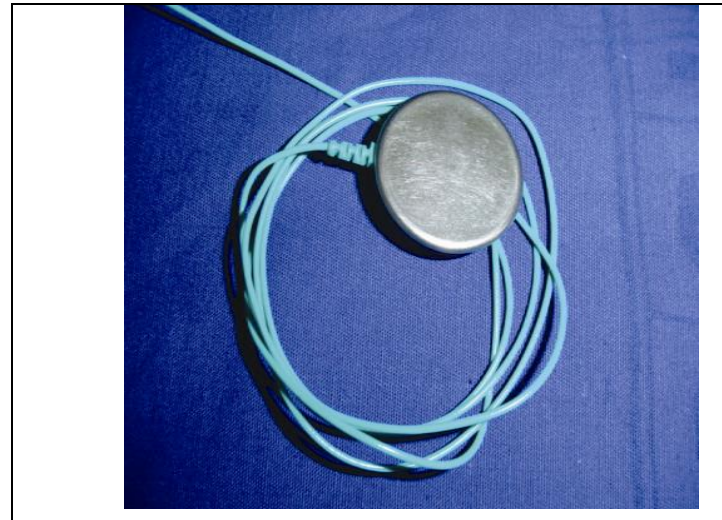

Figura 6. Eletrodo de referência (terra).

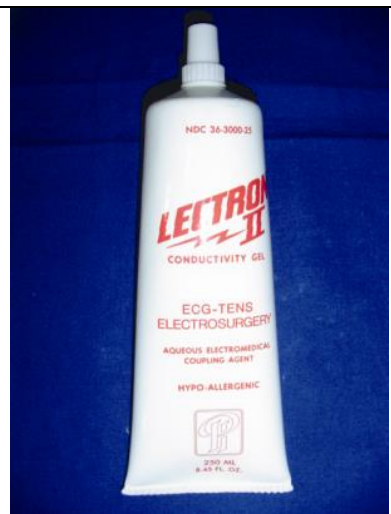

Figura 7. Gel eletrocondutor.

As avaliações das atividades musculares foram obtidas por meio de registros eletromiográficos, bilateralmente, nas seguintes condições clínicas: 1) Repouso por 4 segundos; 2) Apertamento dental máximo por 4 segundos (fator de normalização); 3 ) Mastigação molar bilateral de Parafilme $\mathrm{M}^{\circledR}$ por 10 segundos; 4) Lateralidade direita máxima com contato dental por 10 segundos; 5) Lateralidade esquerda máxima com contato dental por 10 segundos; 6) Protrusão máxima da mandíbula com contato dental por 10 segundos; 8) Mastigação de $5 \mathrm{~g}$ de uvas-passas por 10 segundos; 9) Mastigação de $5 \mathrm{~g}$ de amendoins por 10 segundos. Toda a atividade eletromiográfica mastigatória foi normalizada por meio do 
apertamento dental bilateral máximo por 4 segundos.

As atividades eletromiográficas dos músculos esternocleidomastóideo e trapézio também foram normalizadas por meio da coleta de sinais eletromiográficos durante atividades que promovessem resistência para estes músculos.

A atividade de resistência do músculo esternocleidomastóideo foi realizada com a participante deitada em decúbito dorsal, com membros superiores estendidos aos lados do tronco e inferiores estendidos e unidos. Uma faixa de poliéster foi posicionada na fronte das participantes da pesquisa e presa nos pés da maca de avaliação de modo que ficasse justa e promovesse resistência durante o movimento de flexão do pescoço (Fig. 8).

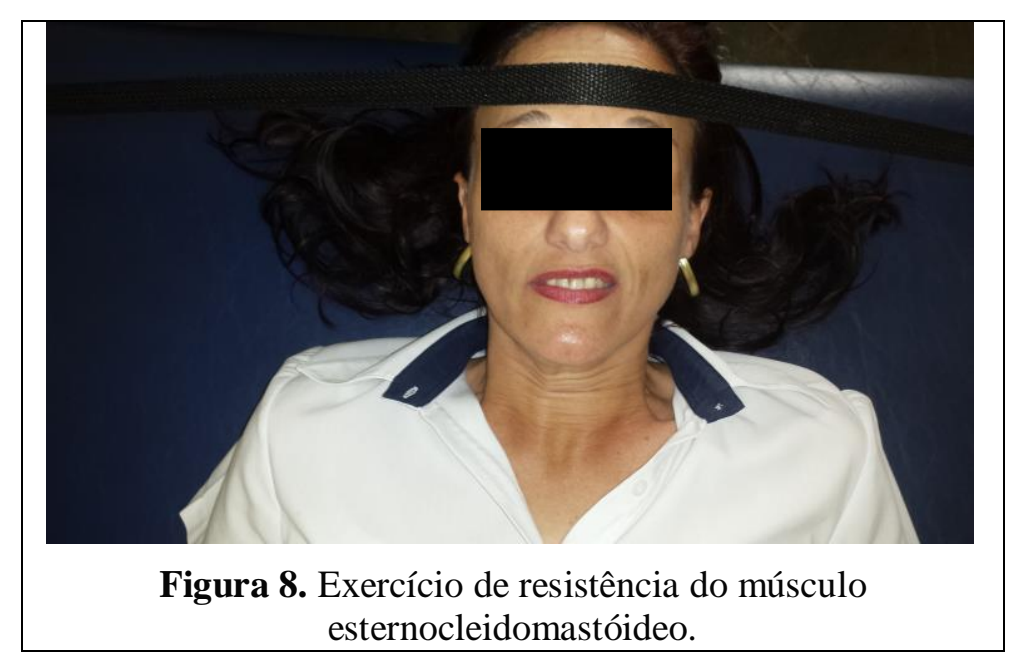

Para a execução da atividade de resistência do músculo trapézio construiu-se uma plataforma de madeira (Fig. 9) medindo 130 x $90 \mathrm{~cm}$ (A) com ganchos reguláveis (B). Faixas de poliéster (C) eram então fixadas nos ganchos de forma que pudessem ficar presas, ao mesmo tempo, para que fosse possível a melhor regulação e adaptação nas participantes. Uma cadeira (46 x $46 \mathrm{~cm}$ ) (D) foi posicionada no centro da plataforma para realização da atividade proposta. Foi solicitado às participantes que ficassem sentadas e recostadas de forma ereta, com o olhar dirigido ao horizonte, os membros superiores repousando sobre as coxas e os pés apoiados no solo. Após o posicionamento, a faixa de poliéster era posicionada na altura dos ombros, de forma a oferecer resistência durante o movimento de elevação dos ombros (Fig. $10)$. 


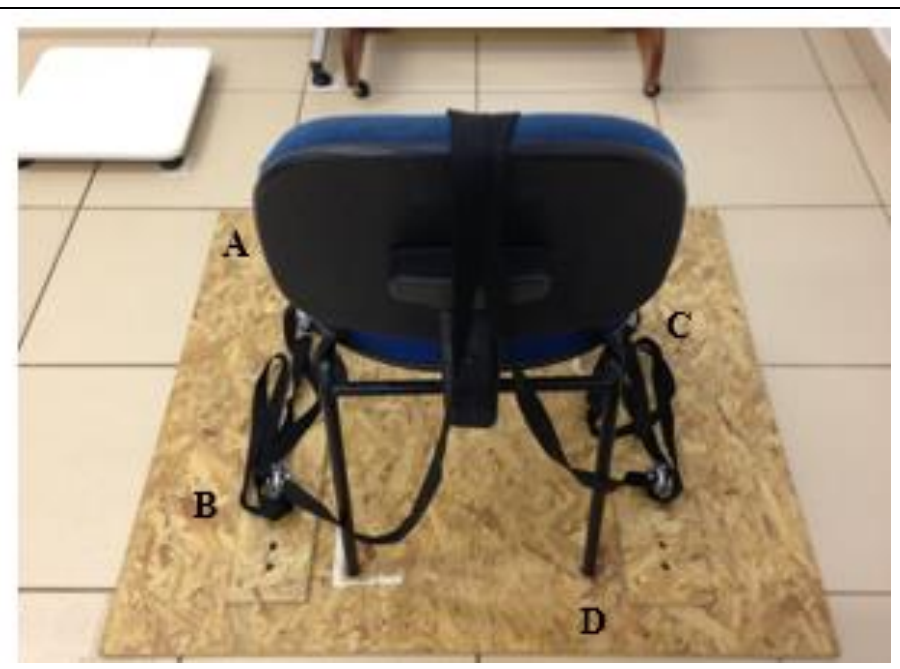

Figura 9. Estrutura para a realização da atividade de resistência do músculo trapézio: (A) Plataforma de madeira; (B) Ganchos reguláveis; (C) Faixas de poliéster; e (D) Cadeira.

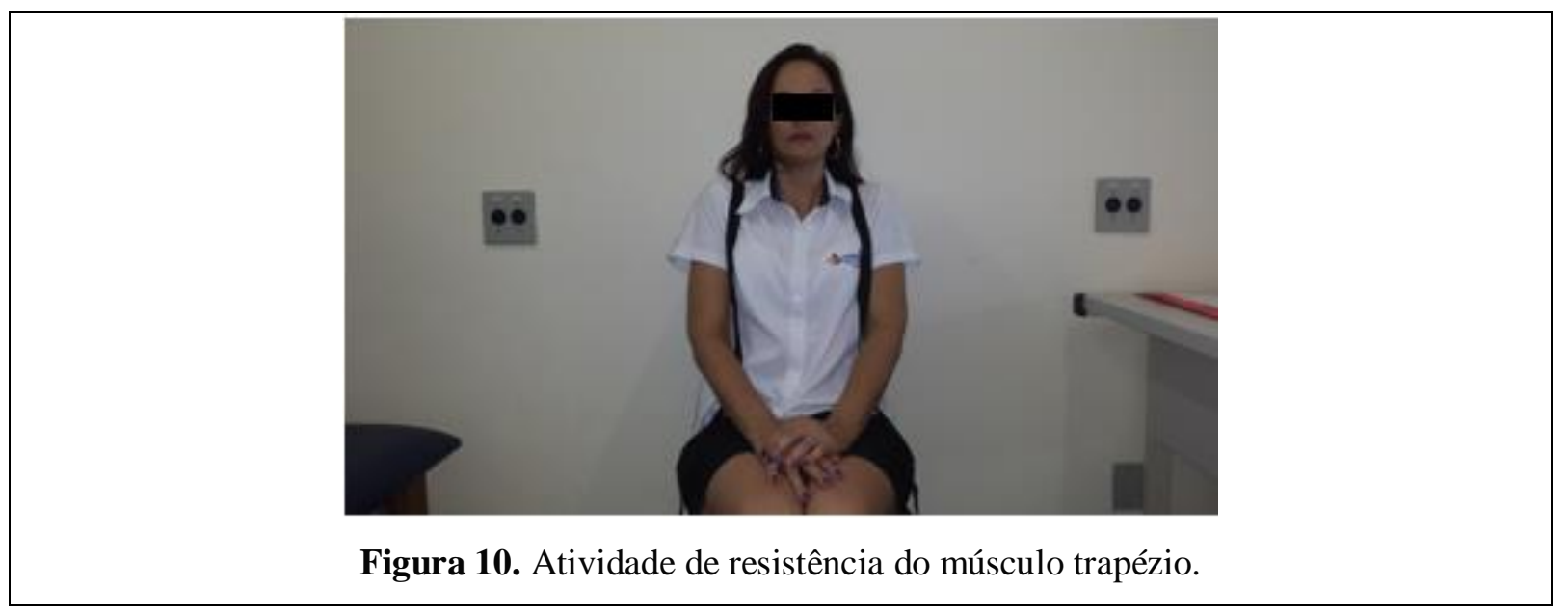

\section{Análise dos ciclos mastigatórios - Eficiência mastigatória}

A avaliação da eficiência do ciclo mastigatório foi obtida nas condições clínicas de mastigação habitual de alimento macio (5 g de uvas-passas), alimento duro (5 g de amendoins) e na mastigação não habitual contínua de um material inerte (10 segundos) constituído de uma folha de parafina (Parafilm $\mathrm{M}^{\circledR}$ ) dobrada $(18$ x 17 x $4 \mathrm{~mm}, 245 \mathrm{mg}$ ), colocada entre as faces oclusais dos dentes molares (superiores e inferiores) das hemiarcadas dentais (direita e esquerda) (Fig. 11). 

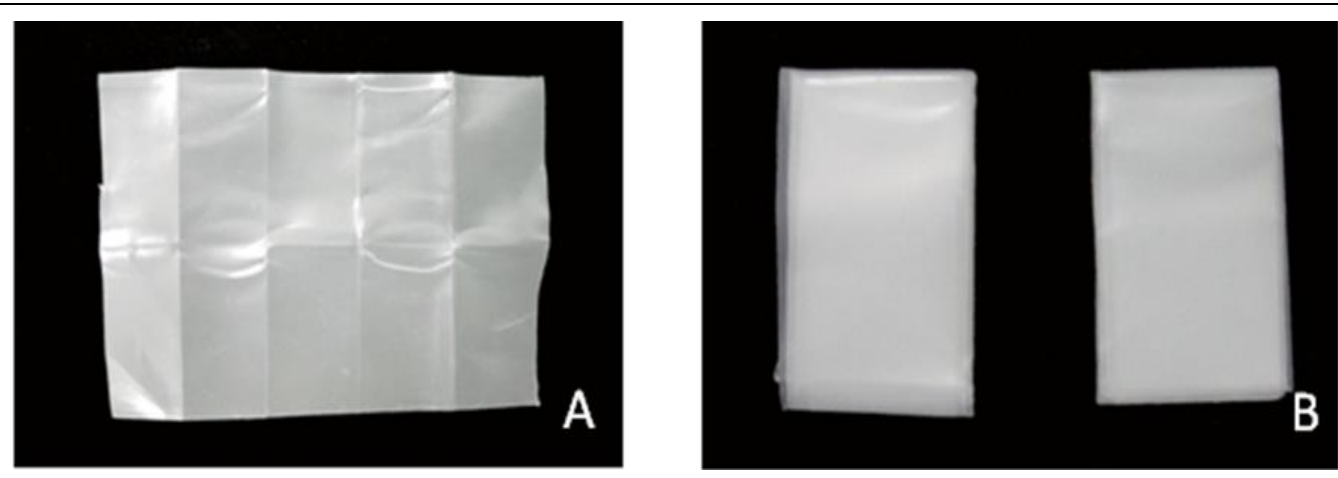

Figura 11. Material inerte - folha de parafina $\left(\right.$ Parafilm $\mathrm{M}^{\circledR}$ ): (A) folha aberta; (B) folha dobrada (18 x 17 x $4 \mathrm{~mm}, 245 \mathrm{mg})$.

O sinal obtido foi analisado por meio da integral da envoltória do sinal eletromiográfico dos músculos temporal, masseter, esternocleidomastóideo e trapézio, bilateralmente, sendo esse valor registrado em microvolts/segundo $(\mu \mathrm{V} / \mathrm{s})$, descartando sempre as contrações isotônicas para avaliar somente as contrações isométricas, obtidas a partir do momento de pressão do alimento entre os dentes ou do contato oclusal, proporcionando medições da área em função do tempo. $\mathrm{Na}$ seleção dos sinais eletromiográficos durante a mastigação, os valores foram obtidos a partir de cinco ciclos mastigatórios centrais, em que os três ciclos iniciais de mastigação foram excluídos, uma vez que, na fase inicial do processo de mastigação, os primeiros ciclos variam consideravelmente durante os movimentos mandibulares (CECILIO et al., 2010). A contração voluntária máxima bilateral foi a condição clínica utilizada para a normalização dos valores da integral da envoltória dos ciclos mastigatórios.

\section{Análise da força de mordida molar máxima}

Para a coleta dos dados de força de mordida molar máxima foi utilizado o dinamômetro modelo IDDK (Fig. 12) pertencente ao Departamento de Morfologia, Fisiologia e Patologia Básica da Faculdade de Odontologia da Universidade de São Paulo de Ribeirão Preto, que apresenta escala em Kgf ou N, com capacidade de $100 \mathrm{Kgf}$. 


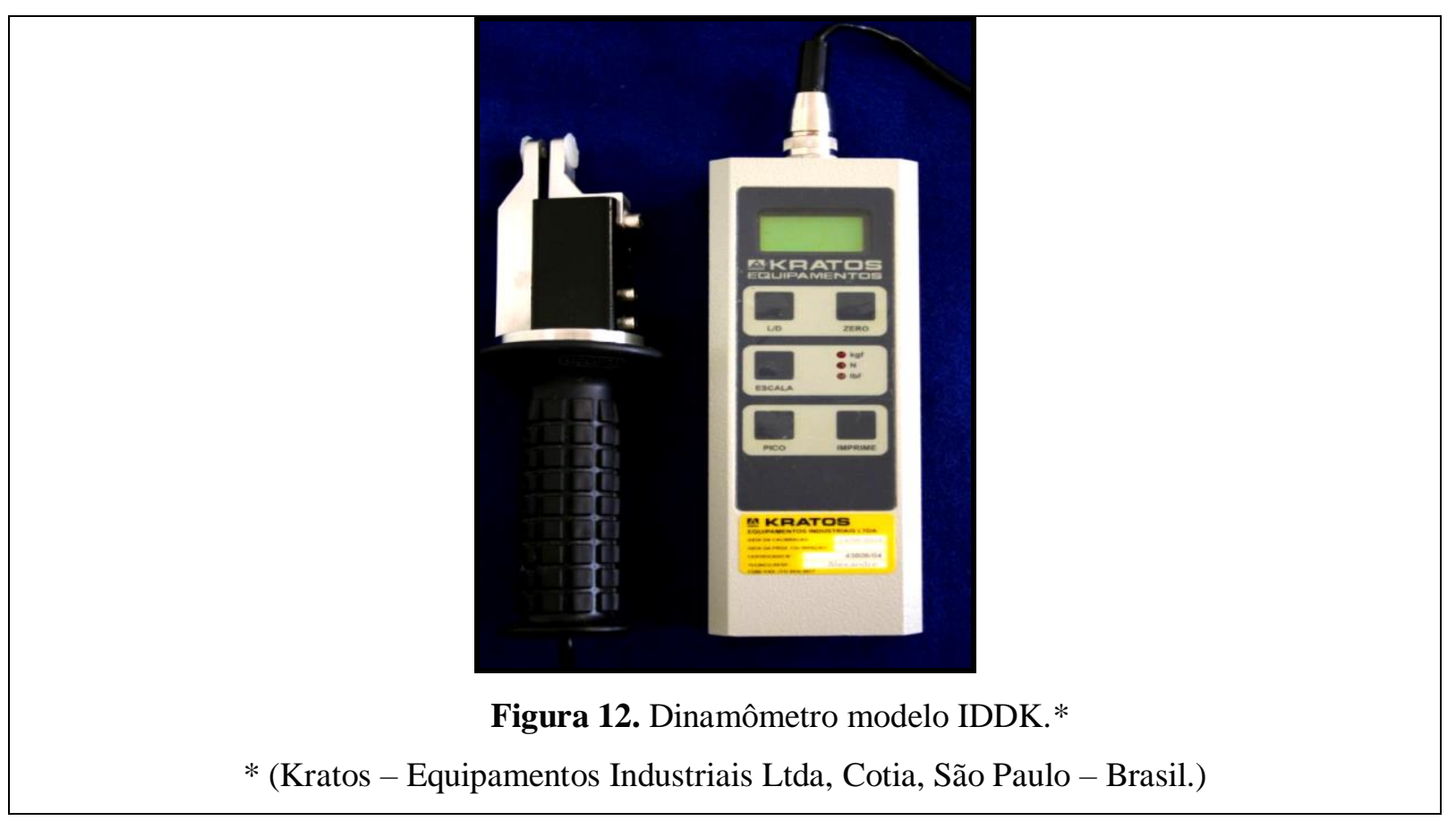

Esse dinamômetro utiliza tecnologia eletrônica e visor digital para indicar a força registrada e, ainda, é constituído por duas hastes que apresentam em suas extremidades discos de teflon, uma célula de carga de alta precisão, sobre as quais a força da mordida é aplicada para ser registrada e uma tecla digital "set-zero", que permite o controle exato dos valores obtidos, além do registro de "pico", o que facilita a leitura da força máxima de mordida durante a obtenção dos valores. As medidas foram realizadas na região dos primeiros molares (direito e esquerdo), em que se desenvolve a maior força de mordida (REGALO et al., 2008). As medidas foram registradas em sessão única, obtendo-se três valores de cada lado, alternando os lados direito e esquerdo, com intervalo de 2 minutos entre cada mordida, realizando-se logo após, a média das três medidas para cada lado (SONNESEN, BAKKE, SOLOW, 2001; KOGAWA et al., 2006). O dinamômetro foi limpo com álcool e protegido com dedeiras de látex descartáveis (Wariper, SP) posicionadas nas hastes de teflon do aparelho, como medida de biossegurança após a avaliação de cada participante da pesquisa e, ainda tomou-se o cuidado, para assegurar a confiabilidade do procedimento, de orientar e treinar as participantes antes da realização da coleta dos registros de mordida.

\section{Análise da espessura muscular}

A espessura muscular foi analisada por meio de ultrassom portátil (SonoSite Titan BR), com transdutor linear $56 \mathrm{~mm}$ de $10 \mathrm{MHz}$ (Fig. 13). 


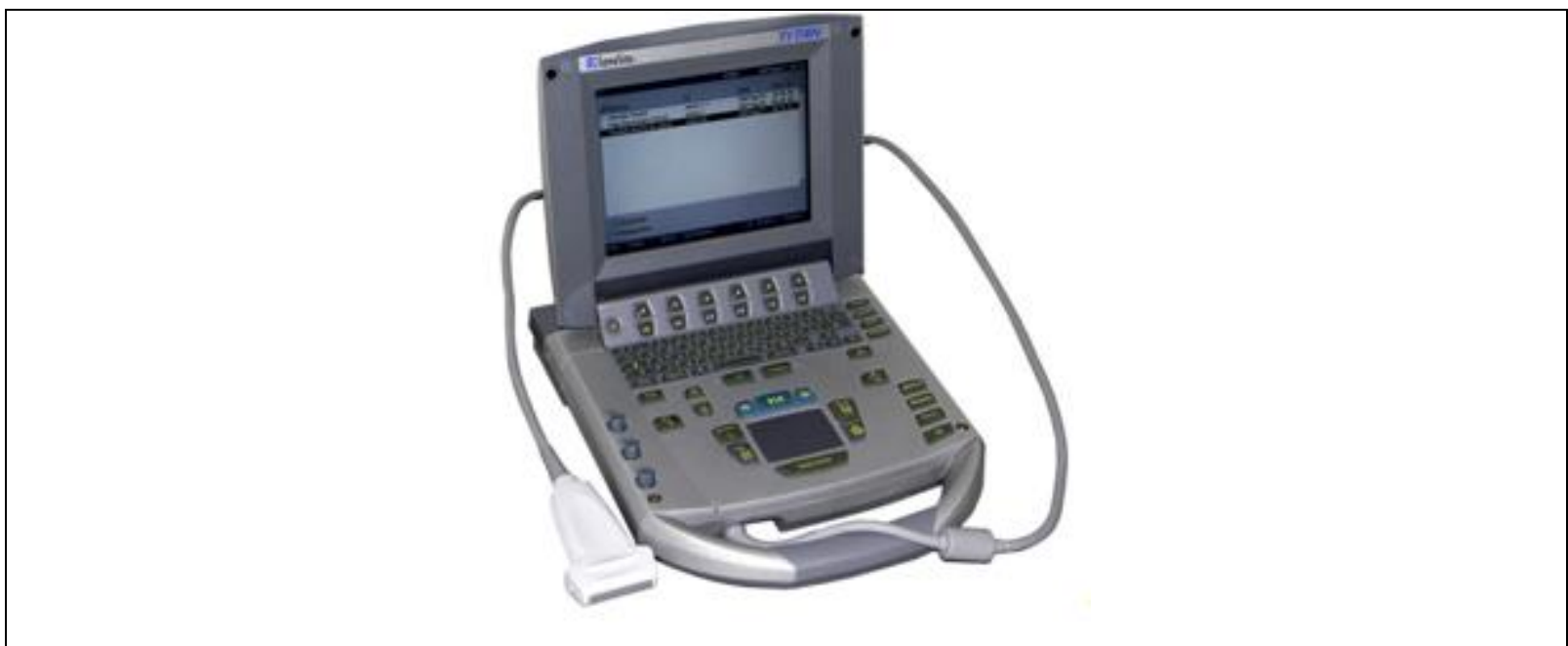

Figura 13. Aparelho de ultrassom portátil Sono Site Titan - BR com transdutor linear acoplado.

Foram adquiridas imagens ultrassonográficas, bilateralmente, dos músculos temporais (ventre anterior), masseteres, esternocleidomastóideo, nas posições de repouso e contração voluntária máxima, e do músculo trapézio superior na posição de repouso e abdução a $90^{\circ}$ dos membros superiores (crucifixo) (Fig. 14 e Fig.15). Entre cada mensuração houve um intervalo de 2 minutos. O transdutor linear foi posicionado transversalmente à direção das fibras musculares dos músculos estudados considerando que para o temporal (ventre anterior) o ponto está localizado cerca de 1 a $1,5 \mathrm{~cm}$ posterior e superiormente a comissura palpebral externa; para o masseter, o ponto se localiza aproximadamente entre 1,5 a $2 \mathrm{~cm}$ superior ao ângulo da mandíbula em direção à pálpebra superior; para o esternocleidomastóideo, foi considerado o ponto médio de seu terço superior; já para o trapézio, considerou-se o ponto médio entre a $7^{\mathrm{a}}$ vértebra cervical (C7) e o acrômio. A localização foi confirmada pelo teste de função e palpação muscular, movimentando-se o transdutor com o intuito de se obter a melhor imagem. As mensurações foram realizadas diretamente sobre a imagem no momento de sua aquisição, com aproximação de $0,1 \mathrm{~mm}$. Foram realizados três exames para cada posição clínica efetuada pela participante do trabalho. 


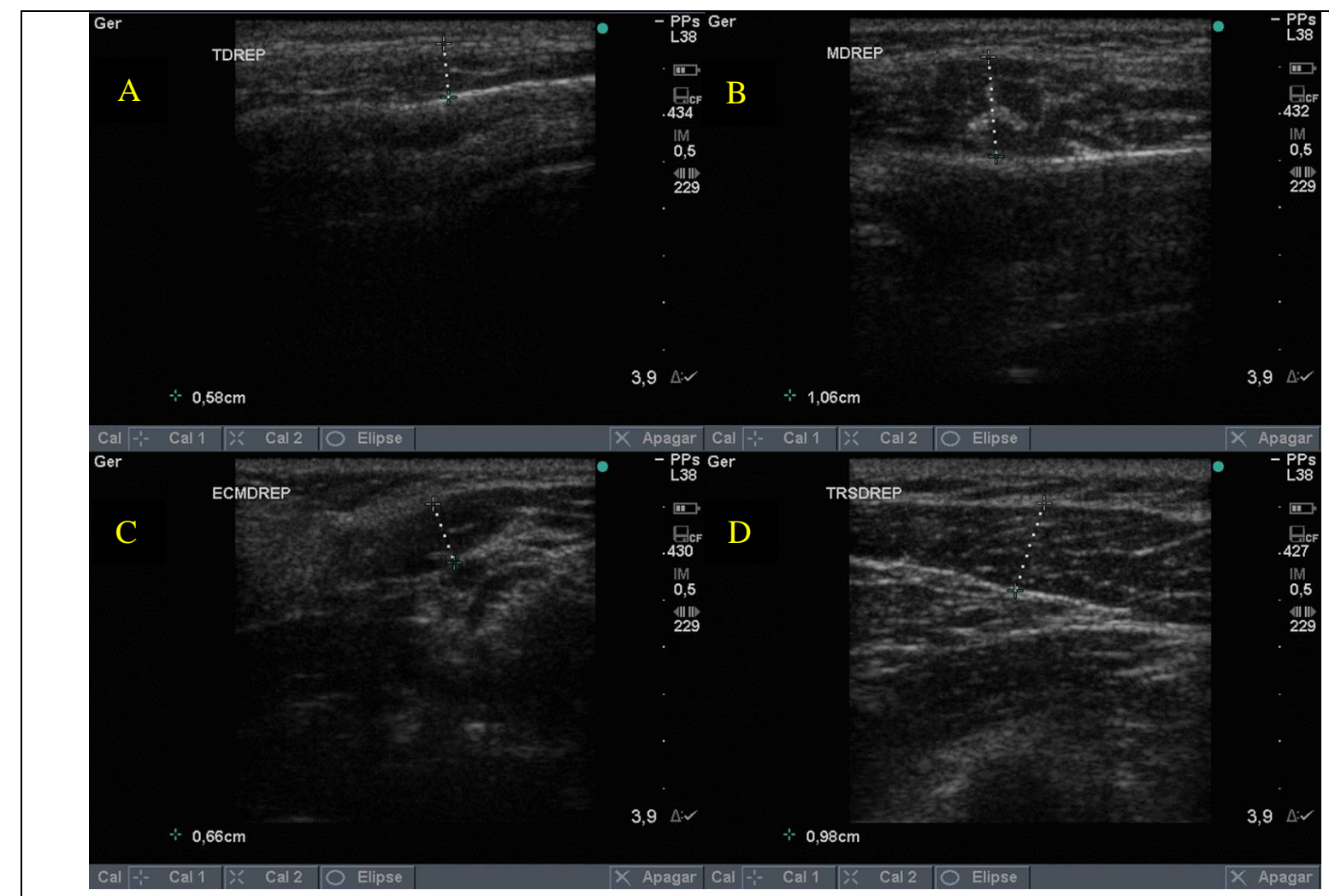

Figura 14. Imagens ultrassonográficas dos músculos temporal (A), masseter (B), esternocleidomastóideo (C) e trapézio (D) em repouso.

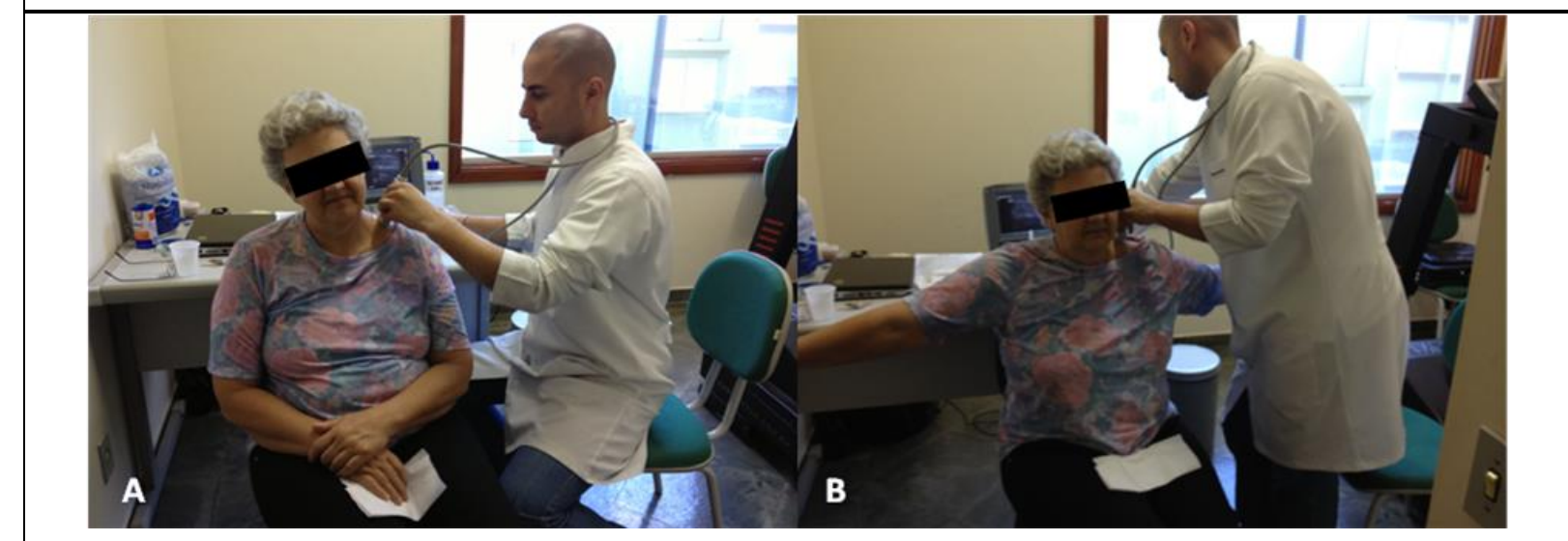

Figura 15. Ultrassonografia do músculo trapézio: (A) Repouso; e (B) Teste de função muscular.

\section{Análise dos dados e estatística}

Os sinais eletromiográficos foram processados no programa Myosystem-Br1 versão 3.56. Após a digitalização, os sinais foram analogicamente amplificados (com ganho de $1.000 \mathrm{x}$ ), filtrados (filtro passa-banda de 0,02-2 kHz) e amostrados por uma placa conversora A/D de 12 bites com frequência de aquisição de $4 \mathrm{KHz}$. O sinal eletromiográfico bruto foi utilizado para derivar valores de amplitude eletromiográfica, obtidos pelo cálculo da raiz quadrada da média (RMS) utilizados para as condições posturais da mandíbula, como repouso, protrusão, lateralidade (direita e esquerda) e atividades dos músculos cervicais. Para 
a obtenção dos valores referentes a eficiência mastigatória, foi utilizada a integral da envoltória (envoltório linear - ENV). Os valores da RMS e fENV obtidos durante o apertamento dental foram utilizados para a normalização dos respectivos valores nas demais situações clínicas. Todos os valores eletromiográficos normalizados foram tabulados e submetidos à análise estatística utilizando o software SPSS versão 21.0 (SPSS Inc.; Chicago, IL, USA). Foi realizada a análise descritiva (médias, desvios padrão e valores máximo e mínimo) para cada variável. Os valores obtidos foram comparados pelo teste $t(\mathrm{p}<0,05)$. 


\section{RESULTADOS}

Os resultados desse estudo foram organizados em tabelas e gráficos considerando a seguinte sequência:

Análise eletromiográfica dos padrões posturais da mandíbula.

> Análise eletromiográfica da função mastigatória.

$>$ Força de mordida molar máxima.

$>$ Análise ultrassonográfica - Espessura muscular. 


\section{RESULTADOS DA ANÁliSE ELETROMIOGRÁFICA (RMS) - PADRÕES POSTURAIS}

\section{Condição clínica de Repouso}

$\mathrm{Na}$ análise das médias eletromiográficas normalizadas para a condição clínica de Repouso, a comparação entre os grupos GC e GF mostrou que a atividade eletromiográfica de todos os músculos analisados foi maior para o GF. Os valores foram estatisticamente significantes para todos os músculos avaliados $(\mathrm{p}<0,05)$ (Tabela 3 e Fig. 16).

Tabela 3. Médias eletromiográficas normalizadas na condição clínica de Repouso, para o GC (controle) e GF (fibromialgia) dos músculos temporal direito e esquerdo (TD, TE), masseter direito e esquerdo (MD, ME), esternocleidomastóideo direito e esquerdo (ECOMD, ECOME) e trapézio superior direito e esquerdo (TSD, TSE).

\begin{tabular}{ccccc}
\hline Músculos & Grupo & $\boldsymbol{p}$ & Média & Erro padrão \\
\hline TD & GC & $0,00^{* * *}$ & 0,04 & $\pm 0,00$ \\
& GF & & 0,17 & $\pm 0,03$ \\
TE & GC & $0,00^{* *}$ & 0,04 & $\pm 0,00$ \\
& GF & & 0,14 & $\pm 0,02$ \\
MD & GC & $0,00^{* *}$ & 0,02 & $\pm 0,00$ \\
& GF & & 0,09 & $\pm 0,01$ \\
ME & GC & $0,00^{* *}$ & 0,02 & $\pm 0,00$ \\
& GF & & 0,08 & $\pm 0,01$ \\
ECOMD & GC & $0,00^{* *}$ & 0,02 & $\pm 0,00$ \\
& GF & & 0,04 & $\pm 0,00$ \\
ECOME & GC & $0,05^{*}$ & 0,02 & $\pm 0,00$ \\
& GF & & 0,05 & $\pm 0,01$ \\
TSD & GC & $0,00^{* *}$ & 0,02 & $\pm 0,00$ \\
& GF & & 0,13 & $\pm 0,01$ \\
TSE & GC & $0,00^{* *}$ & 0,03 & $\pm 0,00$ \\
& GF & & 0,09 & $\pm 0,01$ \\
& & & &
\end{tabular}




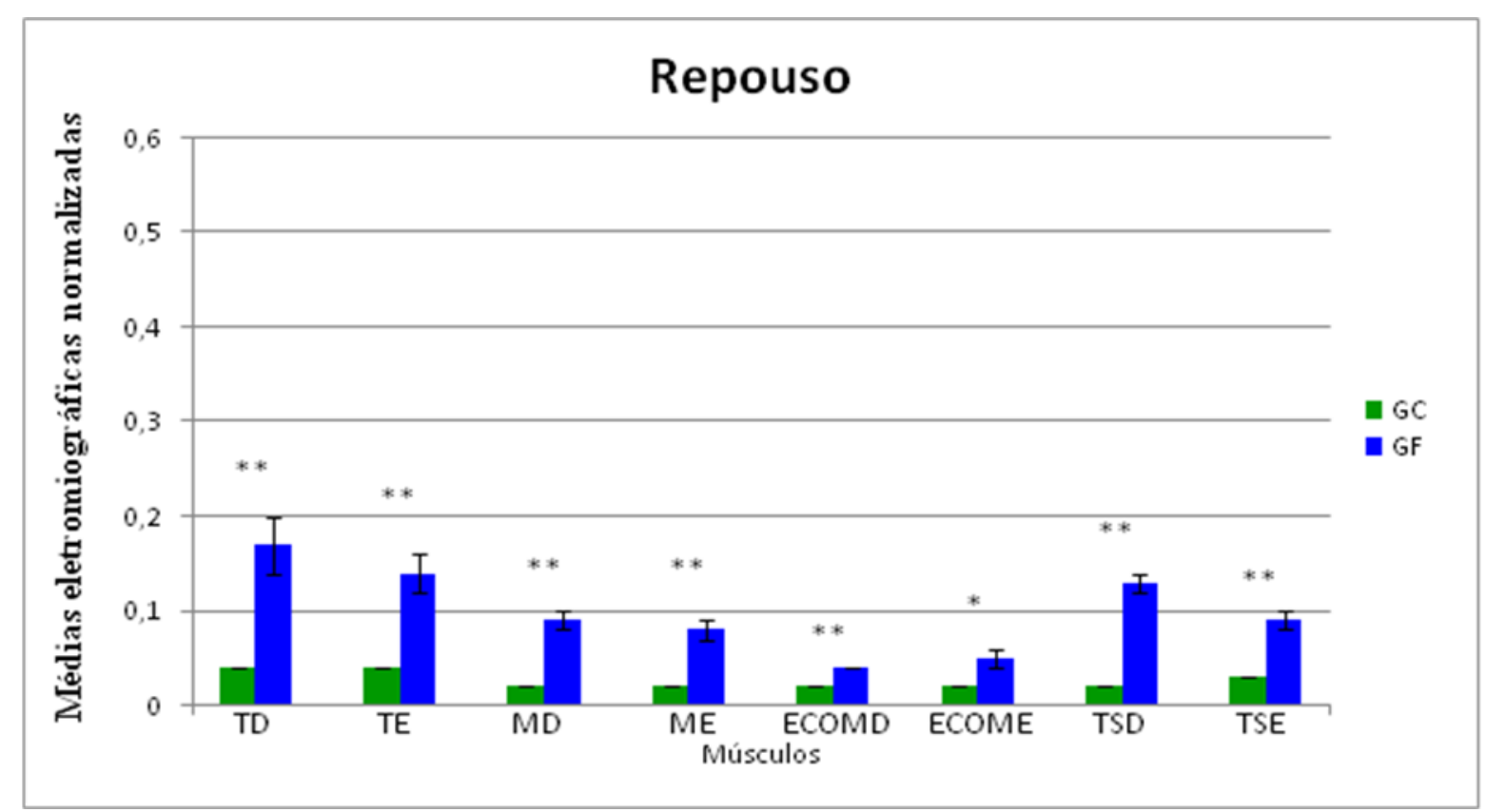

Figura 16. Médias eletromiográficas normalizadas na condição clínica de Repouso, para o GC (controle) e GF (fibromialgia) dos músculos temporal direito e esquerdo (TD, TE), masseter direito e esquerdo (MD, ME), esternocleidomastóideo direito e esquerdo (ECOMD, ECOME) e trapézio superior direito e esquerdo (TSD, TSE) $\left(* * \mathrm{p}<0,01 ;{ }^{*} \mathrm{p}<0,05\right)$. 


\section{Condição clínica de Lateralidade Direita}

Durante a condição clínica de Lateralidade Direita da mandíbula, a análise das médias eletromiográficas normalizadas para o grupo GF apresentou maiores valores quando comparado ao grupo GC, sendo estes estatisticamente significantes para todos os músculos avaliados $(\mathrm{p}<0,05)$, exceto para o músculo masseter esquerdo (Tabela 4 e Fig. 17).

Tabela 4. Médias eletromiográficas normalizadas na condição clínica de Lateralidade Direita, para o GC (controle) e GF (fibromialgia) dos músculos temporal direito e esquerdo (TD, TE), masseter direito e esquerdo (MD, ME), esternocleidomastóideo direito e esquerdo (ECOMD, ECOME) e trapézio superior direito e esquerdo (TSD, TSE).

\begin{tabular}{ccccc}
\hline Músculos & Grupo & $\boldsymbol{p}$ & Média & Erro padrão \\
\hline TD & GC & $0,05^{*}$ & 0,23 & $\pm 0,01$ \\
& GF & & 0,32 & $\pm 0,04$ \\
TE & GC & $0,00^{* *}$ & 0,05 & $\pm 0,00$ \\
MD & GF & 0,17 & $\pm 0,02$ \\
& GC & $0,00^{* *}$ & 0,04 & $\pm 0,00$ \\
ME & GF & 0,18 & $\pm 0,02$ \\
& GC & $0,08^{\text {ns }}$ & 0,22 & $\pm 0,01$ \\
ECOMD & GF & 0,30 & $\pm 0,04$ \\
& GC & $0,00^{* *}$ & 0,04 & $\pm 0,00$ \\
ECOME & GF & & 0,11 & $\pm 0,01$ \\
& GC & $0,00^{* *}$ & 0,04 & $\pm 0,00$ \\
TSD & GF & & 0,11 & $\pm 0,01$ \\
& GC & $0,00^{* *}$ & 0,03 & $\pm 0,00$ \\
TSE & GF & & 0,16 & $\pm 0,01$ \\
& GC & $0,00^{* *}$ & 0,03 & $\pm 0,00$ \\
& GF & & 0,16 & $\pm 0,01$ \\
& & & &
\end{tabular}

${ }^{* *}$ Significante $(\mathrm{p}<0,01)$

*Significante $(\mathrm{p}<0,05)$

${ }^{\text {ns }}$ Não significante 


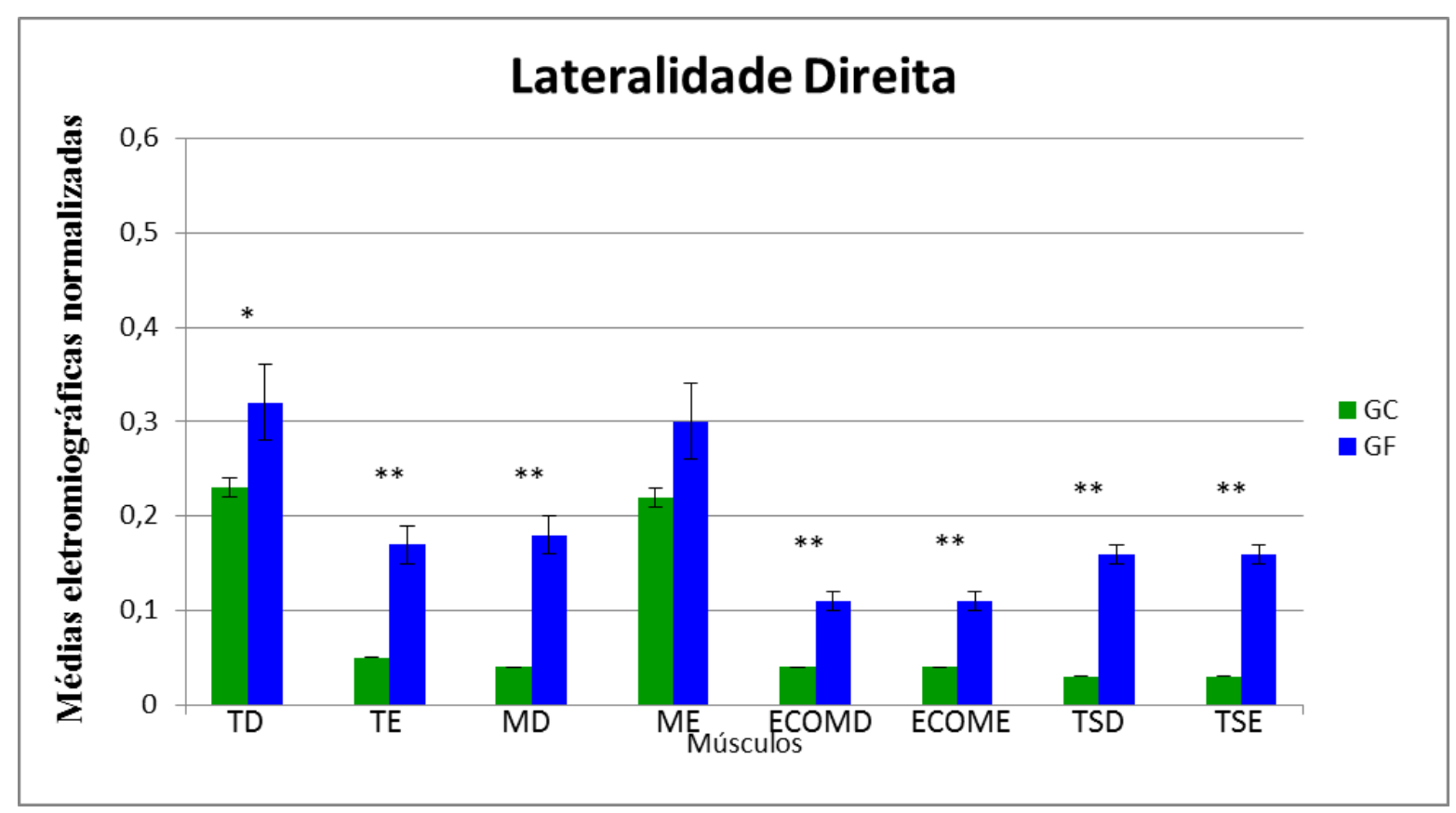

Figura 17. Médias eletromiográficas normalizadas na condição clínica de Lateralidade Direita, para o GC (controle) e GF (fibromialgia) dos músculos temporal direito e esquerdo (TD, TE), masseter direito e esquerdo (MD, ME), esternocleidomastóideo direito e esquerdo (ECOMD, ECOME) e trapézio superior direito e esquerdo (TSD, TSE) $(* * p<0,01 ; * p<0,05)$. 


\section{Condição clínica de Lateralidade Esquerda}

$\mathrm{Na}$ análise das médias eletromiográficas normalizadas para condição clínica de Lateralidade Esquerda, pode-se observar que o GF apresentou maiores valores quando comparado ao GC, sendo esses estatisticamente significantes para todos os músculos avaliados $(\mathrm{p}<0,05)$, exceto para o músculo temporal esquerdo (Tabela 5 e Fig. 18).

Tabela 5. Médias eletromiográficas normalizadas na condição clínica de Lateralidade Esquerda, para o GC (controle) e GF (fibromialgia) dos músculos temporal direito e esquerdo (TD, TE), masseter direito e esquerdo (MD, ME), esternocleidomastóideo direito e esquerdo (ECOMD, ECOME) e trapézio superior direito e esquerdo (TSD, TSE).

\begin{tabular}{|c|c|c|c|c|}
\hline Músculos & Grupo & $p$ & Média & Erro padrão \\
\hline \multirow[t]{2}{*}{ TD } & GC & $0,00^{* *}$ & 0,05 & $\pm 0,00$ \\
\hline & GF & & 0,19 & $\pm 0,03$ \\
\hline \multirow[t]{2}{*}{ TE } & GC & $0,19^{\mathrm{ns}}$ & 0,23 & $\pm 0,01$ \\
\hline & GF & & 0,31 & $\pm 0,05$ \\
\hline \multirow[t]{2}{*}{ MD } & GC & $0,00^{* *}$ & 0,14 & $\pm 0,01$ \\
\hline & GF & & 0,29 & $\pm 0,04$ \\
\hline \multirow[t]{2}{*}{$\mathrm{ME}$} & GC & $0,00^{* *}$ & 0,04 & $\pm 0,00$ \\
\hline & GF & & 0,28 & $\pm 0,07$ \\
\hline \multirow[t]{2}{*}{ ECOMD } & GC & $0,00^{* *}$ & 0,05 & $\pm 0,00$ \\
\hline & GF & & 0,11 & $\pm 0,02$ \\
\hline \multirow[t]{2}{*}{ ECOME } & $\mathrm{GC}$ & $0,00^{* *}$ & 0,04 & $\pm 0,00$ \\
\hline & GF & & 0,16 & $\pm 0,03$ \\
\hline \multirow[t]{2}{*}{ TSD } & GC & $0,00^{* *}$ & 0,03 & $\pm 0,00$ \\
\hline & GF & & 0,15 & $\pm 0,01$ \\
\hline \multirow[t]{2}{*}{ TSE } & GC & $0,00^{* *}$ & 0,03 & $\pm 0,00$ \\
\hline & GF & & 0,16 & $\pm 0,01$ \\
\hline
\end{tabular}

${ }^{* *}$ Significante $(\mathrm{p}<0,01)$

${ }^{\text {ns }}$ Não significante 


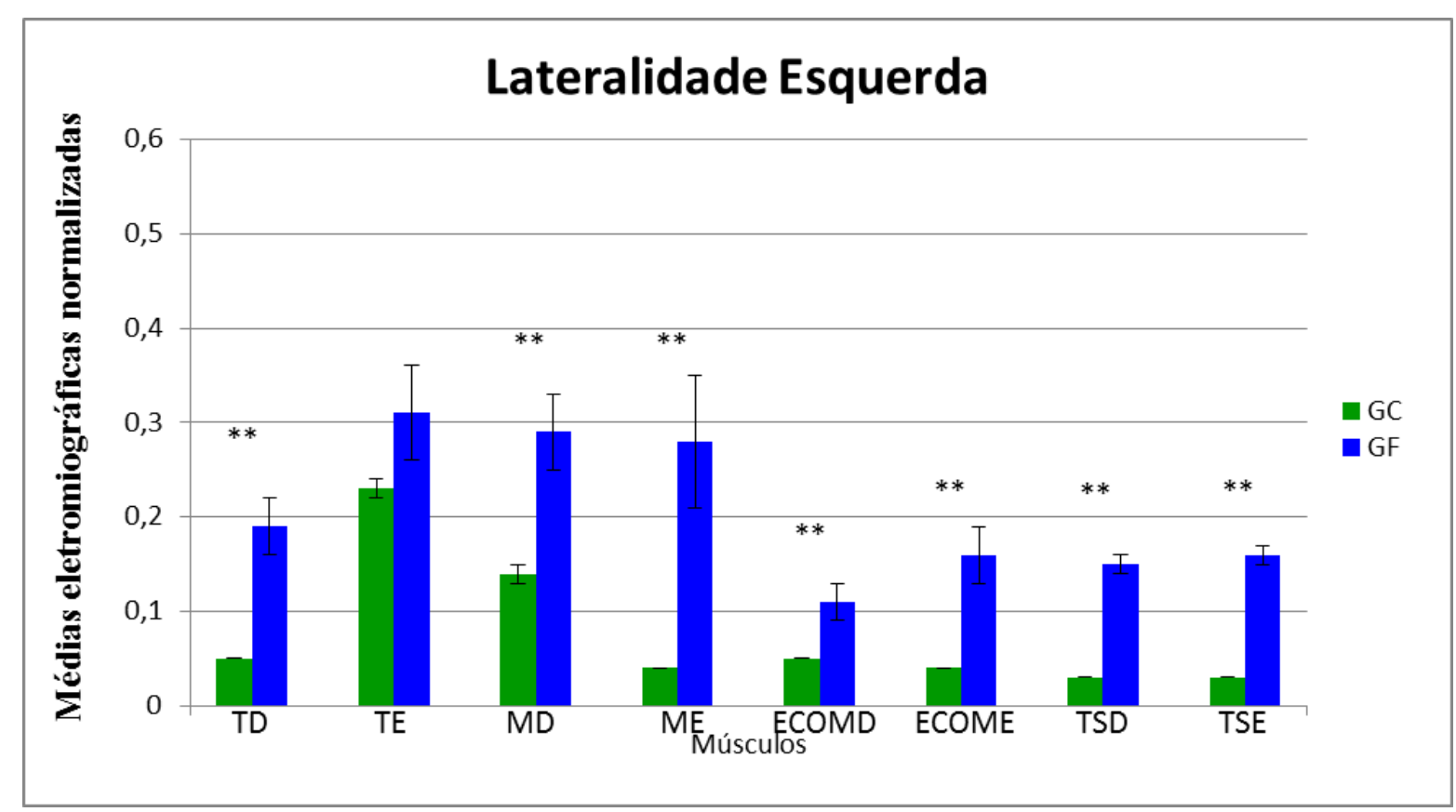

Figura 18. Médias eletromiográficas normalizadas na condição clínica de Lateralidade Esquerda, para o GC (controle) e GF (fibromialgia) dos músculos temporal direito e esquerdo (TD, TE), masseter direito e esquerdo (MD, ME), esternocleidomastóideo direito e esquerdo (ECOMD, ECOME) e trapézio superior direito e esquerdo (TSD, TSE) $(* * p<0,01)$. 


\section{Condição clínica de Protrusão}

Durante o movimento de Protrusão da mandíbula, na análise das médias eletromiográficas normalizadas, pode-se observar que o grupo GF apresentou maior atividade eletromiográfica quando comparado ao grupo GC. Os valores foram estatisticamente significantes para todos os músculos avaliados $(\mathrm{p}<0,05)$, exceto para o músculo masseter direito (Tabela 6 e Fig. 19).

Tabela 6. Médias eletromiográficas normalizadas na condição clínica de Protrusão, para o GC (controle) e GF (fibromialgia) dos músculos temporal direito e esquerdo (TD, TE), masseter direito e esquerdo (MD, ME), esternocleidomastóideo direito e esquerdo (ECOMD, ECOME) e trapézio superior direito e esquerdo (TSD, TSE).

\begin{tabular}{ccccc}
\hline Músculos & Grupo & $\boldsymbol{p}$ & Média & Erro padrão \\
\hline TD & GC & $0,00^{* *}$ & 0,05 & $\pm 0,00$ \\
& GF & & 0,19 & $\pm 0,03$ \\
TE & GC & $0,00^{* *}$ & 0,05 & $\pm 0,00$ \\
& GF & & 0,18 & $\pm 0,02$ \\
MD & GC & $0,06^{\text {ns }}$ & 0,28 & $\pm 0,02$ \\
& GF & & 0,39 & $\pm 0,05$ \\
ME & GC & $0,01^{* *}$ & 0,26 & $\pm 0,02$ \\
& GF & & 0,40 & $\pm 0,04$ \\
ECOMD & GC & $0,00^{* *}$ & 0,04 & $\pm 0,00$ \\
& GF & & 0,10 & $\pm 0,02$ \\
ECOME & GC & $0,00^{* *}$ & 0,04 & $\pm 0,00$ \\
& GF & & 0,12 & $\pm 0,02$ \\
TSD & GC & $0,00^{* *}$ & 0,02 & $\pm 0,00$ \\
& GF & & 0,17 & $\pm 0,01$ \\
TSE & GC & $0,00^{* *}$ & 0,03 & $\pm 0,00$ \\
& GF & & 0,17 & $\pm 0,02$ \\
& & & &
\end{tabular}

${ }^{* * *}$ Significante $(\mathrm{p}<0,01)$

${ }^{n s}$ Não significante 


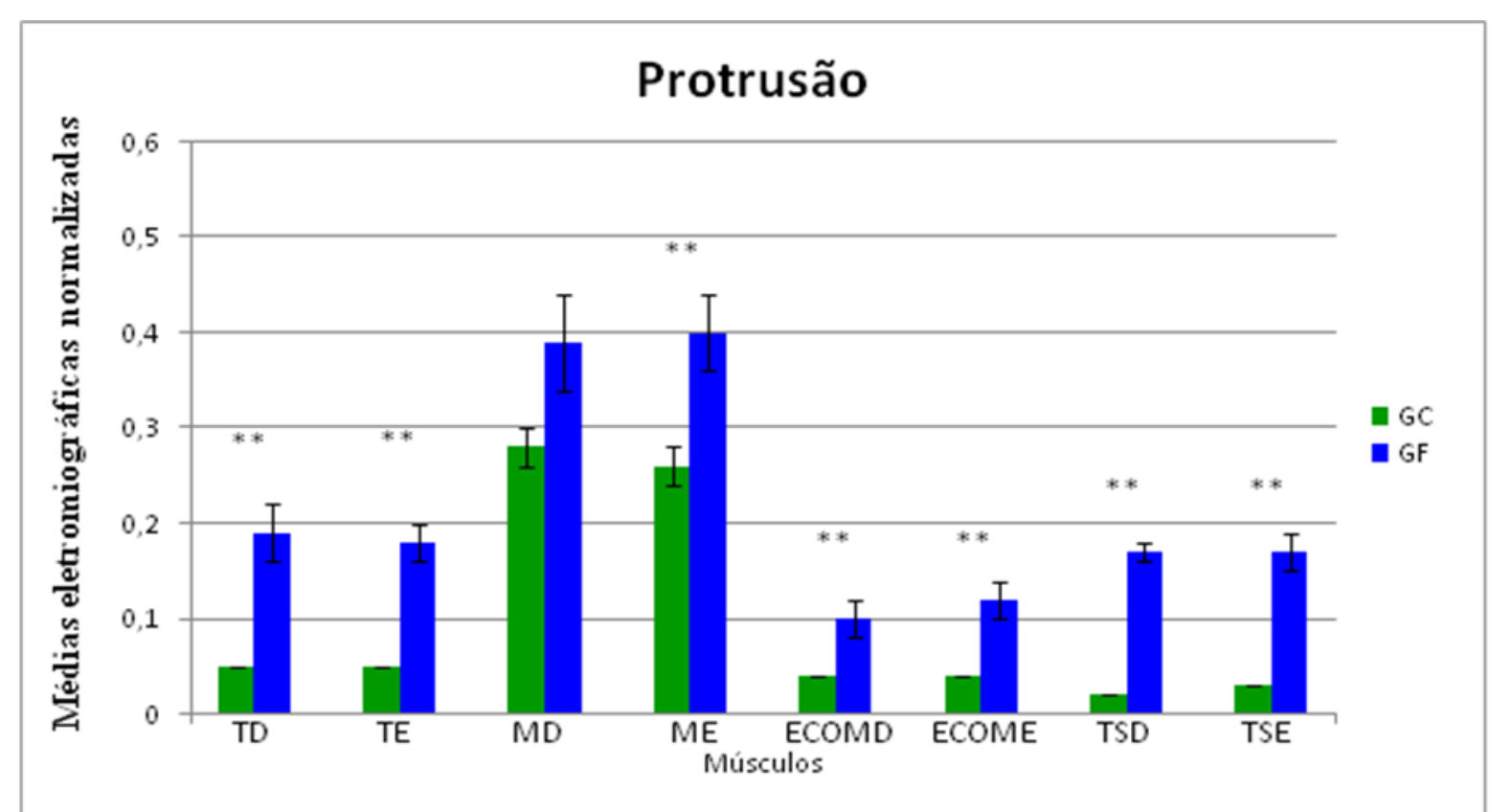

Figura 19. Médias eletromiográficas normalizadas na condição clínica de Protrusão, para o GC (controle) e GF (fibromialgia) dos músculos temporal direito e esquerdo (TD, TE), masseter direito e esquerdo (MD, ME), esternocleidomastóideo direito e esquerdo (ECOMD, ECOME) e trapézio superior direito e esquerdo (TSD, TSE) $(* * p<0,01)$. 


\section{RESULTADOS DA ANÁLISE ELETROMIOGRÁFICA (fENV) - FUNÇÃo MASTIGATÓRIA}

\section{Condição clínica de Mastigação de Parafilme $\mathbf{M}^{\circledR}$}

Todos os músculos apresentaram maiores valores da atividade eletromiográfica no grupo GF, quando comparados ao grupo GC, durante a Mastigação de Parafilme $\mathbf{M}^{\circledR}$. Os valores foram estatisticamente significantes para todos os músculos avaliados $(\mathrm{p}<0,05)$, exceto para o músculo masseter esquerdo (Tabela 7 e Fig. 20).

Tabela 7. Médias eletromiográficas normalizadas na condição clínica de Mastigação de Parafilme $\mathrm{M}^{\circledR}$, para o GC (controle) e GF (fibromialgia) dos músculos temporal direito e esquerdo (TD, TE), masseter direito e esquerdo (MD, ME), esternocleidomastóideo direito e esquerdo (ECOMD, ECOME) e trapézio superior direito e esquerdo (TSD, TSE).

\begin{tabular}{ccccc}
\hline Músculos & Grupo & $\boldsymbol{p}$ & Média & Erro padrão \\
\hline TD & GC & $0,00^{* * *}$ & 0,14 & $\pm 0,01$ \\
& GF & & 0,26 & $\pm 0,02$ \\
TE & GC & $0,00^{* *}$ & 0,15 & $\pm 0,01$ \\
& GF & & 0,26 & $\pm 0,02$ \\
MD & GC & $0,00^{* *}$ & 0,17 & $\pm 0,01$ \\
& GF & & 0,26 & $\pm 0,02$ \\
ME & GC & $0,12^{\text {ns }}$ & 0,16 & $\pm 0,01$ \\
& GF & & 0,39 & $\pm 0,15$ \\
ECOMD & GC & $0,00^{* *}$ & 0,01 & $\pm 0,00$ \\
& GF & & 0,02 & $\pm 0,00$ \\
ECOME & GC & $0,04^{*}$ & 0,01 & $\pm 0,00$ \\
& GF & & 0,03 & $\pm 0,01$ \\
TSD & GC & $0,00^{* *}$ & 0,01 & $\pm 0,00$ \\
& GF & & 0,06 & $\pm 0,00$ \\
TSE & GC & $0,00^{* *}$ & 0,01 & $\pm 0,00$ \\
& & & 0,07 & $\pm 0,01$ \\
& GF & &
\end{tabular}

\footnotetext{
Significante $(\mathrm{p}<0,01)$

*Significante $(\mathrm{p}<0,05)$

${ }^{\text {ns }}$ Não significante
} 


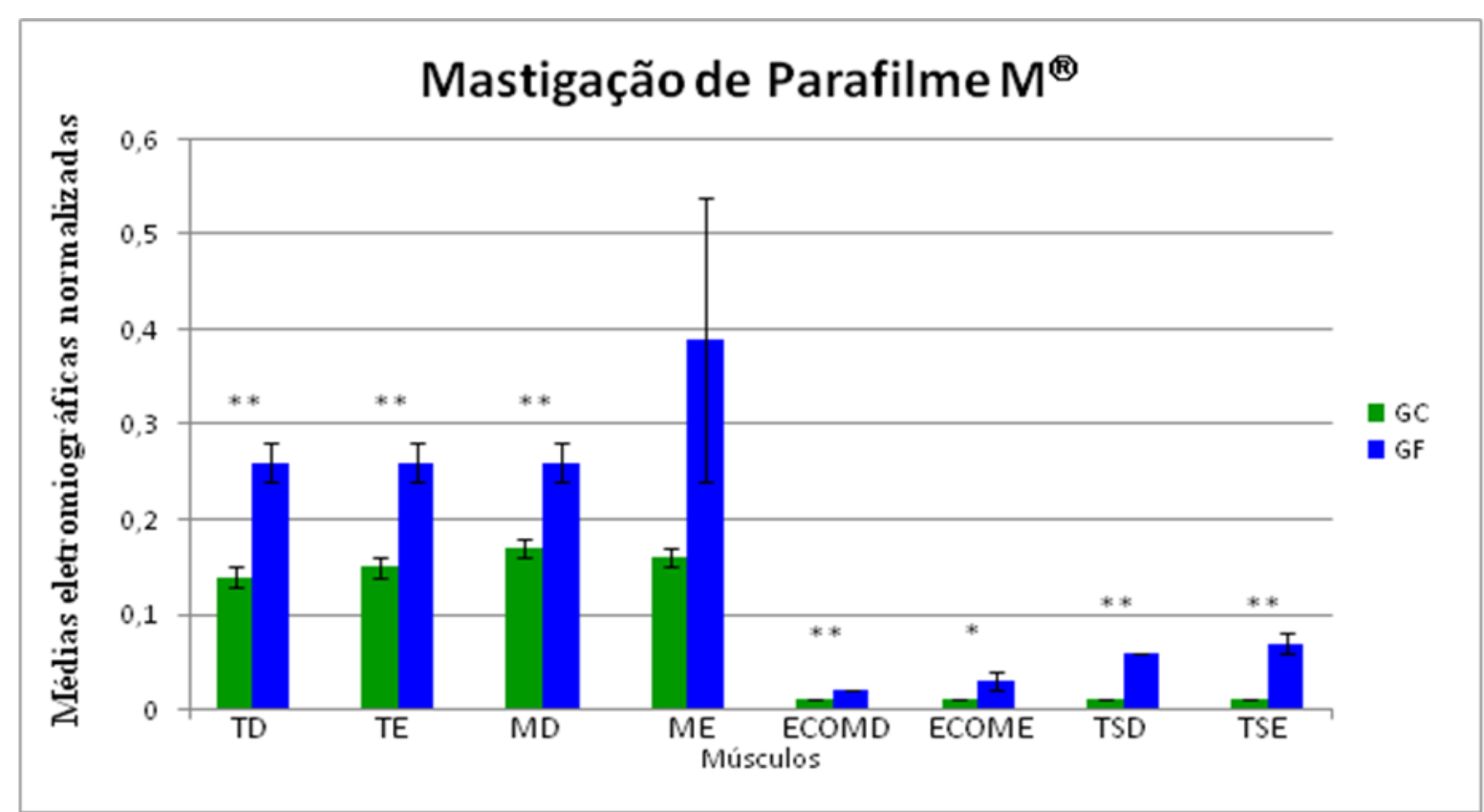

Figura 20. Médias eletromiográficas normalizadas na condição clínica de Mastigação de Parafilme $\mathrm{M}^{\circledR}$, para o GC (controle) e GF (fibromialgia) dos músculos temporal direito e esquerdo (TD, TE), masseter direito e esquerdo (MD, ME), esternocleidomastóideo direito e esquerdo (ECOMD, ECOME) e trapézio superior direito e esquerdo (TSD, TSE) $(* * \mathrm{p}<0,01$; $* \mathrm{p}<0,05)$. 


\section{Condição clínica de Mastigação de Uvas-Passas}

$\mathrm{Na}$ análise das médias eletromiográficas normalizadas para condição clínica de Mastigação de Uvas-Passas, pode-se observar que o grupo GF apresentou maiores médias de atividade muscular quando comparado ao grupo GC. Os valores foram estatisticamente significantes para todos os músculos avaliados ( $p<0,05)$ (Tabela 8 e Fig. 21).

Tabela 8. Médias eletromiográficas normalizadas na condição clínica de Mastigação de Uvas-Passas para o GC (controle) e GF (fibromialgia) dos músculos temporal direito e esquerdo (TD, TE), masseter direito e esquerdo (MD, ME), esternocleidomastóideo direito e esquerdo (ECOMD, ECOME) e trapézios superior direito e esquerdo (TSD, TSE).

\begin{tabular}{|c|c|c|c|c|}
\hline Músculos & Grupo & $p$ & Média & Erro padrão \\
\hline \multirow[t]{2}{*}{ TD } & GC & $0,01^{* *}$ & 0,13 & $\pm 0,01$ \\
\hline & GF & & 0,21 & $\pm 0,03$ \\
\hline \multirow[t]{2}{*}{$\mathrm{TE}$} & GC & $0,01^{* *}$ & 0,13 & $\pm 0,00$ \\
\hline & GF & & 0,20 & $\pm 0,02$ \\
\hline \multirow[t]{2}{*}{$\mathrm{MD}$} & $\mathrm{GC}$ & $0,01^{* *}$ & 0,14 & $\pm 0,01$ \\
\hline & GF & & 0,21 & $\pm 0,02$ \\
\hline \multirow[t]{2}{*}{ ME } & GC & $0,00^{* *}$ & 0,12 & $\pm 0,01$ \\
\hline & GF & & 0,21 & $\pm 0,02$ \\
\hline \multirow[t]{2}{*}{ ECOMD } & GC & $0,00^{* *}$ & 0,01 & $\pm 0,00$ \\
\hline & GF & & 0,02 & $\pm 0,00$ \\
\hline \multirow[t]{2}{*}{ ECOME } & GC & $0,04^{*}$ & 0,01 & $\pm 0,00$ \\
\hline & GF & & 0,03 & $\pm 0,01$ \\
\hline \multirow[t]{2}{*}{ TSD } & GC & $0,00^{* *}$ & 0,01 & $\pm 0,00$ \\
\hline & GF & & 0,05 & $\pm 0,00$ \\
\hline \multirow[t]{2}{*}{ TSE } & GC & $0,00^{* *}$ & 0,02 & $\pm 0,00$ \\
\hline & GF & & 0,06 & $\pm 0,00$ \\
\hline
\end{tabular}

${ }^{* * *}$ Significante $(\mathrm{p}<0,01)$

*Significante $(\mathrm{p}<0,05)$

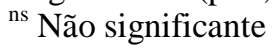




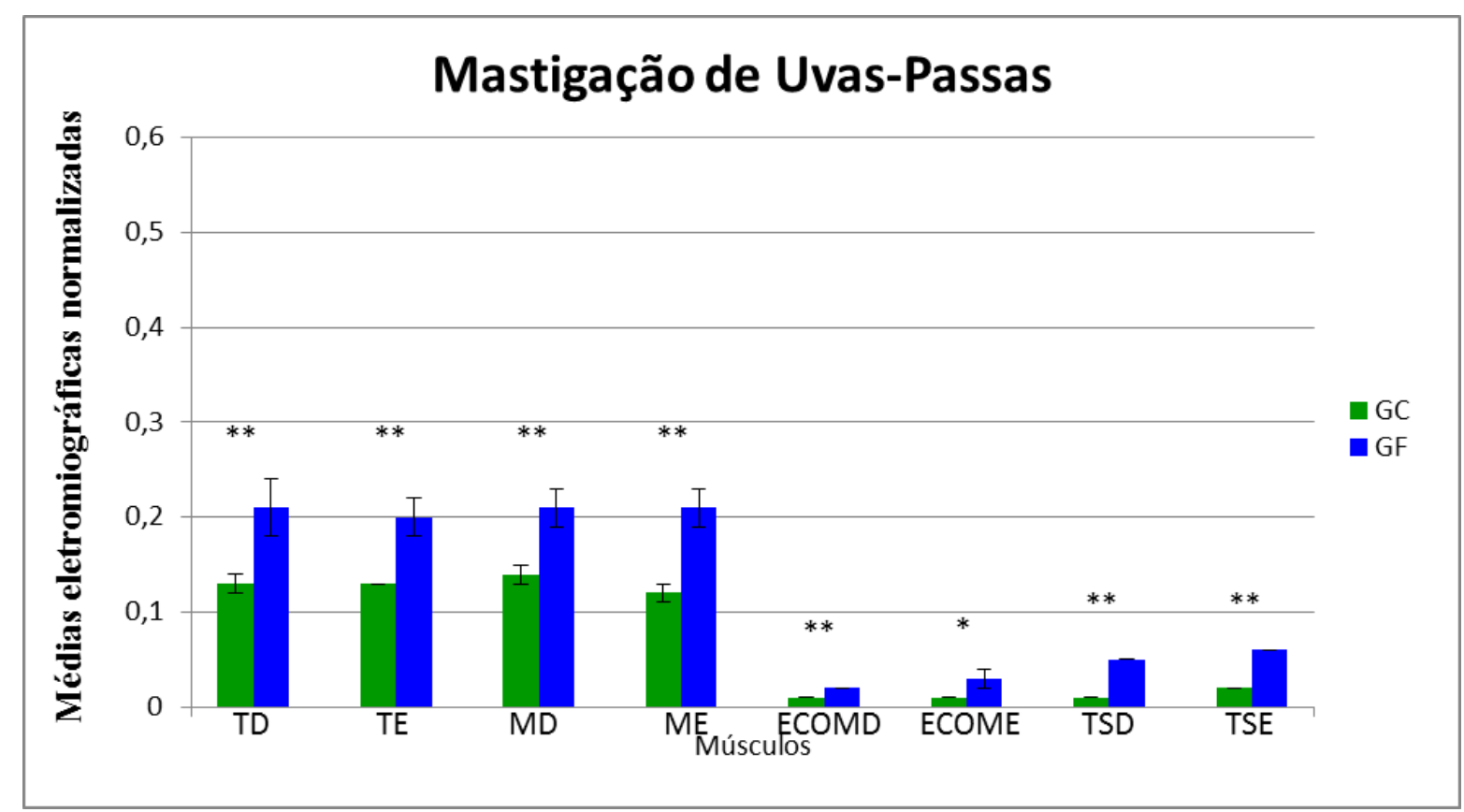

Figura 21. Médias eletromiográficas normalizadas na condição clínica de Mastigação de Uvas-Passas, para o GC (controle) e GF (fibromialgia) dos músculos temporal direito e esquerdo (TD, TE), masseter direito e esquerdo (MD, ME), esternocleidomastóideo direito e esquerdo (ECOMD, ECOME) e trapézio superior direito e esquerdo (TSD, TSE) $(* * p<0,01$; $* \mathrm{p}<0,05)$. 


\section{Condição clínica de Mastigação de Amendoins}

Identificaram-se maiores médias da atividade eletromiográfica para a condição clínica de Mastigação de Amendoins, para o grupo GF quando comparado ao grupo GC. Os valores foram estatisticamente significantes para o músculo temporal esquerdo, esternocleidomastóideo direito, trapézio superior direito e esquerdo $(\mathrm{p}<0,05)$ (Tabela 9 e Fig. 22).

Tabela 9. Médias eletromiográficas normalizadas na condição clínica de Mastigação de Amendoins, para o GC (controle) e GF (fibromialgia) dos músculos temporal direito e esquerdo (TD, TE), masseter direito e esquerdo (MD, ME), esternocleidomastóideo direito e esquerdo (ECOMD, ECOME) e trapézio superior direito e esquerdo (TSD, TSE).

\begin{tabular}{ccccc}
\hline Músculos & Grupo & $\boldsymbol{p}$ & Média & Erro padrão \\
\hline TD & GC & $0,18^{\text {ns }}$ & 0,17 & $\pm 0,01$ \\
& GF & & 0,22 & $\pm 0,04$ \\
TE & GC & $0,05^{*}$ & 0,16 & $\pm 0,01$ \\
& GF & & 0,21 & $\pm 0,02$ \\
MD & GC & $0,08^{\text {ns }}$ & 0,18 & $\pm 0,02$ \\
& GF & & 0,24 & $\pm 0,02$ \\
ME & GC & $0,09^{\text {ns }}$ & 0,17 & $\pm 0,02$ \\
& GF & & 0,24 & $\pm 0,03$ \\
ECOMD & GC & $0,00^{* *}$ & 0,01 & $\pm 0,00$ \\
& GF & & 0,02 & $\pm 0,00$ \\
ECOME & GC & $0,08^{\text {ns }}$ & 0,01 & $\pm 0,00$ \\
& GF & & 0,03 & $\pm 0,01$ \\
TSD & GC & $0,00^{* *}$ & 0,01 & $\pm 0,00$ \\
& GF & & 0,05 & $\pm 0,00$ \\
TSE & GC & $0,00^{* *}$ & 0,02 & $\pm 0,00$ \\
& GF & & 0,04 & $\pm 0,00$ \\
& & & &
\end{tabular}

\footnotetext{
Significante $(\mathrm{p}<0,01)$

*Significante $(\mathrm{p}<0,05)$

${ }^{\text {ns }}$ Não significante
} 


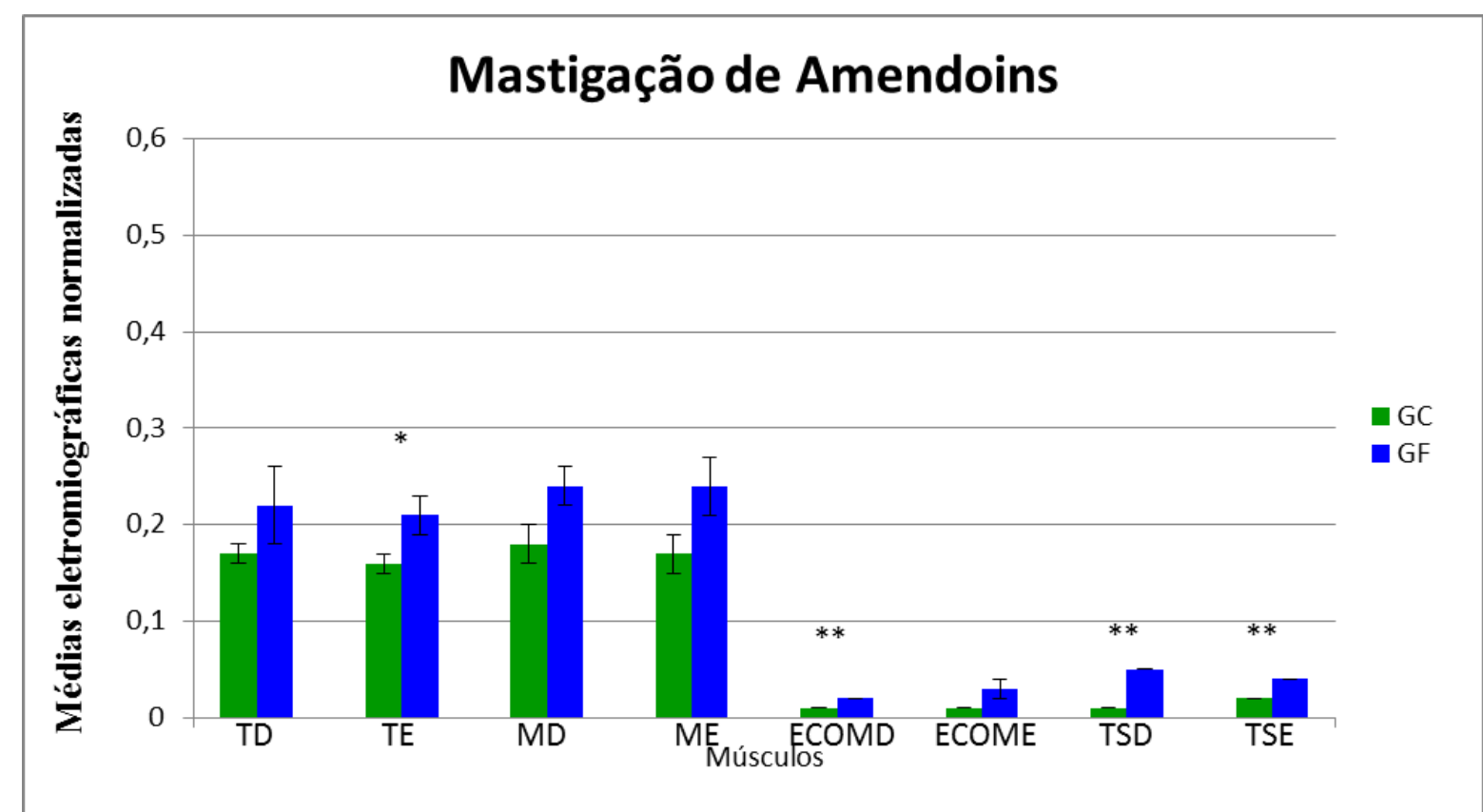

Figura 22. Médias eletromiográficas normalizadas na condição clínica de Mastigação de Amendoins, para o GC (controle) e GF (fibromialgia) dos músculos temporal direito e esquerdo (TD, TE), masseter direito e esquerdo (MD, ME), esternocleidomastóideo direito e esquerdo (ECOMD, ECOME) e trapézio superior direito e esquerdo (TSD, TSE) $(* * p<0,01$, $* p<0,05)$. 


\section{RESULTADOS DA ANÁLISE DA FORÇA DE MORDIDA MOLAR MÁXIMA}

Observaram-se menores valores da Força de Mordida Molar Máxima direita e esquerda para o grupo GF, quando comparados ao grupo GC. Os resultados foram estatisticamente significantes para ambos os lados ( $p<0,05)$ (Tabela 10 e Fig. 23).

Tabela 10. Médias da Força de Mordida Molar Máxima para o GC (controle) e GF (fibromialgia), na região molar direita e esquerda (FMMD e FMME), com valores em $\mathrm{Kg}$ / força.

\begin{tabular}{ccccc}
\hline Condições & Grupo & $\boldsymbol{p}$ & Média & Erro padrão \\
\hline FMMD & GC & $0,00^{* *}$ & 33,68 & $\pm 2,45$ \\
& GF & & 15,21 & $\pm 1,98$ \\
FMME & GC & $0,00^{* *}$ & 36,51 & $\pm 2,71$ \\
& GF & & 14,75 & $\pm 2,10$ \\
\hline
\end{tabular}

${ }^{\text {*** Significante }(\mathrm{p}<0,01)}$

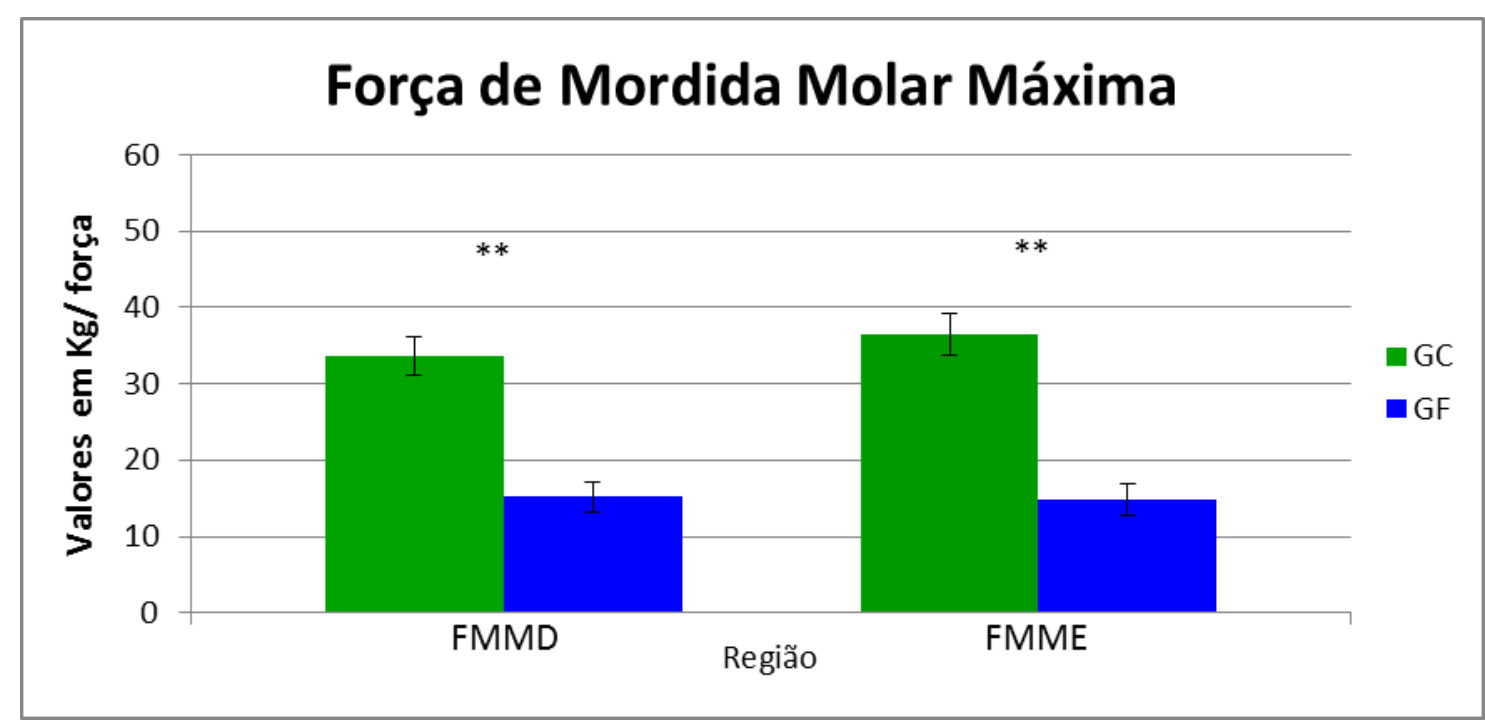

Figura 23. Médias da Força de Mordida Molar Máxima para o GC (Controle) e GF (Fibromialgia), na região molar direita e esquerda (FMMD e FMME), com valores em Kg/ força $(* * p<0,01)$. 


\section{RESULTADOS DA ANÁLISE ULTRASSONOGRÁFICA - ESPESSURA MUSCULAR}

\section{Condição clínica de Repouso}

$\mathrm{Na}$ análise da ultrassonografia de imagem, para a condição clínica de Repouso, observaram-se para o GF menores médias de espessura muscular para a maioria dos músculos avaliados, exceto para o esternocleidomastóideo esquerdo, trapézio direito e esquerdo, quando comparados com o GC. Os valores foram estatisticamente significantes para os músculos temporal direito, esquerdo, masseter direito e trapézio superior esquerdo $(p<0,05)($ Tabela 11 e Fig. 24).

Tabela 11. Médias de espessura muscular $(\mathrm{cm})$ para condição clínica de Repouso para o GC (Controle) e GF (Fibromialgia), para os músculos temporal direito e esquerdo (TD e TE), masseter direito e esquerdo (MD e ME), esternocleidomastóideo direito e esquerdo (ECOMD e ECOME) e trapézio superior direito e esquerdo (TSD e TSE).

\begin{tabular}{ccccc}
\hline Músculos & Grupo & $\boldsymbol{p}$ & Média & Erro padrão \\
\hline TD & GC & $0,00^{* * *}$ & 0,57 & $\pm 0,01$ \\
& GF & & 0,49 & $\pm 0,01$ \\
TE & GC & $0,00^{* *}$ & 0,58 & $\pm 0,01$ \\
& GF & & 0,49 & $\pm 0,01$ \\
MD & GC & $0,03^{*}$ & 0,91 & $\pm 0,02$ \\
& GF & & 0,83 & $\pm 0,02$ \\
ME & GC & $0,19^{\mathrm{ns}}$ & 0,90 & $\pm 0,02$ \\
& GF & & 0,85 & $\pm 0,02$ \\
ECOMD & GC & $0,09^{\mathrm{ns}}$ & 0,73 & $\pm 0,02$ \\
& GF & & 0,68 & $\pm 0,02$ \\
ECOME & GC & $0,61^{\mathrm{ns}}$ & 0,71 & $\pm 0,01$ \\
& GF & & 0,72 & $\pm 0,02$ \\
TSD & GC & $0,06^{\mathrm{ns}}$ & 1,02 & $\pm 0,03$ \\
& GF & & 1,10 & $\pm 0,02$ \\
TSE & GC & $0,03^{*}$ & 0,99 & $\pm 0,03$ \\
& GF & & 1,09 & $\pm 0,02$ \\
\hline
\end{tabular}

\footnotetext{
Significante $(\mathrm{p}<0,01)$

*Significante $(\mathrm{p}<0,05)$

${ }^{\text {ns }}$ Não significante
} 


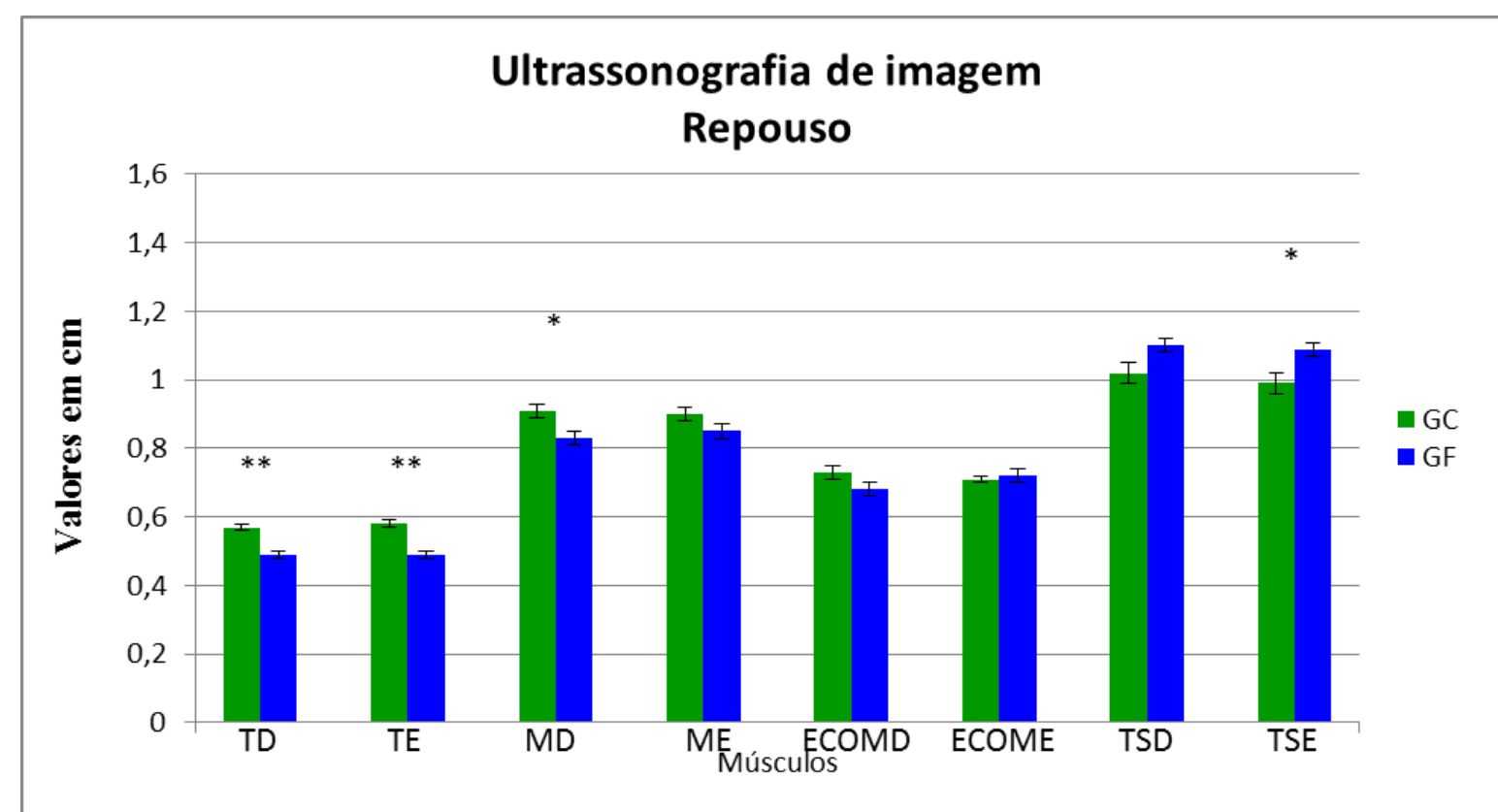

Figura 24. Médias de espessura muscular para condição clínica de Repouso para o GC (Controle) e GF (Fibromialgia), para os músculos temporal direito e esquerdo (TD e TE), masseter direito e esquerdo (MD e ME), esternocleidomastóideo direito e esquerdo (ECOMD e ECOME) e trapézio superior direito e esquerdo (TSD e TSE) $\left(* * \mathrm{p}<0,01 ;{ }^{*} \mathrm{p}<0,05\right)$. 


\section{Condição clínica de Máxima Intercuspidação Habitual}

Os valores médios obtidos da ultrassonografia para a condição clínica de Máxima Intercuspidação Habitual mostraram que o grupo GF apresentou menores médias de espessura muscular para todos os músculos avaliados, exceto para o músculo trapézio superior direito, quando comparados com o GC. Os valores foram estatisticamente significantes para os músculos temporal direito e esquerdo, masseter esquerdo e direito e esternocleidomastóideo direito $(\mathrm{p}<0,05)$ (Tabela 12 e Fig. 25).

Tabela 12. Médias de espessura muscular $(\mathrm{cm})$ para condição clínica de Máxima Intercuspidação Habitual para o GC (Controle) e GF (Fibromialgia), para os músculos temporal direito e esquerdo (TD e TE), masseter direito e esquerdo (MD e ME), esternocleidomastóideo direito e esquerdo (ECOMD e ECOME) e trapézio superior direito e esquerdo (TSD e TSE).

\begin{tabular}{ccccc}
\hline Músculos & Grupo & $\boldsymbol{p}$ & Média & Erro padrão \\
\hline TD & GC & $0,00^{* * *}$ & 0,70 & $\pm 0,02$ \\
& GF & & 0,61 & $\pm 0,02$ \\
TE & GC & $0,01^{* *}$ & 0,70 & $\pm 0,02$ \\
MD & GF & 0,62 & $\pm 0,02$ \\
& GC & $0,02^{*}$ & 1,22 & $\pm 0,02$ \\
ME & GF & & 1,12 & $\pm 0,03$ \\
& GC & $0,01^{* *}$ & 1,24 & $\pm 0,03$ \\
ECOMD & GF & 1,11 & $\pm 0,04$ \\
& GC & $0,05^{*}$ & 0,80 & $\pm 0,02$ \\
ECOME & GF & & 0,73 & $\pm 0,02$ \\
& GC & $0,53^{\text {ns }}$ & 0,78 & $\pm 0,01$ \\
TSD & GF & & 0,76 & $\pm 0,02$ \\
& GC & $0,59^{\text {ns }}$ & 1,38 & $\pm 0,03$ \\
TSE & GF & & 1,41 & $\pm 0,03$ \\
& GC & $0,74^{\text {ns }}$ & 1,40 & $\pm 0,03$ \\
& GF & & 1,38 & $\pm 0,03$ \\
\hline
\end{tabular}

${ }^{\text {** }}$ Significante $(\mathrm{p}<0,01)$

*Significante $(\mathrm{p}<0,05)$

${ }^{\text {ns }}$ Não significante 


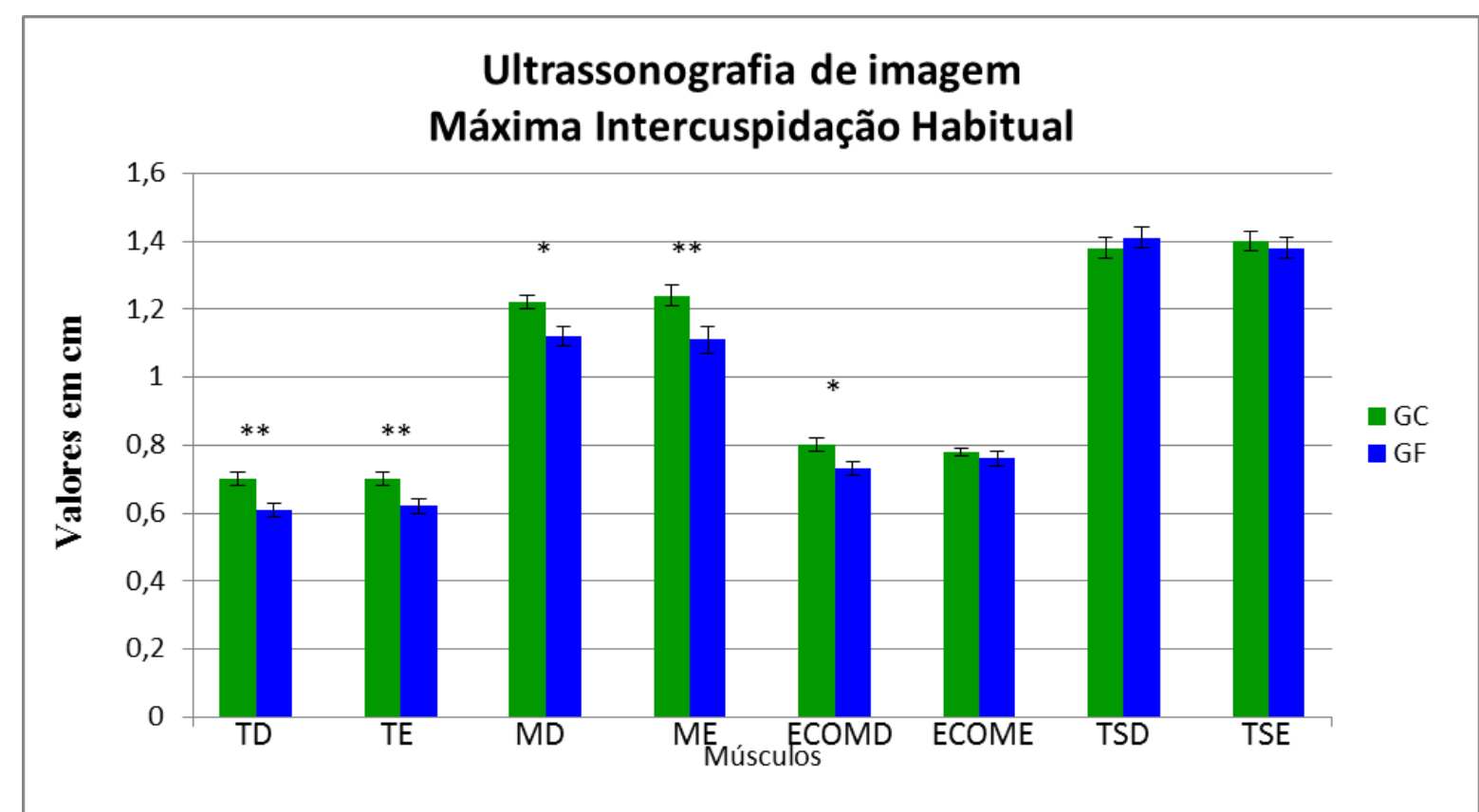

Figura 25. Médias de espessura muscular para condição clínica de Máxima Intercuspidação Habitual para o GC (Controle) e GF (Fibromialgia), para os músculos temporal direito e esquerdo (TD e TE), masseter direito e esquerdo (MD e ME), esternocleidomastóideo direito e esquerdo (ECOMD e ECOME) e trapézio superior direito e esquerdo (TSD e TSE) $(* * \mathrm{p}<0,01, * \mathrm{p}<0,05)$. 


\section{DISCUSSÃO}

A síndrome da fibromialgia é uma síndrome reumática de origem desconhecida, caracterizada por quadros de dor musculoesquelética difusa e crônica e presença de sintomas frequentes, como fadiga, distúrbios de sono, síndrome do colo irritável, dor de cabeça crônica (CASALE et al., 2009; PIMENTEL et al., 2013), episódios depressivos (CLAUW, 2009; MARTINEZ et al., 2013) e dores na região lombar e/ou pescoço (SILVERMAN et al., 2010).

Nos Estados Unidos, a prevalência é de $2 \%$ da população acima dos 18 anos, em sua maioria mulheres com idade a partir de 50 anos (WOLFE et al., 1995). Em estudo Fraga et al. (2012) relataram que a maior prevalência dessa síndrome ainda acomete mais mulheres do que homens, na proporção de 9:1-20:1, com média de idade entre 52 e 57 anos (HAUN et al., 1999; HELFENSTEIN, FELDMAN, 2002). No estudo de Queiroz (2013) verificou-se, no Brasil, que em indivíduos mais idosos, 65 anos ou mais, a taxa de ocorrência dessa síndrome foi de $5,5 \%$.

Tem sido descrito na literatura que essa síndrome está associada ainda a alta prevalência de DTM (75-97\%), sendo que a maior parte dos sinais e sintomas também estão presentes nas mulheres (FRAGA et al., 2011) com idades variando entre 20-40 anos (FRAGA et al., 2012). Em indivíduos de baixa renda da região de Embu (São Paulo - Brasil), com idade maior de 65 anos, e que foram atendidos pelo sistema único de saúde - SUS, a prevalência encontrada foi entre 4,4 e 5,5\% (QUEIROZ, 2013). No nosso estudo, 88,23\% das participantes apresentaram DTM diagnosticada pelo RDC/TMD.

Clauw (2009) descreve que indivíduos com síndrome da fibromialgia podem apresentar também síndrome da fadiga crônica, síndrome da bexiga irritável ou cistite e DTM, e é muito comum a presença de distúrbios orofaciais. Dessa forma, a identificação de possíveis alterações nos músculos do sistema estomatognático e cervicais torna-se relevante, uma vez que a prevalência de DTM nessa síndrome é superior a 70\%.

Pelo fato da dor ser o sintoma primário dessa condição, foi verificado se a síndrome da fibromialgia poderia ser originária de uma alteração do sistema musculoesquelético. Diversos indivíduos com síndrome da fibromialgia apresentam dor orofacial abrangente, distribuída na região do músculo temporal, na articulação temporomandibular, na mandíbula, além de outras partes do corpo, como pescoço e região auricular. Estes dados são concordes com os verificados em nossas participantes que relataram a presença da dor orofacial. A correlação entre dores faciais e corporal, incluindo região cervical está na faixa de 10-20\% 
(SVEENSSON et al., 2004). Pimentel et al. (2013) sugeriram que a dor facial talvez possa ser considerada como parte das manifestações clínicas dessa síndrome. Entre os diversos problemas vivenciados pelos indivíduos com síndrome da fibromialgia, os distúrbios orofaciais estão entre os acometimentos mais prevalentes. A associação entre o sistema estomatognático e a síndrome da fibromialgia vem sendo estudada durante anos (AARON, BURKE, BUCHWALD, 2000; MANFREDINI et al., 2006; BALASUBRAMANIAM et al., 2007; CONSALTER, SANCHES, GUIMARÃES, 2010; FRAGA et al., 2011; FRAGA et al., 2012; PIMENTEL et al., 2013; GUI, PMENTEL, RIZZATTI-BARBOSA, 2015).

A dor muscular cervical tem sido comumente observada em indivíduos com síndrome da fibromialgia e desordem temporomandibular. Entre as evidências comuns está o envolvimento dos músculos levantadores da mandíbula, que podem estar prejudicados durante sua eficiência funcional, com mudanças em sua atividade elétrica e força de contração. A possível associação da desordem temporomandibular com a dor nos músculos cervicais pode ser explicada, pois músculos, tendões, ligamentos e fáscias do crânio que perpassam para a cintura escapular trabalham em estreita coordenação (PALLEGAMA, 2004). Esses músculos agem em coordenação com músculos cervicais e a atuação inadequada em um desses componentes pode acarretar disfunção no outro (STRINI et al., 2013). Todas as participantes desse estudo, independentemente de terem ou não o diagnóstico de DTM, relataram a presença de dor cervical constante.

O músculo esternocleidomastóideo está relacionado com a manutenção da postura da cabeça, podendo ser afetado por distúrbios funcionais e desencadear dor no sistema estomatognático (STRINI et al., 2013). O aumento da atividade desse músculo predominantemente ipsilateral ao trabalho da mandíbula foi observado durante o apertamento dental em indivíduos saudáveis (PALLEGAMA, 2004), assim como para todas as atividades desenvolvidas pelas nossas participantes com síndrome de fibromialgia. Foi observado também aumento da atividade eletromiográfica do músculo trapézio durante o apertamento dental, após a administração de anestésico local em seu ponto gatilho, resultando em redução da condição dolorosa e da atividade eletromiográfica do músculo masseter ipsilateral à aplicação (CARLSON et al., 1993; SVENSSON et al., 2004; LODETTI et al., 2012). Também foram observados valores elevados da atividade eletromiográfica para o esternocleidomastóideo e trapézio em repouso em pacientes com desordem temporomandibular, e a magnitude desta atividade foi influenciada pela presença de dor (STRINI et al., 2013), resultados esse concordes com os verificados neste trabalho.

Possíveis explicações para os resultados encontrados nos músculos do sistema 
estomatognático de indivíduos com síndrome da fibromialgia estão nos conceitos de coativação muscular difusa e contração tetânica. O termo coativação muscular difusa foi definido por Donaldson et al. (2002). Este termo significa um aumento nos níveis de atividade elétrica de repouso (tônus) de qualquer músculo durante um movimento, que não envolva este músculo específico, e em que esse músculo não atue como agonista. Por meio da eletromiografia de superfície, a atividade muscular durante a coativacão muscular foi associada aos pontos dolorosos presentes nos indivíduos com síndrome da fibromialgia, sendo observado um aumento da atividade elétrica nos indivíduos com síndrome da fibromialgia em relação aos controles. A coativação foi mais forte nas proximidades do pescoço e foi diminuindo em intensidade conforme a área registrada movia-se distalmente. Já na contração tetânica, as unidades motoras são estimuladas por múltiplos impulsos pelo neurônio motor, dessa forma, disparam em frequências muito altas, a fim de ativar a contração necessária, que torna a contração muscular ainda mais cansativa, levando a um ciclo de fadiga muscular e dor, resultando na dificuldade de relaxar os músculos de seu corpo (GUI, PIMENTEL, RIZZATTI-BARBOSA, 2015).

Em virtude do estado de contração muscular prolongada associada à dor e à fadiga persistentes nos indivíduos com síndrome da fibromialgia, observam-se alguns distúrbios, como alteração na coordenação motora, alterações dos movimentos, rigidez, fadiga, presença de parestesias nas extremidades por compressão nervosa, além de anormalidades proprioceptivas, como perda de equilíbrio pela interferência dos músculos relacionados à postura (PROVENZA, 1991). De acordo com os resultados obtidos neste trabalho e baseados nos achados da literatura, foi possível verificar que os resultados da atividade eletromiográfica dos músculos mastigatórios das participantes com síndrome da fibromialgia foram maiores, divergindo dos indivíduos controle.

Em nosso estudo, foram observados maiores resultados da atividade eletromiográfica dos músculos mastigatórios e cervicais na condição clínica de Repouso em indivíduos com síndrome da fibromialgia. Os resultados verificados com relação aos músculos mastigatórios foram semelhantes aos do estudo de Gui (2011), que também evidenciou um aumento da atividade eletromiográfica dos músculos mastigatórios durante o repouso. Neste trabalho, foi demonstrado que $87,09 \%$ das participantes com síndrome da fibromialgia apresentaram maior atividade eletromiográfica dos músculos temporais associados a maior dor facial relatada por meio da escala visual analógica de dor. Esse fato poderia ser explicado pelo mecanismo de sensibilização central, no qual um aumento na percepção da dor em indivíduos com fibromialgia é observado. Este mecanismo inclui atividade nervosa espontânea, campos 
receptivos expandidos, resultando em uma distribuição geográfica mais ampla da dor e respostas aumentadas a estímulos na medula espinal (STAUD et al., 2001; STAUD, SMITHERMAN, 2002; SCHMIDT-WILCKE, 2008; LI, BACCEI, 2009), como o aumento da atividade muscular no repouso. Segundo Widmalm, Lee, Mckay (2007) os músculos do sistema estomatognático devem exercer atividade necessária para que esta seja convertida em força pelo sistema muscular, com coordenação motora apropriada e permanecerem em relaxamento durante o repouso da mandíbula. Nesta condição clínica, os lábios estão cerrados e há contato dental mínimo, favorecendo as forças elásticas provenientes dos tecidos moles, mantendo a mandíbula posicionada para realizar suas atividades da melhor forma possível.

Gui (2011) verificou uma correlação positiva entre aumento da atividade eletromiográfica dos músculos mastigatórios durante o repouso e dor no rosto em indivíduos com síndrome da fibromialgia. A dor encontrada em músculos mastigatórios interferem não apenas nas atividades da região dos músculos em questão, mas também em regiões distantes, como nos músculos cervicais. $\mathrm{O}$ aumento da atividade eletromiográfica do músculo trapézio observada durante o apertamento dental, após administração de anestésico local no músculo masseter, demonstra o impacto que a musculatura mastigatória tem na atividade eletromiográfica do trapézio (PALLEGAMA, 2004).

O desenvolvimento de sinais e sintomas de desordem temporomandibular associada a lesões cervicais, fornece fortes evidências para a correlação entre esses dois grupos de distúrbios, embora a natureza do envolvimento dos músculos cervicais e seu significado, incluindo os mecanismos neurológicos dessa relação, ainda precise ser esclarecido. Embora existam evidências para demonstrar uma possível ligação funcional entre músculos mastigatórios e cervicais em indivíduos com desordem temporomandibular durante estados estáticos e dinâmicos, as características das atividades elétricas em repouso dos músculos esternocleidomastóideo e trapézio nos indivíduos com desordem temporomandibular ainda não foram relatadas. Porém existindo uma ligação funcional entre esses grupos musculares é razoável esperar um estado de hiperatividade dos músculos esternocleidomastóideo e trapézio em pacientes com desordem temporomandibular mesmo em repouso (PALLEGAMA et al., 2004).

Outro músculo cervical comumente afetado por esses distúrbios é o músculo trapézio, que normalmente encontra-se dolorido por apresentar vários tender points em indivíduos com síndrome da fibromialgia (MEASE, 2005). Aumentos na prevalência de fibras irregulares de coloração avermelhada, sinais de distúrbios microcirculatórios, além de sinais de sensibilização central foram observados no músculo trapézio de pessoas com síndrome da 
fibromialgia (BANIC et al., 2004).

Durante o exame eletromiográfico, Provenza (1991) verificou maior dificuldade de relaxamento para indivíduos com síndrome da fibromialgia, o que demonstra potenciais de ação musculares mais persistentes, mesmo quando solicitado que relaxassem. Durante o estado de contração mantida, foi demonstrado o envolvimento bilateral evidente do músculo trapézio, evidenciando simetria. Dessa forma, nenhum sinal anormal foi observado nessa síndrome, embora um estado mais persistente de contração tenha sido observado (PROVENZA, 1991), assim como nos dados observados em nosso trabalho. Resultados semelhantes também foram encontrados por Falla et al. (2010), que verificaram maiores atividades eletromiográficas em indivíduos com síndrome da fibromialgia quando comparados aos controles durante abdução sustentada do músculo trapézio, mas após estímulo de anestésico local.

Dessa forma, espera-se que a ativação do músculo trapézio esteja alterada em indivíduos com síndrome da fibromialgia, embora os resultados encontrados apresentam-se algumas vezes divergentes. Alguns estudos relataram aumento da atividade do músculo trapézio, ao passo que outros têm mostrado uma diminuição ou diferenças pouco evidentes em sua atividade quando comparada ao grupo controle. Essa divergência pode ser ocasionada pelas diferentes tarefas executadas, por exemplo, alterações na atividade muscular não são normalmente observadas em condições de repouso ou breves contrações submáximas, mas normalmente durante contrações sustentadas. Durante a estimulação nocioceptiva aguda do músculo trapézio em mulheres, foi observada uma modificação na distribuição da atividade muscular, alterando assim, a adaptação normal do músculo à fadiga. Como resultado, as mesmas regiões do trapézio estão ativas durante a contração na presença de dor aguda (FALLA, ARENDT-NIELSEN, FARINA, 2009). Pode ser esperado que uma adaptação do músculo trapézio à fadiga possa persistir em uma doença muscular crônica, como é o caso da fibromialgia, resultando em sobrecarga das fibras musculares durante a ativação prolongada. Isso poderia ter implicações para a perpetuação da dor, além do estado bioquímico alterado do músculo (FALLA et al., 2010).

Durante os movimentos de lateralidades, direita e esquerda, são esperadas maiores atividades dos músculos temporal ipsilateral e masseter contralateral ao movimento em indivíduos do grupo controle (REGALO et al., 2008; CECILIO et al., 2010). Em nosso trabalho observamos esse padrão de ativação para os dois grupos analisados, entretanto os indivíduos com síndrome da fibromialgia apresentaram maior atividade muscular durante esta condição clínica, fato este que pode ser explicado pela própria fisiopatologia da síndrome da 
fibromialgia, uma vez que contrações musculares prolongadas associadas à dor e à fadiga podem prejudicar a sua função de sincronia e precisão de movimentos, dificultando a execução de atividades que necessitam de coordenação motora para serem realizadas (PROVENZA, 1991).

Durante a condição de protrusão máxima com contato dental, segundo Ash, Ramfjord e Schmidseder (2007), Cecílio et al. (2010) e De Oliveira et al. (2014), o padrão do comportamento muscular necessário para manter a posição se revela com a maior ativação dos músculos masseteres quando comparado com os músculos temporais. Nossos resultados encontraram o padrão descrito pelos autores para os dois grupos analisados, mas novamente, as participantes com fibromialgia apresentaram uma maior ativação de toda a musculatura avaliada.

A capacidade funcional do sistema estomatognático pode ser observada principalmente pela função mastigatória e força de mordida molar máxima, pois essas medidas permitem aos indivíduos executarem a função necessária para que o alimento seja triturado (PEREIRA et al., 2006). Os indivíduos com síndrome da fibromialgia apresentaram uma redução da força muscular, assim como uma redução na eficiência dos ciclos mastigatórios.

A função mastigatória, dita também como desempenho mastigatório, é um processo fisiológico controlado pelo sistema nervoso central que necessita de informações do sistema estomatognático sobre a natureza do alimento a ser triturado (WODA, MISHELLANY, PEYRON, 2006). Dessa forma, diversos fatores influenciam o mecanismo da mastigação, como perda dos dentes, restaurações nos dentes posteriores, força de mordida, idade, sexo, contatos oclusais e função motora (VAN DER BILT, 2002).

Posselt (1973) afirmou que a capacidade funcional mastigatória é dinâmica e que possíveis alterações funcionais no processo são compensatórias, possibilitando que as estruturas anatomofisiológicas permaneçam em perfeita adaptação para realizar o processo da mastigação. Isso poderia explicar as variações nas características da eficiência mastigatória observadas entre indivíduos saudáveis e com disfunção do sistema estomatognático (PIANCINO et al., 2005). Para que ocorra a dinâmica da mastigação são necessários movimentos de contrações isotônicas ou dinâmicas repetitivas, com períodos de contração isométrica que deverão ser abolidas da análise dos sinais (DE LUCA, 1997). O uso da integral da envoltória do sinal eletromiográfico que analisa somente os períodos de contrações isométricas (SIÉSSERE et al., 2009), mensurando a atividade elétrica dos músculos durante a formação dos ciclos mastigatórios permite essa análise da eficiência mastigatória. Quanto 
menor o gasto energético para executar o movimento do ciclo mastigatório, maior a eficiência dos mesmos.

Os registros da integral da envoltória do sinal eletromiográfico possibilitam reconhecer quando e como um músculo é ativado na mastigação (BORGES et al., 2013) e ainda determinam a função dos diferentes músculos envolvidos no movimento, evidenciando as alterações na eficiência mastigatória (PALINKAS et al., 2010; PEPATO et al., 2013).

A função mastigatória, por meio da dinâmica mandibular fisiológica, propicia estímulos mecânicos adequados à cabeça da mandíbula e ligamento periodontal, principais meios de adaptação para o crescimento e desenvolvimento facial, assim como a manutenção dos processos adaptativos, presentes por toda a vida (McNEILL, 2000).

A idade influencia a capacidade dos indivíduos de se adaptarem à alimentos de consistência mais firme. Com o aumento da idade, o número de ciclos mastigatórios aumenta para o mesmo alimento ser triturado, porém a adaptação do sistema estomatognático é variado e as funções se mantêm (PEYRON et al., 2004).

Os resultados verificados nesta pesquisa evidenciaram diminuição na eficiência mastigatória para todas as participantes com fibromialgia, com diferença estatística significante em todas as mastigações, não habitual, com Parafilme $\mathrm{M}^{\circledR}$, e habitual (alimentos macios e duros). Segundo De Rossi et al. (2009), Palinkas et al. (2013), durante a mastigação habitual e não habitual em indivíduos com alterações morfofuncionais, ocorre maior recrutamento das fibras musculares para realizar a mesma função mastigatória, quando comparados aos indivíduos saudáveis, gerando estresse, fadiga e aumento na atividade eletromiográfica. A mastigação não habitual é um movimento com registros dinâmicos, de curta excursão de abertura da boca, do tipo charneira, solicitado para diminuir os efeitos da mudança de comprimento e tensão do músculo (DE LUCA, 1997; PALINKAS et al., 2011).

A força de mordida é executada pelos músculos levantadores da mandíbula e regulada por outros músculos do sistema estomatognático, assim como pelos sistemas neurológico, esquelético e dental (LINDERHOLM, WENNSTRÖM, 1970; SHEIKHOLESLAM et al., 1980; OW, CARLSSON, JEMT, 1989), podendo ser mensurada por métodos diretos, como o dinamômetro que foi utilizado neste trabalho. A força de mordida é resultante da interação complexa de diferentes componentes do sistema estomatognático que são regulados pelo sistema nervoso central (OW, CARLSSON, JEMT, 1989). Trata-se de um importante método auxiliar no diagnóstico de distúrbios no sistema estomatognático, por ser indicador do estado funcional, fornecendo dados úteis para avaliação da função e da atividade dos músculos mastigatórios (KOC, DOGAN, BEK, 2010). Os valores de força de mordida são influenciados 
pela morfologia facial, estrutura física geral, gênero do indivíduo, estado de dentição e idade (RENTES et al., 2002; BONJARDIM et al., 2005). Todas as participantes deste estudo foram avaliadas nesse quesito, principalmente com relação à presença de dentes e de uma oclusão clinicamente normal. Na comparação entre os grupos, para esses fatores não influenciarem nos resultados obtidos, fez-se o pareamento sujeito a sujeito, com base na idade, gênero (somente mulheres), peso e estatura das participantes, assim como era necessário a presença dos primeiros molares permanentes.

Nossos resultados evidenciaram que para ambos os lados ocorreu menor força de mordida nas participantes com síndrome da fibromialgia. Esses dados são concordes com os resultados de Griffin e Mallor (1974 e 1975) e Kawamura (1974) que verificaram que em indivíduos portadores de disfunções do sistema estomatognático, a força de mordida molar máxima é menor. A força de mordida registrada, pode ser maior que os valores reais utilizados durante as atividades funcionais normais da mandíbula, encontradas neste estudo, pois era solicitado às participantes da pesquisa que realizassem a atividade proposta de forma isolada.

Apesar da força de mordida poder variar de indivíduo para indivíduo e sofrer influência da idade, os seus valores permanecem constantes entre 20 e 50 anos (PALINKAS et al., 2010).

Sobre a análise morfológica do tecido muscular, a ultrassonografia tem sido utilizada para mensurar a espessura muscular e se apresenta como método confiável para reprodução dos resultados obtidos (PEREIRA et al., 2006 e PALINKAS et al., 2010). Nesta pesquisa foi observada uma maior espessura muscular dos músculos temporais e masseteres durante as condições clínicas de repouso e máxima intercuspidação habitual. Segundo Koopman e van Loon (2009), o declínio da massa e da capacidade oxidativa muscular em combinação com uma maior massa de gordura contribui para um maior risco de desenvolver doenças crônicas, como é o caso da síndrome da fibromialgia.

Não foram encontrados estudos na literatura que realizassem a avaliação da espessura muscular do sistema estomatognático em indivíduos com síndrome da fibromialgia. Esses resultados são interessantes quando correlacionados com a força de mordida molar máxima, pois verificou-se menores valores de força de mordida para as participantes com síndrome da fibromialgia, observando-se que não existe uma relação direta entre espessura muscular e força de mordida máxima, contradizendo Raadsheer et al. (1999) que afirmaram que quanto maior a espessura muscular, maior será a força de mordida molar máxima. Na PRESENTE pesquisa todas as mensurações realizadas durante o repouso e a contração muscular por 
apertamento dental, revelaram para a maioria dos músculos uma menor espessura, o que foi verificado por outros autores (PEREIRA et al., 2006; PEREIRA et al., 2007).

Em virtude dos distúrbios relacionados à síndrome da fibromialgia, o prejuízo à vida pessoal e profissional torna-se evidente. Devido aos sinais e sintomas que esses indivíduos apresentam, a ida a consultas médicas é frequente até que o diagnóstico seja confirmado. Dessa forma, indivíduos com síndrome da fibromialgia apresentam um grande gasto para a sociedade, pois utilizam mais frequentemente o sistema de saúde. Foi observado que esses indivíduos representam um custo anual de 9.573 dólares, gastando de 3 a 5 vezes mais que a população em geral (HELFENSTEIN JÚNIOR, GOLDENFUM, SIENA, 2012). O prejuízo econômico muitas vezes afeta os indivíduos com síndrome da fibromialgia, particularmente aqueles de menor nível socioeconômico, o que corresponde a cerca de três quartos (3/4) do total de fibromiálgicos. Normalmente, esses indivíduos tendem a desempenhar trabalhos manuais e fazer mais serviços domésticos, o que pode predispor o aparecimento de mais dor e lesões. Outra característica é aquela relacionada ao peso, pois esses indivíduos tendem a ter excesso de peso - outro fator de risco para a dor (GRODMAN et al., 2011). Segundo relatos de indivíduos com síndrome da fibromialgia, os sintomas que mais atrapalham as atividades profissionais são: dor (87\%), fadiga (80\%), fraqueza muscular $(73 \%)$, além de problemas de concentração e memorização (51\%).

Indivíduos com síndrome da fibromialgia relatam que os fatores que desencadearam o início dos sinais e sintomas foram as condições de trabalho e/ou distúrbios psicológicos, como depressão e ansiedade. Entretanto, não há evidência que confirm que a síndrome da fibromialgia tenha etiologia ocupacional ou que possa ser causada por fatores psicológicos. Critérios rígidos de produtividade e pressão no ambiente de trabalho ainda não foram estabelecidos como agravantes dos sintomas vivenciados por esses indivíduos. Como não foram predefinidos quais limites biomecânicos interferem nas atividades laborais desses indivíduos, nenhuma forma de minimizar, modificar ou eliminar atividades por eles desenvolvidas foi descrita (REZENDE et al., 2013).

O conhecimento das possíveis alterações no sistema estomatognático em indivíduos com síndrome da fibromialgia, não é apenas relevante, mas imprescindível, tendo em vista que a falta de informação pode conduzir ao tratamento de forma inapropriada, podendo ocasionar consequências biológicas, psicológicas e econômicas negativas. 


\section{CONCLUSÕES}

Tendo em vista os resultados obtidos é lícito concluir que comparando mulheres saudáveis (GC) com aquelas com síndrome da fibromialgia (GF), a:

1. Atividade eletromiográfica para as mulheres portadoras da síndrome da fibromialgia foi maior para todas as condições clínicas analisadas para todos os músculos estudados.

2. Eficiência mastigatória foi menor para as mulheres portadoras da síndrome da fibromialgia.

3. Atividade da força de mordida molar máxima direita e esquerda foram menores para as mulheres portadoras da síndrome da fibromialgia.

Tais resultados nos fazem crer que mulheres portadoras da síndrome da fibromialgia apresentaram condições comprometedoras do sistema estomatognático que podem refletir no cansaço facial e eventuais dores na região da face e do pescoço. Isso pode comprometer a atividade mastigatória e a formação do bolo alimentar, ou seja, prejuízo do sistema digestório, com consequente prejuízo na qualidade de vida. 


\section{REFERÊNCIAS}

AARON, L.A; BURKE, M.M.; BUCHWALD, D. Overlapping conditions among patients with chronic fatigue syndrome, fibromyalgia, and temporomandibular disorder. Arch Intern Med. 2000; 160(2):221-7.

ACOSTA-ORTIZ, R; SCHULTE, K; SPARKS, B; MARSH, W. Prediction of different mandibular activities by EMG signal levels. J Oral Rehabil. 2004; 31 (5):399-405.

AP BIASOTTO-GONZALEZ, D.; BERZIN, F.; DA COSTA, J.M.; de GONZALEZ, TO. Electromyographic study of stomatognathic system muscles during shewing of diffrent materials. Electromyogr Clin Neurophysiol. 2010; 50(2):121-7.

AQUINO, L.M.M. de.; GUI, M.S.; PIMENTEL, M.J.; REIMÃO, R.; RIZZATTIBARBOSA, C.M. Temporomandibular disorders in fibromyalgia: a critical view. Braz. Dent. Sci. 2012; 15(2): 27-34.

ASH, M.M.; RAMFJORD, S.P.; SCHMIDSEDER, J. Oclusão. $2^{\text {a }}$ ed. Rio de Janeiro (Brasil): Ed. Santos, 2007. Cap 2. Músculos: Função e Disfunção, p.15-30.

BALASUBRAMANIAM, R.; LEEUW, R.; ZHU, H.; NICKERSON, R. B.; OKESON, J. P.; CARLSON, C. R. Prevalence of temporomandibular disorders in fibromyalgia and failed back syndrome patients: a blinded prospective comparison study. Oral Surg Oral Med Oral Pathol Oral Radiol Endod. 2007; 104(2):204-16.

BANIC, B.; PETERSEN-FELIX, S.; ANDERSEN, O.K.; RADANOV, B.P.; VILLIGER, P.M.; ARENDT-NIELSEN, L.; CURATOLO, M. Evidence for spinal cord hypersensitivity in chronic pain after whiplash injury and in fibromyalgia. Pain. 2004;107:715.

BASMAJIAN, J.V.; DE LUCA. C.J. Muscles alive: their functions revealed by electromyography. 5. ed., Baltimore, Williams \& Wilkins, 1985. p.408-428.

BAZZICHI, L.; DINI, M.; ROSSI, A.; CORBIANCO, S.; DE FEO, F.; GIACOMELLI, C.; ZIRAFA, C.; FERRARI, C.; ROSSI, B.; BOMBARDIERI, S. Muscle modifications in fibromyalgic patients revealed by surface electromyography (SEMG) analysis. BMC Musculoskelet Disord. 2009; 10:36. doi: 10.1186/1471-2474-10-36.

BERTRAM, S.; BRANDLMAIER, I.; RUDISCH, A.; BODNER, G.; EMSHOFF, R. Cross-sectional characteristics of the masseter muscle: an ultrasonographic study. Int. J. Oral Maxillofac Surg. 2003; 32:64-68.

BIASOTTO, D. C.; BIASOTTO-GONZALES, D.; PANHOCA, I. Correlation between the clinical phonoaudiological assessment and electromyographic activity of the masseter muscle. J Appl Oral Sci. 2005; 13(4):424-30.

BONJARDIM, L.R.; GAVIÃO, M.B.; PEREIRA, L.J.; CASTELO, P.M. Bite force determination in adolescents with and without temporomandibular dysfunction. J Oral Rehabil. 2005 Aug;32(8):577-83. 
BORGES, T.de.F.; REGALO, S.C.; TABA, M. JR.; SIÉSSERE, S.; MESTRINER, W. JR.; SEMPRINI, M. Changes in masticatory performance and quality of life in individuals with chronic periodontitis. J Periodontol. 2013 Mar;84(3):325-31. doi: 10.1902/jop.2012.120069.

BRAGATTO, M.M.; BEVILAQUA-GROSSI, D.; REGALO, S.C.; SOUSA, J.D.; CHAVES, T.C. Associations among temporomandibular disorders, chronic neck pain and neck pain disability in computer office workers: a pilot study. J Oral Rehabil. 2016 Jan 6. doi: $10.1111 /$ joor. 12377 .

CARLSON, C.R.1.; OKESON, J.P.; FALACE, D.A.; NITZ, A.J.; LINDROTH, J.E. Reduction of pain and EMG activity in the masseter region by trapezius trigger point injection. Pain. 1993 Dec;55(3):397-400.

CASALE, R.; SARZI-PUTTINI, P.; ATZENI, F.; GAZZONI, M.; BUSKILA, D.; RAINOLDI, A. Central motor control failure in fibromyalgia: a surface electromyography study. BMC Musculoskelet Disord. 2009; 10:78. doi: 10.1186/1471-2474-10-78.

CASALE, R.; RAINOLDI, A. Fatigue and fibromyalgia syndrome: clinical and neurophysiologic pattern. Best Pract Res Clin Rheumatol. 2011; 25 (2):241-7. doi: 10.1016/j.berh.2011.01.016.

CECÍlIO, F.A.; REGALO, S.C.H.; PALINKAS, M.; ISSA, J.P.M.; SIÉSSERE, S.; HALLAK, J.E.C.; MACHADO-DE-SOUSA, J.P.; SEMPRINI, M. Aging and surface EMG activity patterns of masticatory muscles. J Oral Rehabil. 2010; DOI 10.1111/j.13652842.2010.02051.

CIMINO, R.; MICHELOTTI, A.; STRADI, R.; FARINARO, C. Comparison of clinical and psychologic features of fibromyalgia and masticatory myofascial pain. J Orofac Pain. 1998 Winter;12(1):35-41.

CLAUW, D.J. Fibromyalgia: an overview. Am J Med. 2009 Dec; 122(12 Suppl):S3S13. doi: 10.1016/j.amjmed.2009.09.006. Review.

CONSALTER, E.; SANCHES, M.L.; GUIMARÃES, A.S. Correlação entre disfunção temporomandibular e fibromialgia. Rev Dor. São Paulo, 2010 jul-set;11(3):237-241.

CORREIA, L.M.F.; HUMMIG, W.; ADAMOWICZ, T.; DE ALMEIDA, D.B. Importance of evaluating the presence of temporomandibular disorders in chronic pain patients. Rev Dor. São Paulo, 2014 jan-mar;15(1):6-8.

CRAM, J.R., KASMAN, G.S., HOLTZ, J. Introduction to Surface Electromyography. Ed. Gaithersburg, Maryland: Aspen Publication ®; p. 257-258, 1998.

DE OLIVEIRA, R.H.; HALLAK, J.E.; SIÉSSERE, S.; DE SOUSA, L.G.; SEMPRINI, M.; DE SENA, M.F.; OSORIO, F.de.L.; NUNES, E.A.; PINTO, J.P.; REGALO, S.C. Electromyographic analysis of masseter and temporal muscles, bite force, masticatory efficiency in medicated individuals with schizophrenia and mood disorders compared with healthy controls. J Oral Rehabil. 2014 jun;41(6):399-408. doi: 10.1111/joor.12164. 
DE LUCA, C.J. The use of surface electromyography in biomechanics. J Appl Biomech. 1997; v.13, p.135-163.

DE ROSSI, M.; DE ROSSI, A.; HALLAK, J.E.; VITTI, M.; REGALO, S.C.H. Electromyographic evaluation in children having rapid maxillary expansion. Am J Orthod Dentofacial Orthop. 2009; v.136, n.3, p.355-360.

DONALDSON, C.C.; MACINNIS, A.L.; SNELlING, L.S.; SELLA, G.E.; MUELLER, H.H. Characteristics of diffuse muscular coactivation (DMC) in persons with fibromyalgia -- part 2. NeuroRehabilitation. 2002;17(1):41-8.

DREWER, A.; ANDREASEN, A.; SCHRIDER, H.; HOGSAA, B.; JENNUM, P. Pathology of skeletal muscle in fibromyalgia: a histo-immuno- chemical and ultrastructural study. Br J Rheumatol. 1993;32:479-83.

DROST, G.; STEGEMAN, D.F.; VAN ENGELEN, B.G.M.; ZWARTS, M.J. Clinical applications of high-density surface EMG: A systematic review. J. Electromyogr Kinesiol. 16:586-602, 2006.

DWORKIN, S.F.; HUGGINS, K.H.; WILSON, L.; MANCL，L.; TURNER, J.; MASSOTH, D.; LERESCHE, L.; TRUELOVE, E. A randomized clinical trial using research diagnostic criteria for temporomandibular disorders-axis II to target clinic cases for a tailored self-care TMD treatment program. J Orofac Pain. 2002; 16(1):48-63.

ELERT, J.; KENDALL, S.A.; LARSSON, B.; MÅNSSON, B.; GERDLE, B. Chronic pain and difficulty in relaxing postural muscles in patients with fibromyalgia and chronic whiplash associated disorders. J Rheumatol. 2001; 28(6):1361-8.

FALLA, D.; ARENDT-NIELSEN, L.; FARINA, D. The pain-induced change in relative activation of upper trapezius muscle regions is independent of the site of noxious stimulation. Clin Neurophysiol. 2009 Jan;120(1):150-7. doi: 10.1016/j.clinph.2008.10.148.

FALLA, D.; ANDERSEN, H.; DANNESKIOLD-SAMSOE, B.; ARENDTNIELSEN, L.; FARINA, D .Adaptations of upper trapezius muscle activity during sustained contractions in women with fibromyalgia. J Electromyogr Kinesiol. 2010; 20(3):457-64.

FRAGA, B.P.; SANTOS, E.B.; FRAGA, T.P.; MACIEIRA, J.C.; FARIAS-NETO, J.P.; JÚNIOR, L.J.Q.; BONJARDIM, L. R. Fibromialgia e disfunção temporomandibular: uma revisão de literatura. RSBO. 2011; 8(1):89-96.

FRAGA, B.P.; SANTOS, E.B.; FARIAS NETO, J.P.; MACIEIRA, J.C.; QUINTANS, L.J.JR.; ONOFRE, A.S.; DE SANTANA, J.M.; MARTINS-FILHO, P.R.; BONJARDIM, L.R. Signs and symptoms of temporomandibular dysfunction in fibromyalgic patients. $\mathbf{J}$ Craniofac Surg. 2012 Mar;23(2):615-8. doi: 10.1097/SCS.0b013e31824cd81a.

FUEKI K, S. T.; YOSHIDA, E.; IGARASHI, Y. Association between food mixing ability and electromyographic activity of jaw-closing muscles during chewing of a wax cube. J Oral Rehabil. 2008; 35(5):345-52.

GERDLE, B.; OSTLUND, N.; GRÖNLUND, C.; ROELEVELD, K.; KARLSSON, J. 
S. Firing rate and conduction velocity of single motor units in the trapezius muscle in fibromyalgia patients and healthy controls. J Electromyogr Kinesiol. 2008; 18(5):707-16.

GERDLE, B.; GRÖNLUND, C.; KARLSSON, S.J.; HOLTERMANN, A.; ROELEVELD, K. Altered neuromuscular control mechanisms of the trapezius muscle in fibromyalgia. BMC Musculoskelet Disord. 2010; 11:42.

GEORGIAKAKI, I.; TORTOPIDIS, D.; GAREFIS, P.; KILIARIDIS, S. Ultrasonographic thickness and electromyographic activity of masseter muscle of human females. J Oral Rehabil. 2007 Feb;34(2):121-8.

GRIFFIN, C.J.; MALLOR, R. An anlaysis of mandibular movement. In: Y. Kawamura. Frontiers of Oral Physiology. Basel, Karger, 1974. p.159-198.

GRIFFIN, C.J.; MALLOR, R. An analysis of controlled mandibular movement. In: C.J. Griffin, R. Harris, eds. Temporomandibular joint syndrome; the masticatory apparatus of man in normal an abnormal function. Monographs of Oral Sciences 4. Basel, Karger, 1975. p.151-169.

GRODMAN, I.; BUSKILA, D.; ARNSON, Y.; ALTAMAN, A.; AMITAL, D.; AMITAL, H. Understanding fibromyalgia and its resultant disability. Isr Med Assoc J. 2011 Dec;13(12):769-72.

GUI, M.S. Estudo da dor facial e da atividade eletromiográfica de músculos mastigatórios em portadores de fibromialgia e distúrbios do sono, com diagnóstico de disfunção temporomandibular. 77 f. Dissertação (Mestrado em Biologia Buco-Dental) Faculdade de Odontologia de Piracicaba, Universidade de Campinas, 2011.

GUI, M.S.; PIMENTEL, M.J.; RIZZATTI-BARBOSA, C.M. Temporomandibular disorders in fibromyalgia syndrome: a short-communication. Rev Bras Reumatol. 2015 MarApr;55(2):189-94. doi: 10.1016/j.rbr.2014.07.004.

HÄKKINEN, K.; PAKARINEN, A.; HANNONEN, P.; HÄKKINEN, A.; AIRAKSINEN, O.; VALKEINEN, H.; ALEN, M. Effects of strength training on muscle strength, cross-sectional area, maximal electromyographic activity, and serum hormones in premenopausal women with fibromyalgia. J Rheumatol. 2002; 29(6):1287-95.

HAUN, M.V.A.; FERRAZ, M.B.; POLLAK, D.F. Validação dos critérios do Colégio Americano de Reumatologia (1990) para classificação da fibromialgia em uma população brasileira. Rev Bras Reumatol. 1999; 39(1):221-230.

HELFENSTEIN JUNIOR, M.; FELDMAN, D. Síndrome da fibromialgia: características clínicas e associações com outras síndromes disfuncionais. Rev Bras Reumatol. 2002; 42(1):8-14.

HELFENSTEIN JUNIOR, M.; GOLDENFUM, M.A.; SIENA, C.A.F. Fibromialgia: aspectos clínicos e ocupacionais Rev Assoc Med Bras. 2012; 58(3):358-365.

HERMENS, H.J.; FRERIKS, B.; DISSELHORST-KLUG, C.; RAU, G. Development of recommendations for SEMG sensors and sensor placement procedures. J Electromyogr 
Kinesiol. 2000; 10 (5):361-74. 120.

KAWAMURA, Y. Neurogenesis of mastication. Front Oral Physiol. 1974;1(0):77-

KIMURA, M; SATO, H.; OCHI, M.; HOSOYA, S.; SADOYAMA, T. Electromyogram and perceived fatigue changes in the trapezius muscle during typewriting and recovery. Eur J Appl Physiol. 2007; 100(1):89-96.

KLAVER-KRÓL, E.G.; HENRIQUEZ, N.R.; OOSTERLOO, S.J.; KLAVER, P.; BOS, J.M.; ZWARTS, M.J. Distribution of motor unit potential velocities in short static and prolonged dynamic contractions at low forces: use of the within-subject's skewness and standard deviation variables. Eur J Appl Physiol. 2007; 101(5):647-58.

KLAVER-KRÓL, E.G.; RASKER, J.J.; HENRIQUEZ, N.R.; VERHEIJEN, W.G.; ZWARTS, M.J. Muscle fiber velocity and electromyographic signs of fatigue in fibromyalgia. Muscle Nerve. 2012; 46(5):738-45.

KOC, D.; DOGAN, A.; BEK, B. Bite force and influential factors on bite force measurements: a literature review. Eur J Dent. 2010; v.4, n.2, p.223-232.

KOGAWA, E.M.; CALDERON, P.S.; LAURIS, J.R.; ARAUJO, C.R.; CONTI, P.C. Evaluation of maximal bite force in temporomandibular disorders patients. J Oral Rehabil. 2006 aug.; v.33, n.8, p.559-565.

KOOPMAN, R.; VAN LOON, L.J. Aging, exercise and muscle protein metabolism. J Appl Physiol. 2009 jun; v.106, n.6, p.2040-2048.

LI, J.; BACCEI, M.L. Excitatory synapses in the rat superficial dorsal horn are strengthened following peripheral inflammation during early postnatal development. Pain. 2009; 143: 56-64.

LINDERHOLM, H.; WENNSTRÖM, A. Isometric bite force and its relation to general muscle force and body build. Acta Odontol Scand. 1970 nov; v.28, n.5, p.678-689.

LODETTI, G.; MAPELLI, A.; MUSTO, F.; ROSATI, R.; SFORZA, C. EMG spectral characteristics of masticatory muscles and upper trapezius during maximum voluntary teeth clenching. J Electromyogr Kinesiol. $2012 \quad$ Feb;22(1):103-9. doi: 10.1016/j.jelekin.2011.10.008.

MANFREDINI, D.; SALVETT, G.; FANTONI, F.; BOSCO, M. Relationship between fibromyalgia and temporomandibular disorders: A review of current understandings. JCCM. 2006; 1:136-141.

MAQUET, D.; CROISIER, J.L.; DUPONT, C.; MOUTSCHEN, M.; ANSSEAU, M.; ZEEVAERT, B.; CRIELAARD, J.M. Fibromyalgia and related conditions: electromyogram profile during isometric muscle contraction. Joint Bone Spine. 2010; 77( 3):264-7.

MARQUES, A.P.; MATSUTANI, L.A., FERREIRA, E.A.G.; DE MENDONÇA, L.L.F. A fisioterapia no tratamento de pacientes com fibromialgia : uma revisão da literatura. 
Rev Bras Reumatol. 2002; 42(1):42-48.

MARTINEZ, J. E.; FERRAZ, M.B.; SATO, E.I.; ATRA, E. Avaliação sequencial do impacto da fibromialgia e da artrite reumatóide da qualidade de vida. Rev. Bras. Reumatol. 1994; 34:309-16.

MARTINEZ, J.E.; CASAGRANDE; P.M.; FERREIRA; P.P.R.; ROSSATTO, B.L.G. Correlação entre variáveis demográficas e clínicas e a gravidade da fibromialgia. Rev Bras Reumatol. 2013; 53(6):460-463.

McNEILL, C. Ciência e prática da oclusão. São Paulo: Editora Santos, 2000. p.538.

MEASE, P. Fibromyalgia syndrome: review of clinical presentation, pathogenesis, outcome measures, and treatment. J Rheumatol Suppl. 2005;75:6-21.

MERLETTI, R.; BOTTER, A.; TROIANO, A.; MERLO, E.; MINETTO, M.A. Technology and instrumentation for detection and conditioning of the surface electromyographic signal: state of the art. Clin Biomech (Bristol, Avon). 2009; 24:122-134.

MOLDOFSKY, H.K. Disordered sleep in fibromyalgia and related myofacial facial pain conditions. Dent. Clin North Am. 2001; 45:701-13.

NASSIRI, L.F.G.; ABDALA, N.; SZEJNFELD, J.; NASSRI, M.R.G. Análise comparativa entre os achados de eletromiografia do músculo facial masseter em participantes com e sem desordem temporomandibular: parte I Comparative analysis between electromyographic findings of masseter muscle in patients with and without tempor. RSBO. 2009; 6(4):393-400.

OKIFUJI, A.; TURK, D.C, SINCLAIR, J.D.; STARZ, T.W.; MARCUS, D.A. A standardized manual tender point survey. I. Development and determination of a threshold point for the identification of positive tender points in fibromyalgia syndrome. J Rheumatol. 1997, Feb;24(2):377-83.

OLSEN, N.J.; PARK, J.H. Skeletal muscle abnormalities in patients with fibromyalgia. Am J Med Sci. 1998, Jun;315(6):351-8.

OW, R.K., CARLSSON, G.E.; JEMT, T. Biting forces in patients with craniomandibular disorders. Cranio. 1989; v.7, n.2, p.119-125.

PALINKAS, M.; NASSAR, M.S.; CECÍLIO, F.A.; SIÉSSERE, S.; SEMPRINI, M.; MACHADO-DE-SOUSA, J.P.; HALLAK, J.E.; REGALO, S.C. Age and gender influence on maximal bite force and masticatory muscles thickness. Arch Oral Biol. 2010; 55(10):797802.

PALINKAS, M.; ONETY, G.C.S.; SEMPRINI, M.; OLIVEIRA, R.H.; SIÉSSERE, S.; REGALO, S.C.H. Efficiency of the Masticatory Cycle in Bilingual Deaf Individuals: Electromyographic Analysis. Rev Bras Terap e Saúde. 2011; v.2, n.1, p.1-6.

PALINKAS, M.; CECILIO, F.A.; SIÉSSERE, S.; BORGES, T.de.F.; DE CARVALHO, C.A.; SEMPRINI, M.; DE SOUSA, L.G.; REGALO, S.C. Aging of 
masticatory efficiency in healthy subjects: electromyographic analysis--Part 2. Acta Odontol Latinoam. 2013; 26(3):161-6.

PALLEGAMA, R.W.; RANASINGHE, A.W.; WEERASINGHE, V.S.; SITHEEQUE, M.A. Influence of masticatory muscle pain on electromyographic activities of cervical muscles in patients with myogenous temporomandibular disorders. J Oral Rehabil. 2004 May;31(5):423-9.

PEPATO, A.O.; PALINKAS, M.; REGALO, S.C.H.; RIBEIRO, M.C.; SOUZA, T.A.S.; SIÉSSERE, S.; SOUSA, L.G.; SVERZUT, C.E.; TRIVELLATO, A.E. Analysis of masticatory efficiency by electromyographic activity of masticatory muscles after surgical treatment of zygomatic-orbital complex fractures. Int J Stomatol Occlusion Med. 2013; v.6, n.3, p.85-90.

PEREIRA, L.J.; DUARTE GAVIAO, M.B.; VAN DER BILT, A. Influence of oral characteristics and food products on masticatory function. Acta Odontol Scand. 2006 Aug;64(4):193-201.

PEREIRA, L.J.; GAVIÃO, M.B.; BONJARDIM, L.R.; CASTELO, P.M.; VAN DER BILT, A. Muscle thickness, bite force, and craniofacial dimensions in adolescents with signs and symptoms of temporomandibular dysfunction. Eur J Orthod. 2007; v.29, n.1, p.72-78.

PEYRON, M.A.; BLANC, O.; LUND, J.P.; WODA, A. Influence of age on adaptability of human mastication. J Neurophysiol. 2004; v.92, n.2, 773-779.

PIANCINO, M.G.; TALPONE, F.; BOLE, T.; CASTROFLORIO, T.; TORSELlO, F.; DEBERNARDI, C.; BRACCO, P. Electromyographic evaluation of neuromuscular coordination during chewing in a subject with organic occlusion. Minerva Stomatol. 2005; v.54, n.6, p.379-387.

PIMENTEL, M.J. Características de disfunção temporomandibular e qualidade do sono em portadores de fibromialgia. Piracicaba, 2011. 74 folhas. Dissertação de mestrado - Faculdade de Odontologia de Piracicaba. Universidade de Campinas - UNICAMP.

PIMENTEL, M.J.; GUI, M.S.; MARTINS, de A. L.M.; RIZZATTI-BARBOSA, C.M. Features of temporomandibular disorders in fibromyalgia syndrome. Cranio. 2013 Jan;31(1):40-5.

POSSELT, U. Fisologia de la Oclusion y Rehabilitacion. Barcelona: Editora Mallat Desplats, 1973. p.352.

PROVENZA, J.R. Fibromialgia: Correlação Clínica, Laboratorial e Eletromiográfica. 1991. 125 f. Tese (Doutorado em Ciências Médicas) - Faculdade de Ciências Médicas, Universidade de Campinas, Campinas, 1991.

PROVENZA, J.R.; POLLAK, D.F.; MARTINEZ, J.E.; PAIVA, E.S.; HELFENSTEIN, M.; HEYMANN, R.; MATOS, J.M.C.; SOUZA, E.J.R. Fibromialgia. Rev. Bras Reumatol. 2004; 44(6):443-449.

QUEIROZ, L.P. Worldwide epidemiology of fibromyalgia. Curr Pain Headache 
Rep. 2013, 17(8):1-6.

RAADSHEER, M.C.; VAN EIJDEN, T.M.; VAN GINKEL, F.C.; PRAHLANDERSEN, B. Contribution of jaw muscle size and craniofacial morphology to human bite force magnitude. J Dent Res. 1999 Jan;78(1):31-42.

REGALO, S.C.; SANTOS, C.M.; VITTI, M.; REGALO, C.A.; DE VASCONCELOS, P.B.; MESTRINER, W. JR.; SEMPRINI, M.; DIAS, F.J.; HALLAK, J.E.; SIÉSSERE, S. Evaluation of molar and incisor bite force in indigenous compared with white population in Brazil. Arch Oral Biol. 2008; 53(3):282-6.

RENTES, A.M.; GAVIÃO, M.B.; AMARAL, J.R. Bite force determination in children with primary dentition. J Oral Rehabil. 2002 dec; v.29, n.12, p.1174-1180.

REZENDE, M.C.; PAIVA, E.S.; HELFENSTEIN, M.; RANZOLIN, A.; MARTINEZ, J.; EDUARDO R.P.; JOSE R.P.; CARLOS E.; RIBEIRO, L.S.; SOUZA, E.J.R.; FELDMAN, D.P.; DE ASSIS, M.R.; HEYMANN, R.E.; EpiFibro - um banco de dados nacional sobre a síndrome da fibromialgia - análise inicial de 500 mulheres. Rev Bras Reumatol. 2013, 53(5):382-387.

RIBERTO, M.; BATTISTELLA, L.R. Comorbidades em fibromialgia. Rev Bras Reumatol. 2002; 42:1-7.

SAWADA, F.; NOMURA, Y.; GOTO, F., MURAKAMI, M.; JIKE, M.; TOI, T.; FURUSAKA, T.; IKEDA, M.; OSHIMA, T. Relationship of physical distress to dizziness in patients with fibromyalgia. Acta Otolaryngol. 2016; Jan;136(1):56-61. doi: 10.3109/00016489.2015.1088662.

SCHMIDT-WILCKE, T. Variations in brain volume and regional morphology associated with chronic pain. Curr Rheumatol Rep. 2008; 10: 467-74.

SERRA, M.D.; DUARTE GAVIÃO, M.B.; DOS SANTOS UCHÔA, M.N. The use of ultrassound in the invertigation of the muscles of mastication. Ultrasound Med Biol. 2008; 34(12):1875-1884.

SHEIKHOLESLAM, A.; MOLLER, E.; LOUS, I. Pain, tenderness and strength of human mandibular elevators. Scand J Dent Res. 1980; 88(1):60-66.

SIÉSSERE, S.; de ALBUQUERQUE LIMA, N.; SEMPRINI, M.; de SOUSA, L.G.; PAULO MARDEGAN ISSA, J.; APARECIDA CALDEIRA MONTEIRO, S.; CECÍLIO HALLAK REGALO, S. Masticatory processe in individuals with maxillary and mandibular osteoporosis: electromyographic analysis. Osteoporos Int. 2009; 20(11):1847-1851.

SILVERMAN, S.; SADOSKY, A.; EVANS, C.; YEH, Y.; ALVIR, J.M.; ZLATEVA, G. Toward characterization and definition of fibromyalgia severity. BMC Musculoskelet Disord. 2010; Apr 8;11:66. doi: 10.1186/1471-2474-11-66.

SIMMS, R.W.; GOLDENBERG, D.L. Symptoms mimicking neurologic disorders in fibromyalgia syndrome. J Rheumatol. 1988 Aug;15(8):1271-3. 
SONNESEN, L.; BAKKE, M.; SOLOW, B. Temporomandibular disorders in relation to craniofacial dimensions, head posture and bite force in children selected for orthodontic treatment. Eur J Orthod. 2001; Apr;23(2):179-92.

SPAETH, M. Epidemiology, costs, and the economic burden of fibromyalgia. Arthritis Res Ther. 2009; 11(1):117.

STAUD, R.; VIERCK, C.J.; CANNON, R.L.; MAUDERLI, A.P.; PRICE，D.D. Abnormal sensitization and temporal summation of second pain (wind-up) in patients with fibromyalgia syndrome. Pain. 2001 Mar; 91(1-2):165-75.

STAUD, R.; SMITHERMAN, M.L. Peripheral and central sensitization in fibromyalgia: pathogenetic role. Curr Pain Headache Rep. 2002 Aug;6(4):259-66.

STRINI, P.J.; STRINI, P.J.; BARBOSA, T.de.S.; GAVIÃO, M.B. Assessment of thickness and function of masticatory and cervical muscles in adults with and without temporomandibular disorders. Arch Oral Biol. 2013 Sep;58(9):1100-8. doi: 10.1016/j.archoralbio.2013.04.006.

STYLIANOU, A. P. et al. The use of correlation integrals in the study of localized muscle fatigue of elbow flexors during maximal efforts. J Electromyogr Kinesiol. 2005; 15(5):437-43.

SVENSSON, P.; WANG, K.; SESSLE, B.J.; ARENDT-NIELSEN, L. Associations between pain and neuromuscular activity in the human jaw and neck muscles. Pain. 2004 Jun;109(3):225-32.

TSUGA, K.; CARLSON, G.E.; OSTERBERG, T.; KARLSSON, S. Self-assessed masticatory ability in relation to maximal bite force and dental state in 80 -year-old subjects. $\mathbf{J}$ Oral Rehabil. 1998; 25:117-124.

VALENTINE, M. Aetiology of fibrositis: a review. Ann Rheum Dis. 1947; 6:241-50.

VALKEINEN, H.; ALEN, M.; HANNONEN, P.; HÄKKINEN, A.; AIRAKSINEN, O.; HÄKKINEN, K. Changes in knee extension and flexion force, EMG and functional capacity during strength training in older females with fibromyalgia and healthy controls. Rheumatology (Oxford). 2004 Feb; 43(2), 225-228.

VALKEINEN, H.; HÄKKINEN, K.; PAKARINEN, A.; HANNONEN, P.; HÄKKINEN, A.; AIRAKSINEN, O.; NIEMITUKIA, L.; KRAEMER, W.J.; ALÉN, M.; Muscle hypertrophy, strength development, and serum hormones during strength training in elderly women with fibromyalgia. Scand J Rheumatol. 2005 Jul-Aug;34(4):309-14.

VAN DER BILT, A. Human oral function: a review. Bras J Oral Sci. 2002; 1(1):718.

WIDMALM, S.E.; LEE, Y.S.; MCKAY, D.C. Clinical use of qualitative electromyography in the evaluation of jaw muscle function: a practitioner's guide. Cranio. 2007 Jan;25(1):63-73. 
WODA, A.; MISHELLANY, A.; PEYRON, M.A. The regulation of masticatory function and food bolus formation. J Oral Rehabil. 2006 Nov;33(11):840-9.

WOLFE, F.; SMYTHE, H.A.; YUNUS, M.B.; BENNETT, R.M.; BOMBARDIER, C.; GOLDENBERG, D.L.; TUGWELL, P.; CAMPBELL, S.M.; ABELES, M.; CLARK, P.; FAM, A.G.; FARBER, S.J.; FIECHTNER, J.J.; FRANKLIN, C.M.; GATTER, R.A.; HAMATY, D.; LESSARD, J.; LICHTBROUM, A.S.; MASI, A.T.; McCAIN, G.A.; HEYNOLDS, W.J.; ROMANO, T.J.; RUSSELL, I.J.; SHEON, R.P. The American College of Rheumatology 1990 criteria for the classification of fibromyalgia: report of the multicenter criteria committee. Arthritis Rheum. 1990; 33:160-72.

WOLFE, F.; ROSS, K.; ANDERSON, J.; RUSSELL, I.J.; HEBERT, L. The prevalence and characteristics of fibromyalgia in the general population. Arthritis Rheum. 1995; 38(1):19-28.

YACHIDA, W.; CASTRILLON, E.E.; BAAD-HANSEN, L.; JENSEN, R.; ARIMA, T.; TOMONAGA, A.; OHATA, N.; SVENSSON, P. Craniofacial pain and jaw-muscle activity during sleep. J Dent Res. 2012;91(6):562-7.

YUNUS, M.; MASI, A.T.; CALABRO, J.J.; MILLER, K.A.; FEIGENBAUM, S.L. Primary fibromyalgia (fibrositis): clinical study of 50 patients with matched normal controls. Semin Arthritis Rheum. 1981 Aug; 11(1):151-71.

YVEN, C.; BONNET, L.; CORMIER, D.; MONIER, S.; MIOCHE, L. Impaired mastication modifies the dynamics of bolus formation. Eur J Oral Sci. 2006; 114(3):184190.

ZIVKO-BABIĆ, J.; PANDURIĆ, J.; JEROLIMOV, V.; MIOC, M.; PIZETA, L.; JAKOVAC, M. Bite force in subjects with complete dentition. Coll Antropol. 2002; 26:293302. 


\section{APÊNDICES}

\section{APÊNDICE - A - TERMO DE CONSENTIMENTO LIVRE E ESCLARECIDO}

\section{CONVITE PARA PARTICIPAR DE PESQUISA CLÍNICA}

Você está sendo convidado para participar do estudo $\mathbf{O}$ impacto da fibromialgia na musculatura mastigatória e cervical: análises eletromiográfica, ultrassonográfica, força de mordida e eficiência mastigatória. A decisão de participar deste estudo é totalmente sua. Você pode recusar ou decidir parar de participar desta pesquisa a qualquer momento e por qualquer razão.

Por favor, leia cuidadosamente todas as informações a seguir. Peça explicação sobre quaisquer palavras, termos ou seções que não estejam claros para você. Você também pode sanar qualquer dúvida que tenha sobre esta pesquisa. Não assine este formulário de consentimento, caso não tenha compreendido todas as informações contidas nele e tenha esclarecido satisfatoriamente todas as suas dúvidas. Se você decidir participar deste estudo, será necessário assinar este formulário. Você receberá uma cópia deste formulário assinado. Você deve manter sua via guardada em seus arquivos. Este documento apresenta informações como nomes e números de telefones importantes que você poderá necessitar no futuro. Durante este estudo, novos dados poderão ser aprendidos e você terá conhecimento disto.

Rubrica do pesquisador responsável Rubrica do voluntário 


\section{TERMO DE CONSENTIMENTO LIVRE E ESCLARECIDO}

Convidamos você, para participar voluntariamente do projeto de pesquisa $O$ impacto da fibromialgia na musculatura mastigatória e cervical: análises eletromiográfica, ultrassonográfica, força de mordida e eficiência mastigatória, tendo como pesquisadora responsável a Profa. Dra. Simone Cecílio Hallak Regalo, professora da Faculdade de Odontologia de Ribeirão Preto - USP e o doutorando Ft. Victor Rodrigues Nepomuceno.

Declaro que tomei ciência e que fui esclarecido(a) de maneira a não restarem quaisquer dúvidas sobre minha participação no estudo, de acordo com os termos abaixo relacionados:

1) O objetivo deste estudo será avaliar a forma como os músculos do seu rosto, do pescoço e dos ombros trabalham, seus tamanhos, sua força de mordida e a eficiência durante a mastigação.

2) Estas avaliações serão feitas usando vários equipamentos, como o eletromiógrafo necessário para ver como os músculos do rosto, pescoço e ombro estão trabalhando e funcionando; o aparelho de ultrassom para ver e medir o tamanho dos músculos do rosto, pescoço e ombro; o aparelho de força de mordida para ver o quanto de força será atingido durante a sua mordida. Para ver a forma da sua mastigação (eficiência mastigatória) será pedido a você que mastigue um material chamado parafilme, que é um pedaço estreito de parafina e dois tipos de alimentos (amendoins e uvas-passas). Estes métodos não aquecem, não provocam dor e não causam risco à saúde.

3) Em sua avaliação física, serão observadas sua altura, peso e massa corporal e, se existem modificações na forma do rosto, pescoço e ombros.

4) Para a avaliação dos pontos dolorosos da fibromialgia será usado um aparelho para medir a quantidade de pressão aplicada na pele, até você começar a sentir. Este método não aquece, não provoca dor e não causa risco à saúde.

5) No exame de eletromiografia, o desconforto causado será apenas da fita adesiva (esparadrapo) sobre a pele no local dos músculos estudados no seu rosto (temporal e masseter), pescoço (esternocleidomastóideo) e ombro (trapézio) nos dois lados do corpo. Os riscos são mínimos e o resultado esperado é saber como estes músculos trabalham durante a mastigação e elevação dos braços. Este método não aquece, não provoca dor e não causa risco à saúde.

Rubrica do pesquisador responsável

Rubrica do voluntário 
6) Em seguida será feito o exame da força de mordida, que consiste em colocar um aparelho com duas pontas na boca, na região dos dentes do fundo e morder por três vezes, durante três segundos, para ver os maiores valores da força de mordida. Este método poderá ser um pouco incômodo ao colocar o aparelho na boca, mas não provoca dor e não causa risco à sua saúde.

7) Serão aplicados questionários para avaliar problemas para abrir a sua boca (RDC/TMD), além do questionário sobre a fibromialgia em sua qualidade de vida (QIF). O primeiro é composto de várias perguntas dividido em duas partes. A parte I tem questões para verificar a abertura, presença de dor e barulhos incomuns em sua boca. Já a parte II são questões de sintomas físicos, além de sexo, raça, escolaridade, estado civil. $\mathrm{O}$ segundo questionário tem questões sobre sua profissão e sua forma de viver com a fibromialgia.

8) Por fim, será feito o exame de ultrassonografia, que vai medir o tamanho de seus músculos e é realizado passando-se um gel gelado no rosto, pescoço e ombro, em seguida, o aparelho de ultrassom será aplicado de forma suave e sem pressão. Este método não aquece, não provoca dor e não causa risco a saúde.

9) $\mathrm{Se}$ for descoberto algum problema, você será informado, receberá ajuda e encaminhamento para tratamento.

10) Todas as avaliações têm riscos mínimos e você está sendo esclarecido que todos esses testes não machucam, não causam dor, não aquecem e não causam riscos para a saúde, apresentando apenas o incômodo da colocação do esparadrapo na pele, gel no rosto e o tempo que você passa sendo avaliado.

11) Não será oferecido nenhum tipo de pagamento pela sua participação na pesquisa. Caso necessário, você receberá alimentação e será ressarcido do seu gasto com transporte.

12) Você terá total liberdade para não participar da pesquisa.

13) Sua identidade será mantida em segredo e você terá total liberdade para pedir maiores esclarecimentos antes e durante o desenvolvimento da pesquisa. Se tiver qualquer dúvida, você poderá ligar para o pesquisador e/ou Comitê de Ética em Pesquisa para pedir qualquer informação sobre o projeto.

14) Participando desta pesquisa, você autoriza, para os devidos fins, o uso, a divulgação e publicação em revistas científicas dos dados obtidos e terá, por parte dos pesquisadores, a garantia do sigilo (segredo) que garantem a sua privacidade.

15) Saiba que você não terá benefício direto com este estudo, mas ao autorizar sua participação, os resultados encontrados poderão ajudar outras pessoas.

Rubrica do pesquisador responsável

Rubrica do voluntário 
16) Você terá permissão para fazer qualquer pergunta sobre tudo o que acontecer na pesquisa e que estará livre para cancelar (tirar) seu consentimento e parar a sua participação nesta pesquisa a qualquer momento, sem nenhum prejuízo.

Fui informado de todo conteúdo deste documento e concordo em participar desta pesquisa, por isso assino o mesmo.

de de $20 \ldots .$.

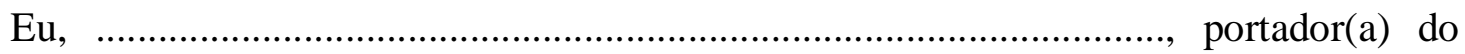
$\mathrm{RG} \mathrm{n}^{\circ}$ residente à

$\mathrm{n}^{\mathrm{o}}$.............., na cidade de Fone Estado de estou

ciente das informações acima e concordo a participar da pesquisa.

Assinatura da participante

Profa. Dra. Simone Cecilio Hallak Regalo (RG: 15.281.645)

Victor Rodrigues Nepomuceno (RG: 15.695.777-2)

Telefones para contato: Profa. Dra. Simone (16) 8801-1234 ou 3602-4015 Secretário do CEP: Ana Ap. F. do Nascimento - Avenida do Café, s/n..$^{\circ}$ 14040-904 Ribeirão Preto/SP Telefones: (16) 3602-4122 / 3602-3963 
APÊNDICE - B - FICHA DE AVALIAÇÃO DOS VOLUNTÁRIOS

\section{CHECKLIST}

( ) TCLE - ASSINADO

( ) RDC

( ) G1-Controle ( ) G2-Fibromialgia

\section{ANAMNESE}

Nome

Idade: Peso: Estatura: IMC:

Realiza atividade física? ( ) $\operatorname{sim}$ ( ) não

Tipo: Duração: Frequência:

Dor > que três meses nos quatro quadrantes do corpo? ( ) $\operatorname{sim}($ ) não

Realiza terapia física?

( ) $\operatorname{sim} \quad($ ) não

Realiza terapia cognitivo-comportamental?

( ) $\operatorname{sim}$

( ) não

Utiliza algum medicamento? Qual (ais)?

( ) $\operatorname{sim}$

( ) não

Utilizou relaxante muscular nos últimos cinco dias?( ) sim ( ) não Atualmente é fumante?

( ) $\operatorname{sim}$

( ) não

Está gestante?

( ) $\operatorname{sim}$

( ) não

Tem diagnóstico de doença?

( ) $\operatorname{sim}$

( ) não

( ) psiquiátrica

( ) neurológica

( ) metabólica

( ) endócrina

( ) renal

( ) hepática

( ) cardíaca 


\title{
ANEXOS
}

\section{ANEXO A - DECLARAÇÃO DAS INSTITUIÇÕES \\ UNIFAFIBE \\ BEBEDOUROISP}

\begin{abstract}
AUTORIZAÇÃo
Programa de Reabilitação e Desempenho Funcional da Faculdade de

Fisioterapia da Universidade de São Paulo - Ribeirão Preto
\end{abstract}

Bebedouro, 42 de junho de 2013.

Declaro para fins de pesquisa minha participação na pesquisa intitulada "O impacto da Síndrome da Fibromialgia na Musculatura Mastigatória e Cervical: Análise Eletromiográfica, Ultrassonográfica, Força de Mordida e Eficiência Mastigatória", que será desenvolvida pelo pós-graduando Victor Rodrigues Nepomuceno estudante do Programa de Reabilitação e Desempenho Funcional da Faculdade de Fisioterapia da Universidade de São Paulo - Campus Ribeirão Preto sob a orientação da Prof. Dra. Simone Cecilio Hallak Regalo, Professora Associada do Departamento de Morfologia, Fisiologia e Patologia Básica da Faculdade de Odontologia da Universidade de São Paulo - Campus Ribeirão Preto.

A pesquisa será realizada na Clínica Escola de Fisioterapia do Centro Universitário - UNIFAFIBE - Bebedouro - SP e os participantes da pesquisa deverão participar de dois encontros sendo que no primeiro encontro será realizada entrevista, avaliação física e aplicação de questionários e no segundo encontro serão realizadas as seguintes avaliações: eletromiográfica, ultrassonográfica, análise da força de mordida e da eficiência mastigatória. Todo material e equipamento necessários para as avaliações clínicas serão de responsabilidade do pesquisador sem qualquer ônus para os participantes da pesquisa e para esta instituição de ensino (UNIFAFIBE).

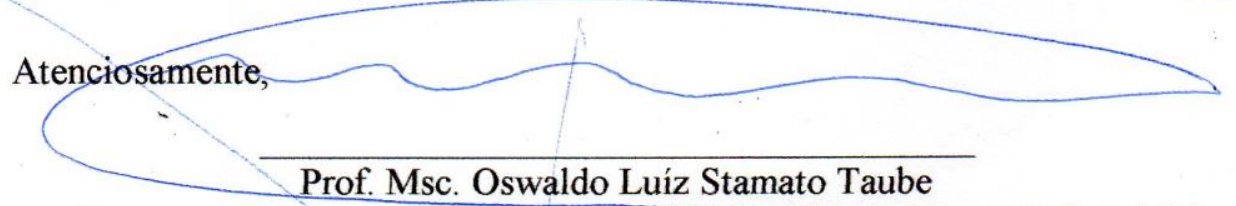

Prof. Responsável pela Clínica Escola de Fisioterapia do Centro Universitário - UNIFAFIBE / Bebedouro (SP) 


\section{AUTORIZAC̄̃o}

Programa de Reabilitação e Desempenho Funcional da Faculdade de Fisioterapia da Universidade de São Paulo - Ribeirão Preto

Palmas, 14 de dezembro de 2013.

Declaramos para os devidos fins, que autorizamos a realização da pesquisa intitulada "O impacto da síndrome da fibromialgia na musculatura mastigatória e cervical: análise eletromiográfica, ultrassonográfica, força de mordida e eficiência mastigatória", realizada pelo pós-graduando Victor Rodrigues Nepomuceno, do Programa de Reabilitação e Desempenho Funcional da Faculdade de Fisioterapia da Universidade de São Paulo - Ribeirão Preto, orientado pela Profa. Dra. Simone Cecilio Hallak Regalo, Professora Associada do Departamento de Morfologia Fisiologia e Patologia Básica da Faculdade de Odontologia de Ribeirão Preto. Esta pesquisa será realizada na Clínica Escola de Fisioterapia do Centro Universitário Luterano de Palmas - CEULP/ULBRA - Palmas - TO. Serão realizados dois encontros com os voluntários da pesquisa. No primeiro encontro será entrevista, avaliação física e aplicação de questionários; no segundo encontro serão realizadas avaliações eletromiográfica, ultrassonográfica, força de mordida e eficiência mastigatória. Estas etapas ocorrerão apenas nas instalações onde acontecem os atendimentos, sem utilização de qualquer material desta Instituição e sem qualquer ônus para os voluntários da pesquisa e para esta Instituição.

Atenciosamente,

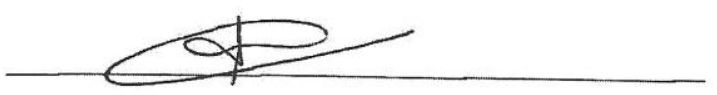

Prof. Msc. Luciana Fernandes Maia Marin

Coordenadora da Clínica Escola de Fisioterapia do Centro Universitário

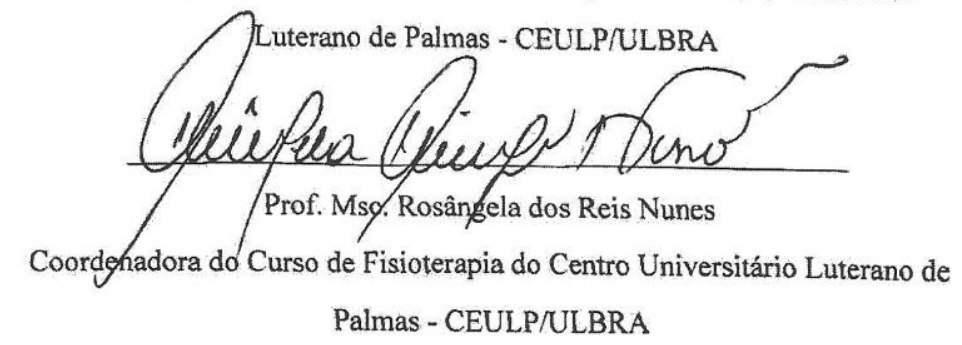


ANEXO B - CERTIFICADO DE APRESENTAÇÃO PARA APRECIAÇÃO ÉTICA

(CAAE)

\section{FACULDADE DE
ODONTOLOGIA DE RIBEIRÃO
PRETO/ FORP/ USP}

\section{PARECER CONSUBSTANCIADO DO CEP}

\section{DADOS DO PROJETO DE PESQUISA}

Título da Pesquisa: $O$ impacto da síndrome da fibromialgia na musculatura mastigatória e cervical: análise eletromiográfica, ultrassonográfica, força de mordida e eficiếncia mastigatória

Pesquisador: Victor Rodrigues Nepomuceno

Área Temática:

Versão: 2

CAAE: 15268413.7 .0000 .5419

Instituição Proponente: Universidade de Sao Paulo

Patrocinador Principal: Financiamento Próprio

DADOS DO PARECER

Número do Parecer: 317.340

Data da Relatoria: 20/06/2013

Apresentação do Projeto:

A sindrome da fibromialgia é caracterizada pela presença de dor difusa e crônica, sintomas de rigidez matinal, fadiga, distúrbios do sono e presença de pontos dolorosos à palpaçăo, com alta prevalência de sintomas orofaciais.

\section{Objetivo da Pesquisa:}

Este estudo tem por objetivos avaliar bilateralmente as açôes dos músculos temporal, masseter, esternocleidomastóideo e trapézio (porçăo média) por meio das análises eletromiográfica, ultrassonográfica, força de mordida e eficiência mastigatória em indivíduos com síndrome da fibromialgia e compará-las com individuos saudáveis, além de verificar possiveis relaçôes com os aspectos clínicos da doença, tais como: dor, fadiga e cansaço muscular.

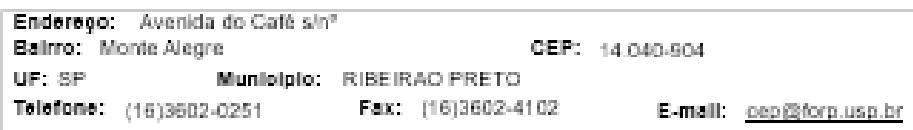




\section{FACULDADE DE \\ ODONTOLOGIADE RIBEIRÃO \\ PRETO/ FORP/ USP}

Custinuaçă do Partectr: 317.340

Avaliação dos Riscos e Benefícios:

O desenho desta pesquisa se enquadrará em um estudo observacional

de corte transversal, que irá avaliar a associaçăo da atividade eletromiográfica, espessura muscular, força

de mordida, desempenho mastigatório e postural em indivíduos com

fibromialgia. Sendo o estudo observacional, realizado por meio de exames näo invasivos, informa que

05 riscos gà่

inexistentes e o beneficio é o conhecimento que os resultados podem trazer.

Comentários e Considerações sobre a Pesquisa:

Relevante e com metodologia adequada a0s propositos. Chama a atençăo o fato de usar amendoim e uva passa, às vezes passiveis de alergia, que năo consta nos critérios de exclusảo o paciente nảo recabe nenhuma informação a respeito.

Considerações sobre 05 Termos de apresentaçäo obrigatória:

Adequados.

Recomendações:

Nada a relatar.

Conclusões ou Pendèncias e Lista de Inadequações:

Projeto adequado.

Situaçäo do Parecer:

Aprovado

Necessita Apreciaçäo da CONEP:

Não

Considerações Finais a critério do CEP:

Conforme deliberado na $149^{2}$ Reuniăo do CEP/FORP.

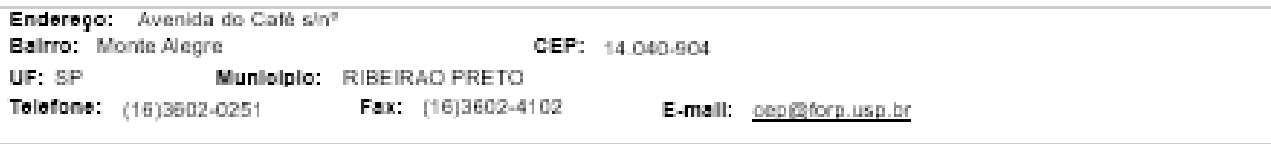




\section{FACULDADE DE ODONTOLOGIA DE RIBEIRÃO Q Plotoformo PRETO/ FORP/ USP}

Cuetinuaças do Parbeer: 317.346

RIBEIRAO PRETO, 26 de Junho de 2013

Assinador por:

Ana Maria Razaboni

(Coordenador) 
ANEXO - C - AVALIAÇÃO DAS ÁREAS DOLOROSAS
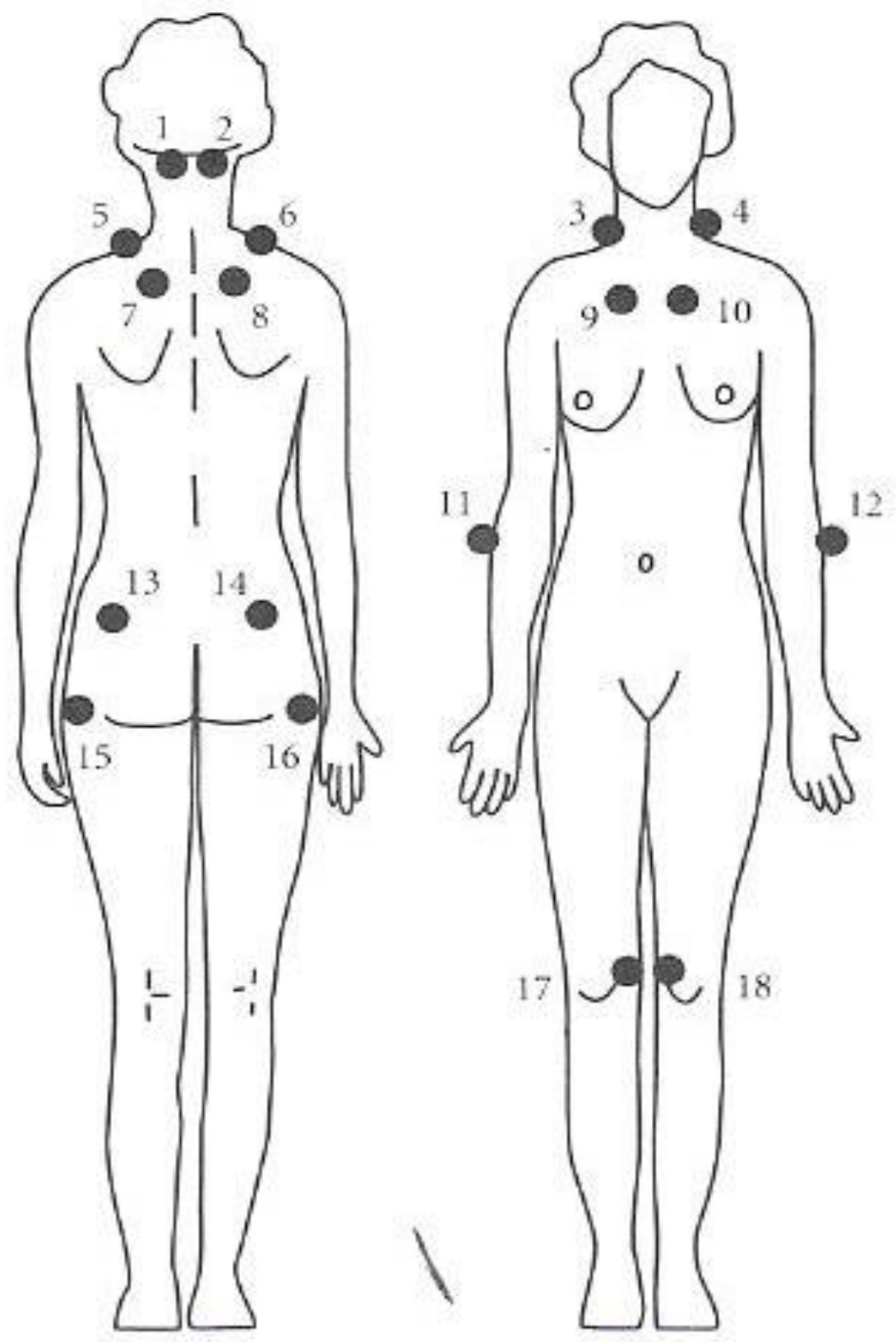

Dor no esqueleto axial e a dígito-pressão em pelo menos 11 dos 18 TP bilateralmente?
( ) $\operatorname{sim}$
( ) não 
ANEXO - D - AVALIAÇÃO DOLOROSA OU ESCALA NUMÉRICA DE DOR

Escala Numérica

\begin{tabular}{|l|l|l|l|l|l|l|l|l|l|l|}
\hline 0 & 1 & 2 & 3 & 4 & 5 & 6 & 7 & 8 & 9 & 10 \\
\hline
\end{tabular}




\section{ANEXO - E - RESEARCH DIAGNOSTIC CRITERIA FOR TEMPOROMANDIBULAR DISORDERS (RDC/TMD) - VERSÃO EM PORTUGUÊS}

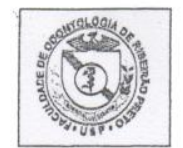

UNIVERSIDADE DE SÄO PAULO

FACULDADE DE ODONTOLOGIA DE RIBEIRÄO PRETO

DEPARTAMENTO DE ODONTOLOGIA RESTAURADORA - ÁREA DE OCLUSÃO

$$
- \text { RDC / TMD - }
$$

CURSO DE OCLUSĀO, DISFUNÇÄO TEMPOROMANDIBULAR E DOR OROFACIAL EM PACIENTES COM NECESSIDADES ESPECIAIS:

ABORDAGEMI MULTIDISCIPLINAR

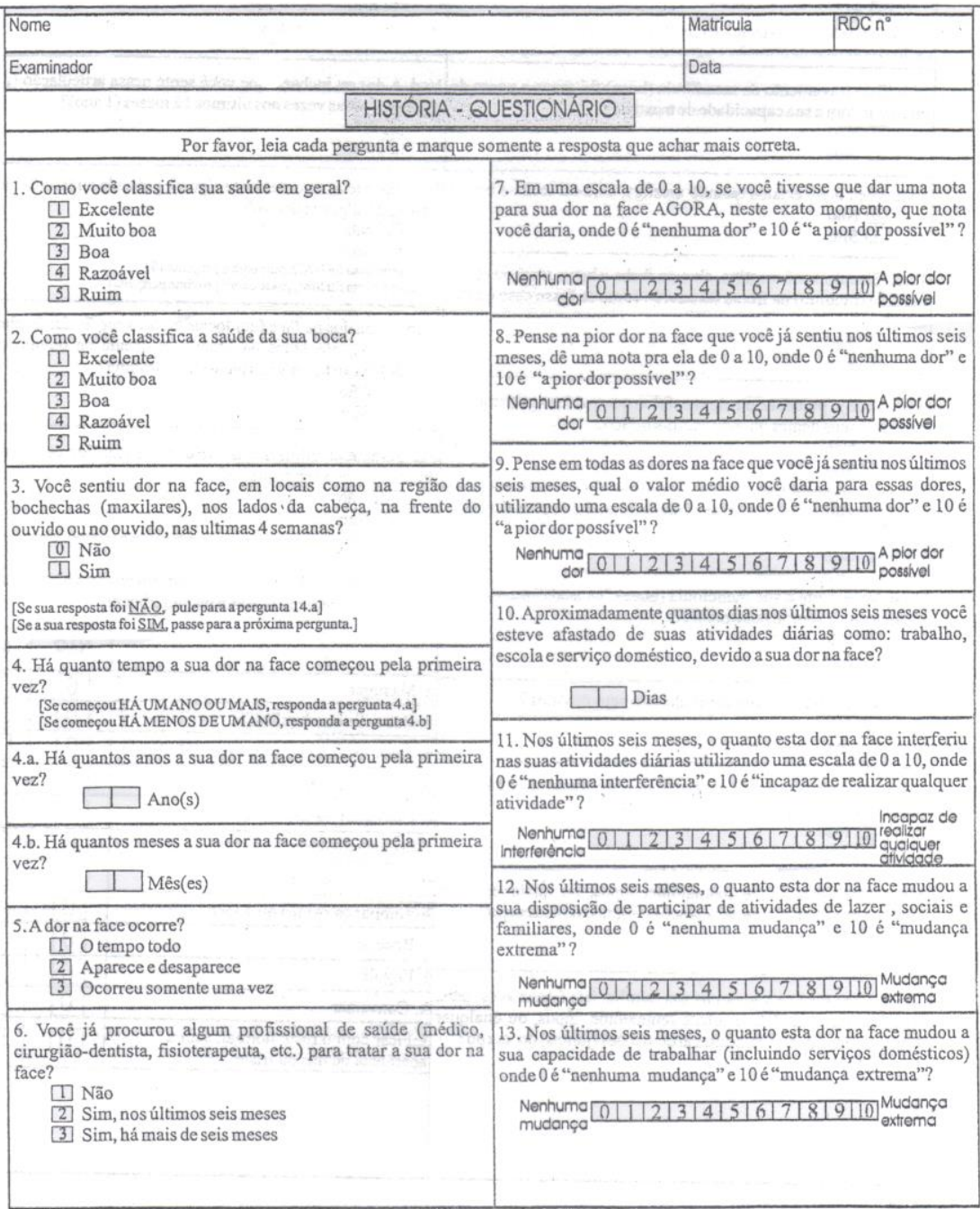

c B 


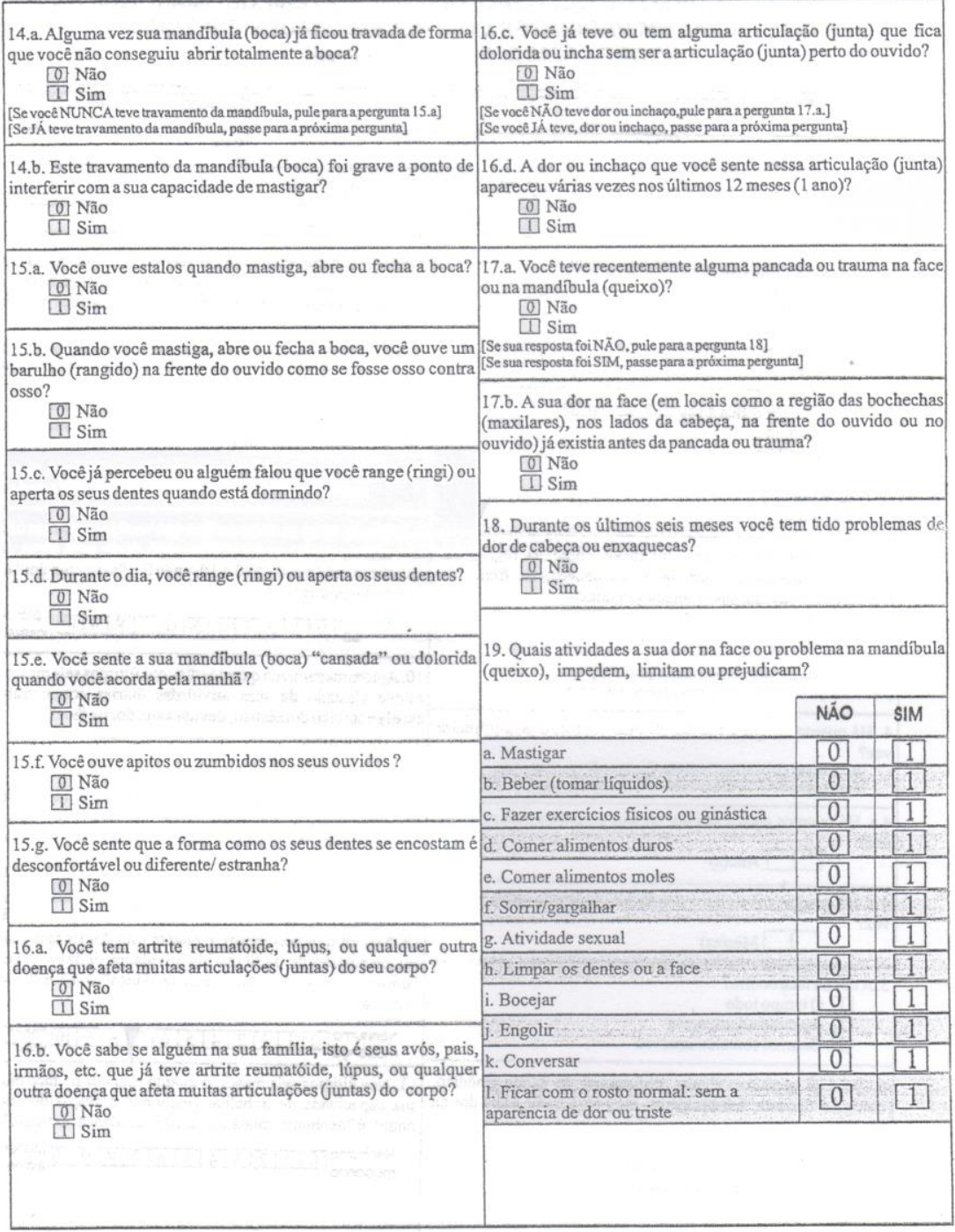

C 8 


\begin{tabular}{|c|c|c|c|c|c|c|}
\hline \multicolumn{7}{|c|}{ 20. Nas últimas quatro semanas, o quanto você tem estado angustiado ou preocupado: } \\
\hline Phander & & $\begin{array}{c}\text { Nem um } \\
\text { pouco }\end{array}$ & $\begin{array}{c}\text { Um } \\
\text { Pouco }\end{array}$ & Modardimento & Muito & Exurumanconte \\
\hline \multicolumn{2}{|l|}{ a. Por sentir dores de cabeça } & 0 & 1 & 2. & 3. & 4 \\
\hline \multicolumn{2}{|l|}{ b. Pela perda de interesse ou prazer sexual } & 0 & $1]$ & 2 & 3 & 4 \\
\hline \multicolumn{2}{|l|}{ c. Por ter fraqueza ou tontura } & 0 & 1 & 2. & 3 & 4. \\
\hline \multicolumn{2}{|l|}{ d. Por sentir dor ou "aperto" no peito ou coração } & 0 & 1 & 2 & 3 & 4 \\
\hline \multicolumn{2}{|l|}{ e.Pela sensação de falta de energia ou lentidão } & 0 & 1 & 2 & 3 & 4 \\
\hline \multicolumn{2}{|l|}{ f. Por ter pensamentos sobre morte ou relacionados ao ato de morrer } & 0 & 1 & 2 & 3 & 4 \\
\hline \multicolumn{2}{|l|}{ g. Por ter falta de apetite. } & 0 & 1 & 2 & 3. & 4 \\
\hline \multicolumn{2}{|l|}{ h. Por chorar facilmente } & 0 & 1 & 2 & 3 & 4 \\
\hline \multicolumn{2}{|l|}{ i. Por se culpar pelas coisas que acontecem ao seu redor } & 0 & 1. & 2 & 3. & 4. \\
\hline \multicolumn{2}{|l|}{ j. Por sentir dores na parte inferior das costas } & 0 & 1 & 2 & 3 & 4 \\
\hline \multicolumn{2}{|l|}{ k. Porse sentir só } & 0 & $1]$ & 2 & 3 & 4 \\
\hline \multicolumn{2}{|l|}{ 1.Por se sentir triste } & 0 & 1 & 2 & 3 & 4 \\
\hline \multicolumn{2}{|l|}{ m. Por se preocupar muito com as coisas } & 0 & $1]$ & 2 & 3. & 4 \\
\hline \multicolumn{2}{|l|}{ n. Por não sentir interesse pelas coisas } & 0 & 1 & 2 & 3 & 4 \\
\hline \multicolumn{2}{|l|}{ o. Por ter enjôo ou problemas no estômago } & 0 & $1]$ & 2. & 3. & 4. \\
\hline \multicolumn{2}{|l|}{ p. Por ter músculos doloridos } & 0 & 1 & 2 & 3 & 4 \\
\hline \multicolumn{2}{|l|}{ q.Porter dificuldade em adormecer } & 0. & 17 & 2. & 3 & 4 \\
\hline \multicolumn{2}{|l|}{ ๘. Por ter dificuldade em respirar } & 0 & 1 & 2 & 3 & 4 \\
\hline \multicolumn{2}{|l|}{ s.Por sentir de vez em quando calor ou frio } & 0 & $1]$ & 2 & 3 & 4 \\
\hline \multicolumn{2}{|l|}{ t. Por sentir dormência ou formigamento em partes do corpo } & 0 & 1 & 2 & 3 & 4 \\
\hline \multicolumn{2}{|l|}{ u. Porsentirum "nó na garganta" } & 0 & 1. & 2. & 3 & 4. \\
\hline \multicolumn{2}{|l|}{ v. Por se sentir desanimado sobre o futuro } & 0 & 1 & 2 & 3 & 4 \\
\hline \multicolumn{2}{|l|}{ w. Por se sentir fraco em partes do corpo } & 0 & $1]$ & 2 & 3 & 4 \\
\hline \multicolumn{2}{|l|}{ x. Pela sensação de peso nos braços ou pernas } & 0 & 1 & 2 & 3 & 4 \\
\hline \multicolumn{2}{|l|}{ y. Porterpensamentos sobre acabar com a sua vida } & 0 & $1]$ & 2 & 3 & 4 \\
\hline \multicolumn{2}{|l|}{ z. Por comer demais } & 0 & 1 & 2 & 3 & 4 \\
\hline \multicolumn{2}{|l|}{ aa. Por acordar de madrugada } & 0 & 1 1) & 2. & 3 & 4 \\
\hline bb. Por ter sono agitado ou perturbado & & 0 & 1 & 2 & 3 & 4 \\
\hline cc. Pela sensação de que tudoé um esforço/sacrificio & & 0 & 1 & 2 & 3 & 4 \\
\hline dd. Por se sentir inútil & & 0 & 1 & 2 & 3 & 4 \\
\hline ee.Pela sensação de ser enganado ou iludido & & 0 & 1 & 2 & 3 & 4 \\
\hline ff. Por ter sentimentos de culpa & & 0 & 1 & 2 & 3 & 4 \\
\hline $\begin{array}{l}\text { 21. Como você classificaria os cuidados que tem tomado coma a } \\
\text { sua saúde deuma forma geral? } \\
\text { 1] Excelente } \\
\text { [2. Muito bom } \\
\text { (3) Bom } \\
\text { [4 Razoável } \\
\text { [5] Ruim } \\
\end{array}$ & $\begin{array}{r}22 . \text { C } \\
\text { saúde } \\
5 \\
5 \\
5 \\
5\end{array}$ & $\begin{array}{l}\text { mo você c } \\
\text { da sua boc } \\
\text { 1] Excelet } \\
\text { 2. Muito t } \\
\text { 3. Bom } \\
\text { 4. Razoáv } \\
\text { 5. Ruim }\end{array}$ & & & & \\
\hline
\end{tabular}

\footnotetext{
CB
} 


\begin{tabular}{|c|c|c|}
\hline \multicolumn{2}{|c|}{ 23. Qual a data do seu nascimento? } & \multirow{2}{*}{$\begin{array}{l}\text { 28a. Durante as } 2 \text { últimas semanas, você trabalhou no emprego } \\
\text { ou negócio pago ou não (não incluindo trabalho em casa)? } \\
\text { [1] Não } \\
\text { [1] Sim } \\
\text { [Se a sua resposta foi SIM, pule para a pergunta 29] } \\
\text { [Se a sua resposta foi NÃO, passe para próxima pergunta] }\end{array}$} \\
\hline $\begin{array}{l}\text { 24. Qual seu sexo? } \\
\text { [1] Masculino } \\
2 \text { Feminino }\end{array}$ & & \\
\hline \multirow{2}{*}{\multicolumn{2}{|c|}{ 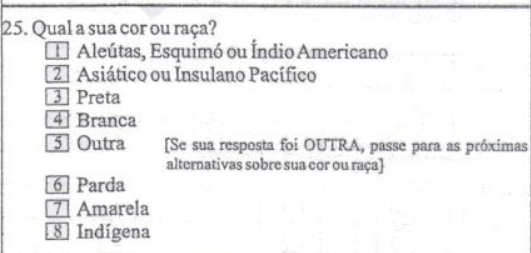 }} & $\begin{array}{l}\text { 28b. Embora você não tenha trabalhado nas duas últimas } \\
\text { semanas, você tinhauumemprego ou negócio? } \\
\text { [0 Não } \\
\text { [1] Sim } \\
\text { [Se sua resposta foi SIM, pule para pergunta 29] } \\
\text { [Se a sua resposta foi NâO, passe para próxima pergunta] }\end{array}$ \\
\hline & & $\begin{array}{l}\text { 28c. Você estava procurando emprego ou afastado } \\
\text { temporariamente do trabalho, durante as } 2 \text { últimas semanas? } \\
\text { W Sim, procurando emprego } \\
\text { 2. Sim, afastado temporariamente do trabalho }\end{array}$ \\
\hline \multirow{3}{*}{\multicolumn{2}{|c|}{ 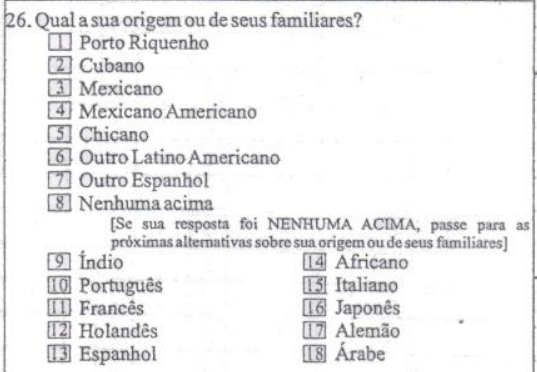 }} & $\begin{array}{l}\text { [3] Sim, os dois, procurando emprego e afastado } \\
\text { temporariamente do trabalho } \\
\text { (4) Não }\end{array}$ \\
\hline & & $\begin{array}{l}\text { 29. Qual o seu estado civil? } \\
\text { T1 Casado (a) esposa (o) morando na mesma casa } \\
\text { [2] Casado (a) esposa (o) não morando na mesma casa } \\
\text { [3] Viúvo (a) } \\
\text { [4] Divorciado (a) } \\
\text { 5. Separado (a) } \\
\text { [6. Nunca casei } \\
\text { [7] Morando junto }\end{array}$ \\
\hline & & 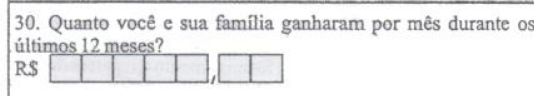 \\
\hline \multicolumn{2}{|l|}{$\begin{array}{l}\text { [19] Outra, favor especificar } \\
\text { [20] Não sabe especificar }\end{array}$} & $\begin{array}{l}\text { Näo preencher. Deverá ser preenchido pelo profissional } \\
\square \text { Até } 1 / 1 \text { do salário minimo } \\
\square \text { De } 1 / 4 \text { a } 1 / 2 \text { salário mínimo }\end{array}$ \\
\hline \multicolumn{2}{|l|}{$\begin{array}{l}\text { 27. Até que ano da esc } \\
\text { Nunca freqüentei a es } \\
\text { Ensino fundamental } \\
\text { (primário) } \\
\\
\text { Ensino fundamental } \\
\text { (ginásio) }\end{array}$} & $\begin{array}{l}\square \text { De } 1 / 2 \text { a } 1 \text { salário mínimo } \\
\square \text { De } 1 \text { a } 2 \text { salários mínimos } \\
\square \text { De } 2 \text { a } 3 \text { salários mínimos } \\
\square \text { De } 3 \text { a } 5 \text { salários mínimos } \\
\square \text { De } 5 \text { a } 10 \text { salários mínimos } \\
\square \text { De } 10 \text { a } 15 \text { salários mínimos } \\
\square \text { De } 15 \text { a } 20 \text { salários mínimos } \\
\square \text { De } 20 \text { a } 30 \text { salários mínimos } \\
\square \text { Mais de } 30 \text { salários mínimos } \\
\square \text { Sem rendimento }\end{array}$ \\
\hline \multirow{2}{*}{$\begin{array}{l}\text { Ensino médio } \\
\text { (científico) } \\
\text { Ensino superior } \\
\text { (faculdade ou pós-graduação) }\end{array}$} & 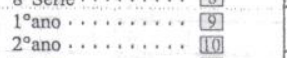 & \begin{tabular}{|l|l|l|l|l|l|l|} 
31. Qual o seu CEP? & & & & & & \\
\end{tabular} \\
\hline & 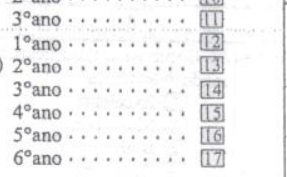 & $\begin{array}{l}\text { Muito Obrigado. } \\
\text { Agora veja se você deixou de responder alguma questão. }\end{array}$ \\
\hline
\end{tabular}




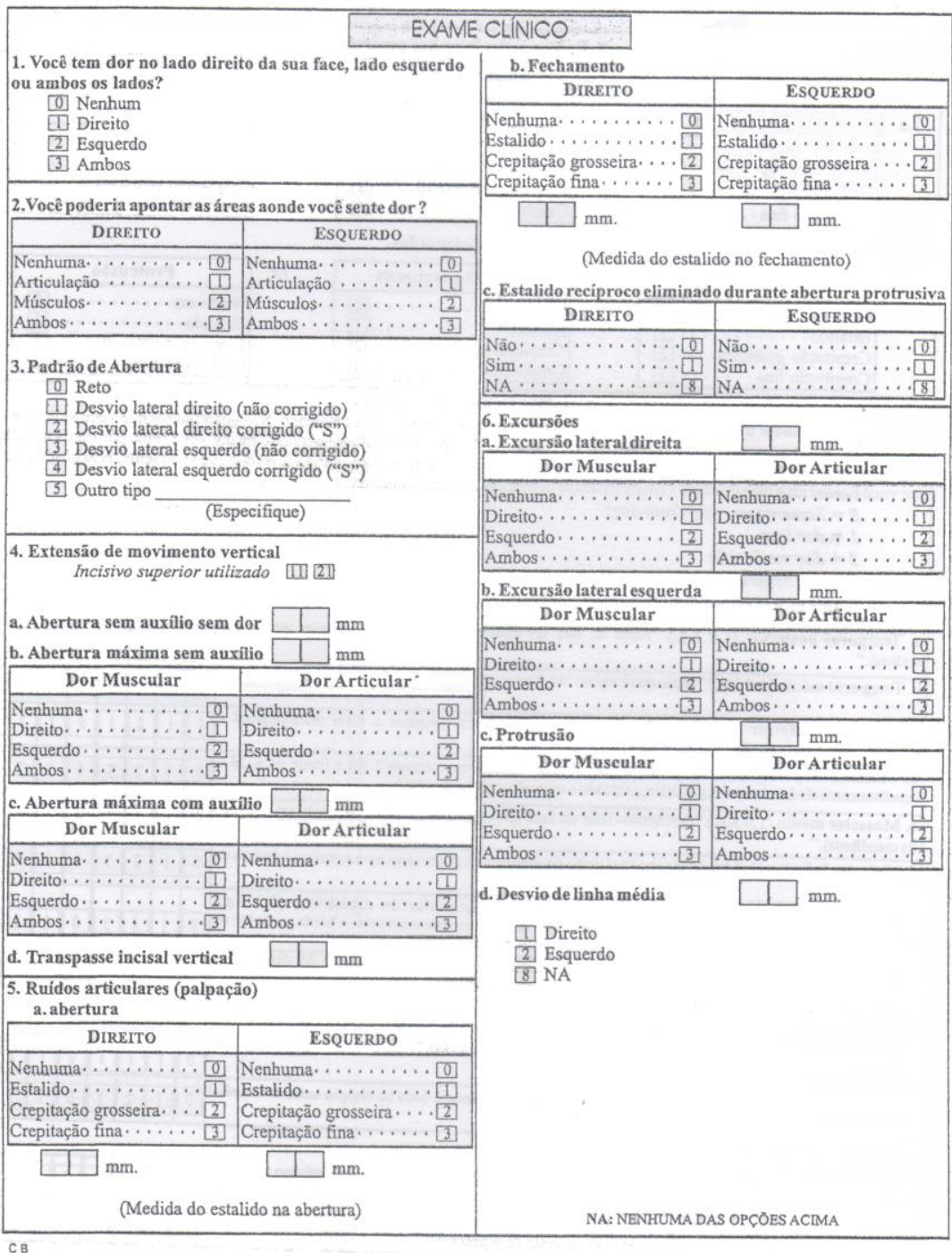


7. Ruidos articulares nas excursōes

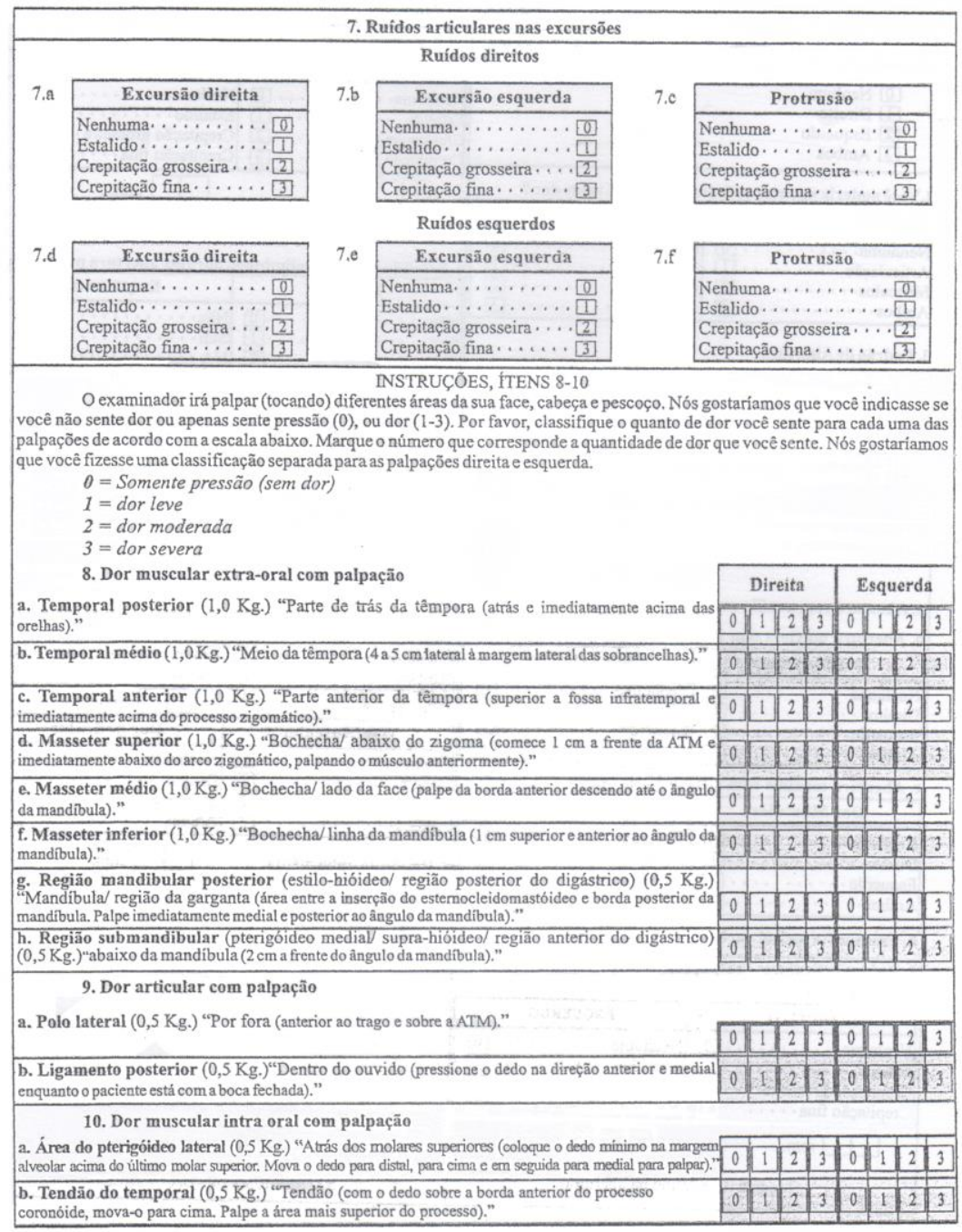
CB 